JOSÉ GIL OLIVEIRA

\title{
AVALIAÇÃO DE DISTÚRBIOS EM SISTEMAS DE DISTRIBUIÇÃO DE ENERGIA ELÉTRICA, DEVIDO Às DISTORÇÕES HARMÔNICAS
}

Dissertação apresentada ao Programa Interunidades de Pós-Graduação em Energia da Universidade de São Paulo para obtenção do título de Mestre em Ciências da Energia

São Paulo

JUNHO/95 
JOSÉ GIL OLIVEIRA

\section{AVALIAÇÃO DE DISTÚRBIOS EM SISTEMA \\ DE DISTRIBUIÇÃO DE ENERGIA ELÉTRICA, DEVIDO ÀS DISTORÇÕES HARMÔNICAS}

Dissertação apresentada ao Programa Interunidades de Pós-Graduação em Energia da Universidade de São Paulo para obtenção do título de Mestre em Ciências da Energia

Área de Concentração:

Ciências da Energia

Orientador:

Murilo Tadeu W. Fagá

São Paulo

ЛUNHO/95 
À minha esposa Waldete e ao meu filhinho Róbson Gil 


\section{AGRADECIMENTOS}

Ao amigo e orientador Murilo Tadeu Werneck Fagá, pelo incentivo e valiosa orientação;

Ao Prof. Ildo Sauer e ao Prof. Lineu Belico pela contribuição nas sugestões deste trabalho;

À direção do Instituto de Eletrotécnica e Energia da USP pela oportunidade de desenvolvimento dos trabalhos;

Ao Eng ${ }^{\circ}$ Vernei Giallucca e ao técnico José Carlos Dias e a equipe da Companhia Paulista de Força e Luz pela valiosa colaboração no fornecimento dos dados;

Ao Eng $^{\circ}$ Francisco Carlos Bianchi, da empresa que foi analisada neste estudo, pela prestativa colaboração no fornecimento dos dados;

Aos funcionários da Seção Técnica de Sistemas Eletrônicos do IEE-USP, pela colaboração e compreensão;

À bibliotecária Maria de Fátima Atanásio Mochizuki, pela ajuda na formatação das referências bibliográficas;

Aos amigos que, direta ou indiretamente, colaboraram na realização deste trabalho. 


\section{RESUMO}

As redes de Distribuição de Energia Elétrica podem ser submetidas a perturbações, causadas pela proliferação de cargas não-lineares, provocando distúrbios nos alimentadores das sub-estações e afetando cargas sensiveis, obrigando as empresas de energia elétrica e aos consumidores a adotarem medidas preventivas e corretivas. Esses distúrbios quando afetam a forma de onda da tensão ou da corrente, provocando o aparecimento de freqüências múltiplas as da fundamental, é um fenômeno conhecido como distorção harmônica.

Para avalia-la, foi desenvolvido um equipamento eletrônico controlado por microprocessadores, possibilitando medições em campo da tensão e corrente harmônica, assim como o módulo e fase de cada harmônico, múltiplo de $60 \mathrm{~Hz}$, até o $40^{\circ}$ harmônico.

Com base nos dados coletados pelo equipamento, foram avaliados os distúrbios provocados pelas cargas não-lineares num consumidor gerador de harmônicos.

Foram realizadas comparações entre os registros de consumo medidos pelo equipamento e o registrado pela concessionária. Foi comparada também a distorção harmônica, na corrente e na tensão, com as normas nacionais e internacionais.

Os resultados indicaram, mesmo em se considerando uma série histórica pouco expressiva, coerência com o estado do conhecimento sobre o fenômeno. 


\section{ABSTRACT}

The distribution lines can be affected by disturbances, caused by the increase of nonlinear loads, provoking disturbances in substation feeders. These disturbances can affect sensitive loads, demanding therefore from the Utilities preventive and remedial actions. When they affect the voltage waveforms, current and voltage, causing the occurrence of multiply frequency at the fundamental frequency, it is a phenomena known as harmonic distortion.

An electronic equipment controlled by microprocessors was developed to the disturbance assessment and to make measurements in site possible, sampling the waveform and calculating the first 40 harmonics of the $60 \mathrm{~Hz}$, fundamental, for both voltage and current waveform.

The data bases were collected by the equipment and the disturbances caused by nonlinear loads were verified, at a certain consumer who generates harmonics.

Two comparisons were performed: the data consumption measured by equipment versus the Utility's data consumption and the harmonic distortion current and voltage, versus international and local standards.

Results have shown coherence with the state of knowledge. In spite of the presented data being of a short period duration. 


\section{SUMÁRIO}

Resumo

"Abstract"

1. INTRODUÇÃO.

1.1 Motivação.

1.2 Apresentação

2. OBJETIVO 5

3. CONSIDERAÇÕES GERAIS. 6

3.1 Histórico. 6

3.2 Fenomenologia.

3.3 Fontes Harmônicas.

3.4 Efeitos dos Harmônicos em Equipamentos

3.4.1 Introdução

3.4.2 O estado do conhecimento. 26

3.5 Limites para Harmônicos em Sistemas Elétricos de Potência .48

4. MEDIÇÕES DE COMPONENTES HARMÔNICAS .51

4.1 Métodos Simples para Constatação de Corrente e Tensões Harmônicas

4.2 Medição através de Analisadores de Harmônicos e Espectros .52 
5. REGISTRADOR DESENVOLVIDO NO IEE.

5.1 Histórico

5.2 Princípio de Funcionamento

5.3 Descrição Funcional.

5.3.1Hardware.

5.3.2 Software 68

5.4 Avaliação de Desempenho de Equipamentos

6. MEDIÇÕES REALIZADAS EM CAMPO

6.1 Características do Consumidor 98

6.2 Instalação 99

6.3 Resultados obtidos.

7. ANÁLISE E DISCUSSÃO DOS RESULTADOS 105

8. CONCLUSÕES E RECOMENDAÇÕES 129

9. BIBLIOGRAFIA 


\section{INTRODUÇÃO \\ 1.1 Motivação}

O trabalho a ser apresentado nos capítulos seguintes refere-se ao desenvolvimento de um equipamento digital microprocessado que possibilita a realização de medições em campo da tensão e corrente harmônica, assim como o módulo e fase de cada harmônico, múltiplo de $60 \mathrm{~Hz}$, até o $40^{\circ}$ harmônico.

Com base nos dados coletados pelo equipamento, serão avaliados os distúrbios que podem estar sendo provocados pelas cargas não-lineares nos alimentadores das concessionárias.

A motivação desta dissertação advêm da necessidade de se conhecer melhor as características de um consumidor com uma carga comprovadamente geradora de harmônicos que tenha seu sistema de medição configurado de modo não-convencional (delta aberto).

Este tipo de ligação no sistema de medição, se não for bem interpretado, pode provocar muitas dúvidas nos dados a serem analisados, já que os equipamentos tradicionalmente utilizados pelas concessionárias apresentam características que dificultam a análise dos resultados.

Devido a relevância do tema harmônicos, tem-se também a oportunidade de aprofundar a análise dos dados conseguidos em campo com o objetivo de se avaliar os distúrbios provocados pelos harmônicos nos sistemas de distribuição de energia elétrica sob o ponto de vista de um planejamento energético que leve em consideração estas perturbações.

Outro fator de motivação foi estar-se desenvolvendo um equipamento do porte do Registrador de Curvas de Carga (R.C.C.), no Brasil, possibilitando assim que se possa aliar teoria, ao analisar-se os harmônicos 
como fenômeno e prática, ao poder-se medi-los e concluir sobre a validação do desempenho do equipamento desenvolvido.

É extremamente interessante comparar o R.C.C. com outros equipamentos que estão atualmente no mercado internacional, mas que tenham a desvantagem de não poderem ser alterados, para atender condições específicas, pois toda a inteligência do programa residente (firmware) está fora do território brasileiro, ao contrário do R.C.C .

Este projeto possibilita a formação de recursos humanos na área de instrumentação digital voltada para Sistemas de Potência, fazendo com que o Instituto de Eletrotécnica e Energia da Universidade de São Paulo (IEEUSP), possa acompanhar o desenvolvimento científico e tecnológico, compatível com a sua tradição como referência na área de medição de grandezas elétricas.

Também possibilita uma maior aproximação e cooperação tecnológica com as empresas concessionárias de energia elétrica, principalmente a Companhia Paulista de Força e Luz (C.P.F.L.), que nos apoiou durante toda a realização das medições em campo.

\subsection{Apresentação}

As redes de Distribuição de Energia Elétrica podem ser submetidas a perturbações causadas pela proliferação de alguns tipos de dispositivos ou equipamentos elétricos (cargas não-lineares), provocando distúrbios nos alimentadores das sub-estações, afetando equipamentos sensiveis (cargas sensíveis), obrigando as empresas de energia elétrica e os consumidores a adotarem medidas preventivas e corretivas. Os dispositivos ou equipamentos elétricos (cargas não-lineares) que se enquadram como perturbadores, são por exemplo: conversores estáticos $\mathrm{CA} / \mathrm{CC}$ (utilizados 
em indústrias eletrometalúrgicas, eletroquímicas), controladores de velocidade de motores, fornos a arco, fornos de indução, máquina de solda, sistemas de tração elétrica (trens, metrô), compensadores estáticos e rotativos. Os equipamentos sensíveis (cargas sensiveis) que são afetados pelas cargas não-lineares são por exemplo: caixa automático, computador, vídeo-cassete, rádio-relógio digital, medidores digitais de energia.

Estes distúrbios que degradam a Qualidade de Energia fornecida aos consumidores, podem se manifestar de diversas formas [1]: interrupções, ondulações, depressões, distorções harmônicas, cintilações (flicker), desbalanceamento de fases e variações na freqüência são os mais comuns tipos de distúrbios. Vide figura 1.1

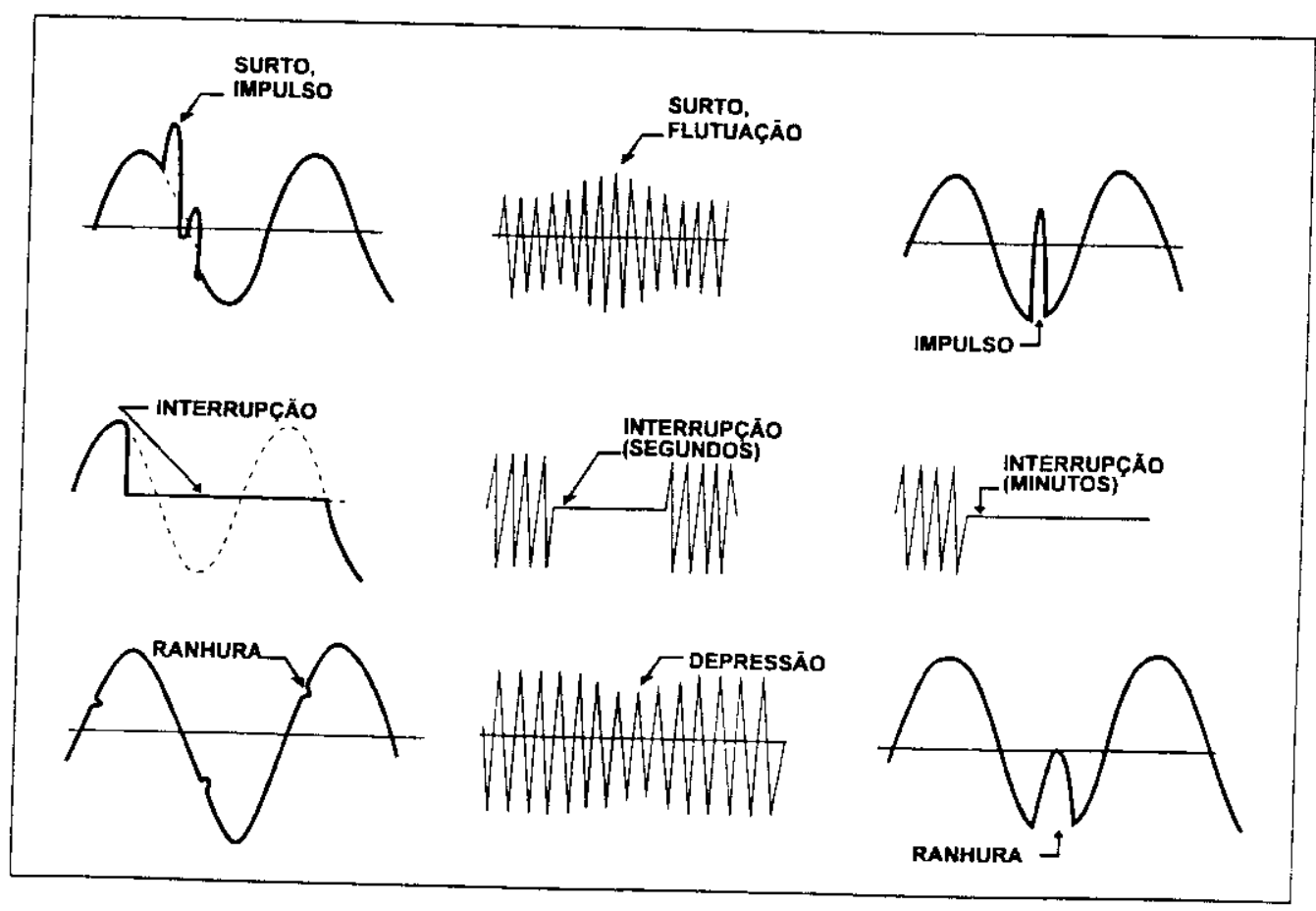

Figura 1.1 - Definições Gráficas dos Distúrbios 
Como conseqüência, estes distúrbios podem alterar o desempenho dos equipamentos alimentados por estas redes de Distribuição de Energia Elétrica, podendo até causar danos irreversíveis.

Dentre os distúrbios que degradam a Qualidade de Energia esta dissertação pretende analisar a distorção harmônica total e individual, da tensão e da corrente.

Diversos estudos tem sido realizados sobre o assunto através de modelos matemáticos e experimentais, e devido a complexidade do fenômeno, e aos vários parâmetros envolvidos, verificou-se que esta área de conhecimento encontra-se aberta a investigações, modelagens e soluções.

As considerações realizadas pelos pesquisadores são geralmente similares, porém, são encontradas diferenças nos resultados, assim como, no mecanismo de propagação dos harmônicos, que ainda não é bem entendido [2].

No Brasil ainda não existe uma normatização oficial sobre os harmônicos, porém, recomendações no Setor Elétrico estabelecem critérios e procedimentos que auxiliam o planejamento, a operação e o controle de perturbações causadas pelas cargas não-lineares, intermitentes ou desequilibradas, genericamente chamadas de cargas especiais [3].

Tais recomendações fornecem elementos que permitem às concessionárias avaliarem a Qualidade do Serviço em relação às perturbações, quantificar o impacto da instalação de cargas perturbadoras no horizonte do planejamento e controlar as perturbações causadas pelas cargas em operação, identificando a necessidade de medidas corretivas. Elas podem servir também como orientação aos consumidores e aos fabricantes de equipamentos eletro-eletrônicos, para que não sejam produzidos ou utilizados dispositivos ou processos excessivamente causadores ou excessivamente sensiveis às perturbações. 
No país e principalmente no exterior, o assunto Qualidade de Energia enfocando os harmônicos é considerado um tema atual [4], apesar de ser um fenômeno que vem sendo estudado há várias décadas.

Também são muito enfatizados os estudos sobre o comportamento dos alimentadores submetidos às distorções harmônicas [5,6] e a influência dos harmônicos sobre os equipamentos [4].

\section{OBJETIVO}

A dissertação de mestrado tem como tema a avaliação dos distúrbios em sistemas de distribuição de energia elétrica, devido às distorções harmônicas. Neste estudo serão analisadas as medições de campo, para um dado consumidor, utilizando um aparelho eletrônico digital, controlado por microprocessadores.

De posse dessas informações e de alguns dados do sistema de distribuição de energia elétrica pode-se mensurar quais são os impactos envolvidos para a concessionária de energia elétrica, para o consumidor e para a sociedade, devido aos distúrbios causados pela distorção harmônica total, da tensão e da corrente. 


\section{CONSIDERAÇÕES GERAIS}

\subsection{Histórico}

Em 1888, foi publicado pela primeira vez um estudo sobre oscilações de potência entre uma tensão alternada e a carga causadas pelo ângulo de fase entre tensão e corrente. A explicação dada então por Stanley e Shallenberger [8,9] é ainda encontradas em livros textos e normas de engenharia, porém com algumas modificações.

Nos dias de hoje os engenheiros aceitam, sem reservas, as definições de potência aparente $(S)$, potência ativa $(P)$ e potência reativa $(Q)$ em sistemas senoidais. Indústrias e instituições metrológicas cooperam harmoniosamente no desenvolvimento e uso de instrumentação que medem esses parâmetros.

Os Programas de Gerenciamento de Energia assim como estudos de fluxo de potência são também dependentes dos modelos onde a Potência Ativa e a Potência Reativa $(P+j Q)$ são as variáveis complexas sobre as quais as otimizações econômicas são baseadas (correção de fator de potência por exemplo).

Após 1888 foram requeridos mais do que 40 (quarenta) anos e os talentos de Steinmetz [10], Houston e Kenelly [11], Iliovici [12], Budeanu [13], Emde [14], Knowlton [15], e Fortescue [16], para que fosse reconhecida e aceita a importância do fator de potência e da potência reativa.

Hoje o aumento do uso de conversores estáticos de potência, da proliferação de controladores de velocidade de motores, e o uso de capacitores de shunt para a minimização dos custos de energia, contribui para a criação de condições da análise da distorção da forma de onda da tensão e da corrente (distorção harmônica). 
Enquanto que as implicações sobre as formas de onda não-senoidais na liberação de energia elétrica foram claramente indicadas, vários pesquisadores anteriores $[13,14,17]$ e a comunidade de engenheiros, não têm chegado a um consenso para a aceitação universal da definição de potência nas redes elétricas em condições não-senoidais.

Os dois maiores modelos que dominam atualmente são as definições e componentes da potência reativa. A primeira é a escola de Budeanu, que é sancionada através das normas ANSI/IEEE 100-1977. A segunda escola é a de Fryze que influenciou a posição da IEC [18].

Fryze propõe um modelo com a potência aparente sendo igual a $\mathrm{S}^{2}=$ $\mathrm{P}^{2}+\mathrm{Qt}^{2}$ e provou que a potência reativa total $\mathrm{Qf}$ é composta de quatro tipos distintos de potências reativas elementares. Cada uma dessas potências reativas básicas são identificadas como sendo a amplitude de uma oscilação da potência instantânea. Recomendou também a separação de $Q_{r}$ em Q é a potência reativa do sistema na freqüência fundamental, e $Q_{H}$ a potência reativa das freqüências harmônicas, como sendo um método eficaz de monitoração da eficiência dos filtros e da compensação do fator de potência. As definições de Budeanu de potência reativa e de distorção em circuitos com formas de onda não-senoidais têm sido difundidas na área de engenharia elétrica, a despeito de algumas objeções, por quase 60 anos. As objeções tem sido feitas pois existem dúvidas se essas potências ( de distorção e reativa) podem ser definidas no domínio da freqüência e se elas podem ser medidas conforme a definição. Ele definiu a potência reativa como sendo $Q_{b}=\Sigma U_{n^{*}} I_{n^{*}}$ sen $\phi_{n}$ e ainda definiu uma nova quantidade, $D_{b}=$ $\sqrt{ } S^{2}-P^{2}-Q^{2}$, chamada de potência de distorção. As duas definições anteriores não fornecem qualquer atributo que possa ser relacionado com o fenômeno da potência no circuito em que este parâmetro esteja sendo calculado. Além disso seus valores não fornecem qualquer informação que 
possa habilitar o projeto de circuitos de compensação de fator de potência. Portanto, se os conceitos de Budeanu não forem reformulados podem conduzir a teoria dos circuitos com formas de onda não-senoidais a um impasse.

Os primeiros relatos sobre os efeitos criados por harmônicos ocorreram com a operação das primeiras instalações de conversores estáticos, aos quais, produzindo correntes harmônicas induzem ruídos em sistemas de comunicações.

Um dos primeiros problemas ocorreu na refinaria de cobre a oeste de Salt Lake City, E.U.A., na década de vinte, quando esta instalação foi energizada, interrompendo as conversações telefônicas transcontinentais que eram feitas no momento. Isto ocorreu porque o sistema C.A. de alimentação dos retificadores da refinaria seguia paralelamente às linhas telefônicas transcontinentais, e os harmônicos causados pelos retificadores induziam nas linhas tensões suficientes para criarem ruído nos circuitos telefônicos.

Outro evento interessante ocorreu numa mina no Canadá, durante a energização de uma instalação retificadora. As linhas de comunicações, partilhando o mesmo caminho que a alimentação C.A. da mina, tiveram induzido um nível de ruído tão forte que um chamado de socorro não podia ser entendido.

\subsection{Fenomenologia}

A palavra harnônico foi originalmente definida em acústica, significando a vibração de um fio ou uma coluna de ar, com freqüência múltipla à da fundamental, provocando uma distorção na qualidade de som resultante. 
Um fenômeno semelhante a este em acústica, tem ocorrido em Sistemas de Potência, cuja deformação tem sido observada.

Como se supõe, dentre os objetivos de uma concessionária de energia elétrica, destaca-se a qualidade do fornecimento de energia elétrica aos consumidores. Esta energia deve ser fornecida com uma tensão puramente senoidal, de frequiência e amplitude constantes.

Entretanto, na prática a operação de fornecimento de energia aos usuários causa deformações no sistema de suprimento. Este tipo de deformação é a distorção na forma de onda da tensão, a qual deve ser fornecida de forma mais senoidal possível. Conter estas distorções a níveis aceitáveis tem sido a preocupação dos profissionais que trabalham em Sistemas Elétricos de Potência.

Desenvolveu-se ao longo dos anos, análises matemáticas, com base no estudo das ondas não-senoidais periódicas, permitindo que qualquer onda constituida de distorção, possa ser decomposta através da série de Fourier, em uma componente de mesma freqüência que a onda distorcida, comumente denominada, "Onda Fundamental", e em outras também senoidais de frequiências múltiplas à fundamental, que como em acústica, receberam a denominação de "harmônicos". Vide figura 3.2.1.

A figura 3.2.1 (a) apresenta uma forma de onda característica do fenômeno no domínio do tempo, a figura 3.2.1 (b) apresenta um caso real do fenômeno sendo medido no domínio da freqüência (observar o comportamento do $5^{\circ}$ harmônico), a figura 3.2 .1 (c), apresenta o fenômeno sendo medido em termos de distorção harmônica total da tensão durante a transmissão de uma partida de futebol na Copa do Mundo de 1986, num alimentador de uma sub-estação de $230 \mathrm{kV}$ em Fortaleza.(observar o comportamento do $5^{\circ}$ harmônico durante o horário de transmissão da partida, entre as 15 e as 17 horas, curva "b"). 


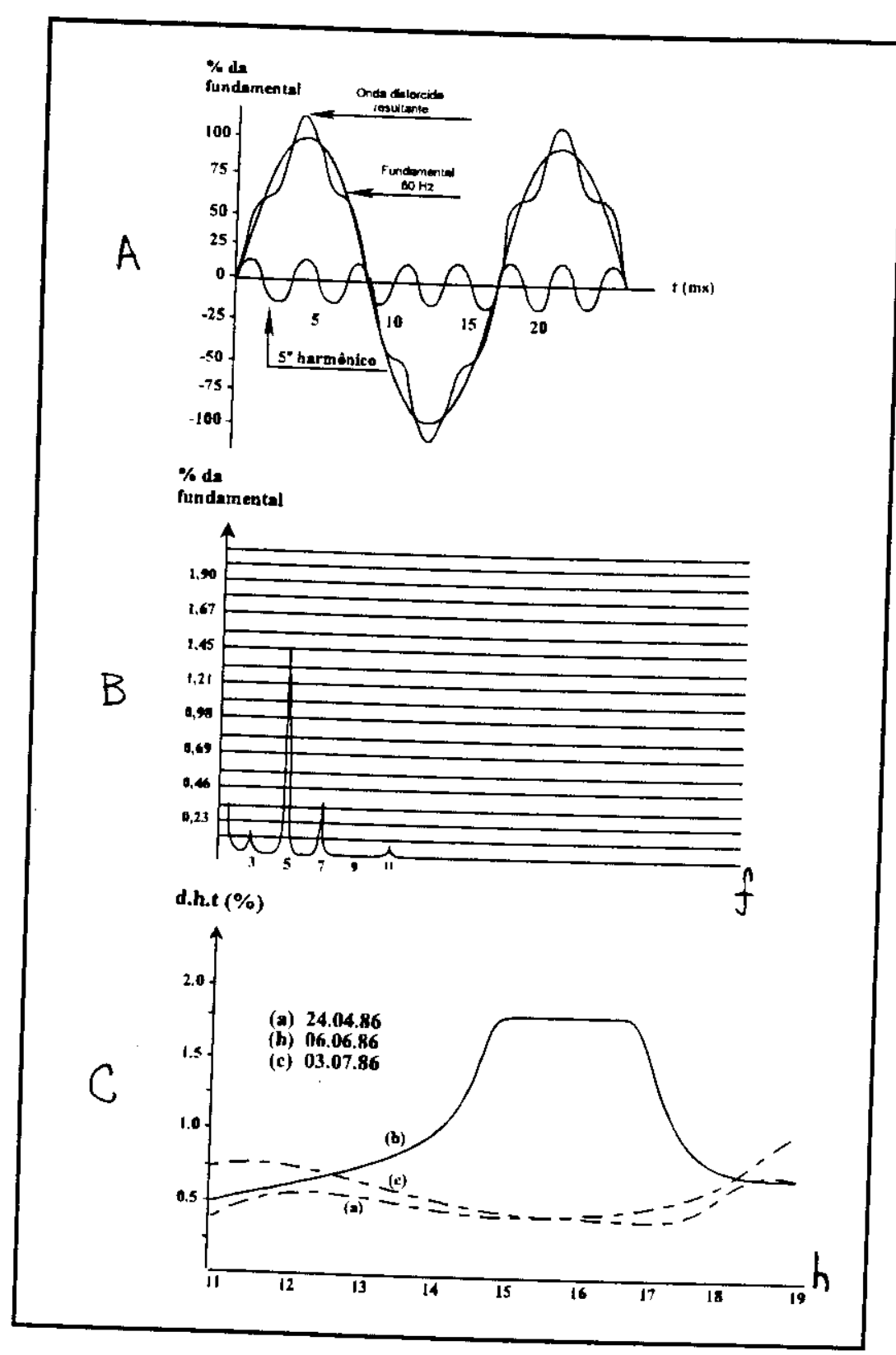

Figura 3.2.1 (a), (b), (c) - O Fenômeno harmônicos

Existe hoje um interesse muito grande sobre esta questão devido ao número elevado de cargas elétricas "não-lineares" produzindo sinais distorcidos conectados junto ao sistema alimentador e também ao aumento de cargas elétricas "sensíveis" a essas distorções dificultando a manutenção da Qualidade de Energia para os consumidores. 
A expressão Qualidade de Energia ou de Potência, é nova e sua definição ainda não é um consenso dentre a comunidade que milita na área eletro-eletrônica. Uma das definições aceita pelos membros do IEEE (Instituto dos Engenheiros Eletro-Eletrônicos dos Estados Unidos) no que se refere ao suprimento de energia elétrica, é a seguinte: ao manter-se a energia elétrica (corrente, tensão) dentro de padrões normalizados ou aceitáveis no que se refere à amplitude, freqüência, desbalanceamento entre fases, distorção da forma de onda tem-se uma energia elétrica de Qualidade (Power Quality).

As cargas "não-lineares" são definidas como sendo àquelas que ao serem excitadas por uma tensão cuja forma de onda seja senoidal, terão a forma de onda da corrente não-senoidal. Como exemplos temos: Conversores Estáticos de Potência, Transformadores de Máquinas Rotativas, Fornos a Arco Elétrico, Fornos a indução, Reatores Eletrônicos, etc.

As cargas "sensíveis" são definidas como sendo aquelas cargas que ao serem excitadas por uma tensão não-senoidal apresentam mau funcionamento podendo até sofrerem danos por isso. Como exemplo temos: Microcomputadores, Caixas Eletrônicos, Terminais de Dados, VideoCassete, Rádio-Relógio Digital, etc. 


\subsubsection{Forma de Onda Ideal da Tensão}

Quando um sistema de potência trifásico alimenta um conjunto de refiticadores configurados em ponte, vide figura 3.2.1.1, e assumindo-se o circuito sem carga no lado de corrente contínua dos retificadores, a maior tensão de linha (fase-fase) será conectada para o circuito de carga produzindo uma forma de onda de tensão conforme a figura 3.2.1.2:

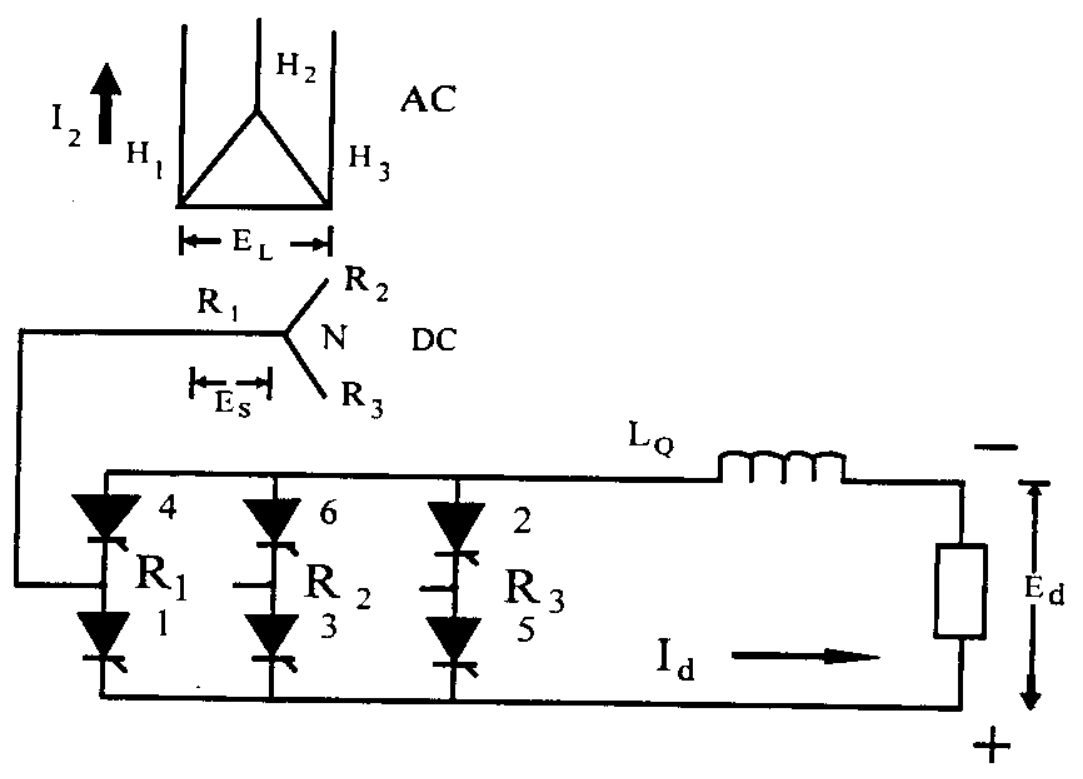

Figura 3.2.1.1 - Circuito trifásico com retificador em ponte

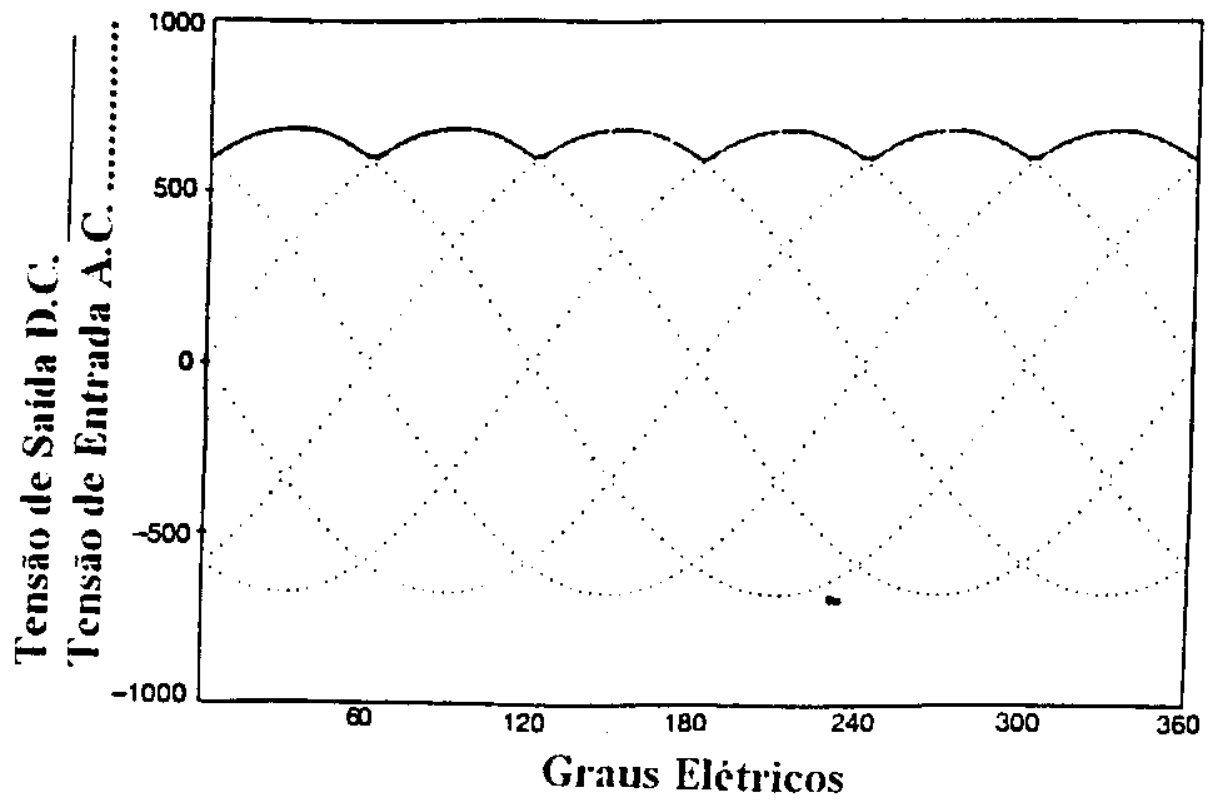

Figura 3.2.1.2 - Forma de Onda Ideal da saída do retificador em ponte 


\subsubsection{Forma de Onda Ideal da Corrente}

A figura 3.2.2.2 ilustra a forma de onda ideal da corrente de um retificador em ponte. Seu formato retangular é baseado na premissa que a corrente contínua não possui nenhuma ondulação (ripple), e que a corrente contínua é transferida de uma fase para outra, fase "R" para fase "S" no exato instante em que a tensão sobre a fase que entra fase " $S$ ", por exemplo, excede a tensão sobre a fase que sai, fase "R" por exemplo. A equação para as componentes das correntes harmônicas da forma de onda da corrente alternada é:

$$
h=k q \pm 1
$$

$\mathrm{Ih}=\mathrm{I}_{1} / \boldsymbol{h}$

onde:

$h$ é a ordem harmônica

$\boldsymbol{k}$ é qualquer integração positiva

q é o número de pulsos do circuito retificador

Ih é a amplitude da corrente harmônica de ordem $h$

I é a amplitude da corrente fundamental

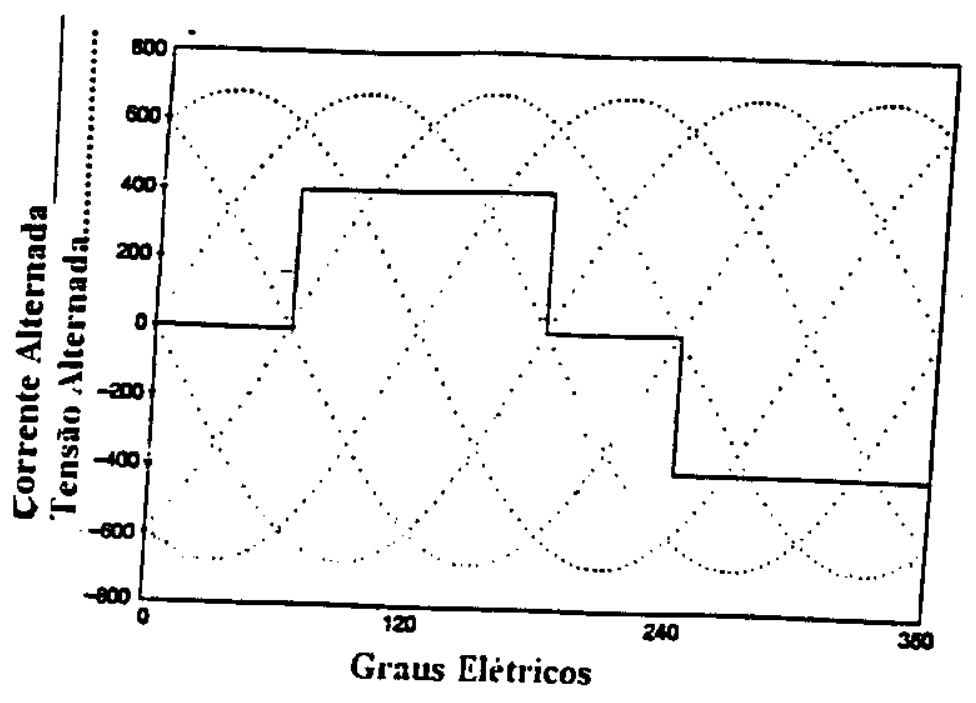

Figura 3.2.2.2 - Forma de Onda Ideal da Corrente Alternada 


\subsubsection{Fenômeno da Comutação}

Uma forma de onda de corrente retangular sugere que a indutância é zero ou a fonte é infinita num circuito de corrente alternada alimentando o retificador, neste caso, não ocorrem cortes na tensão. Quando a indutância está presente, a corrente não é transferida instantaneamente de uma fase para outra, em vez disso, existe um período de sobreposição (ou comutação) durante o qual os dois dispositivos estão conduzindo. Durante a sobreposição, existe um transitório de corrente alternada devido a um curtocircuito através dos dois dispositivos que estão conduzindo. Este curtocircuito, é interrompido por uma corrente reversa que sai do dispositivo. A duração do período de sobreposição depende do fechamento do ângulo de curto-circuito em corrente alternada e seu valor provável.

A figura 3.2.3.1 ilustra as condições de comutação com o ângulo $\alpha$, igual a zero, que é o ângulo que define o tempo de atraso; e o ângulo $\mu=25$ graus, que é o ângulo que define o tempo de comutação.

As diferenças entre os dois casos são devido a taxas diferentes de aumento da corrente na entrada da fase. Quando $\alpha$ igual 0 , as condições de curto-circuito são correspondentes à máxima assimetria com uma característica lenta de crescimento inicial da corrente. Para $\alpha$ igual a 90 graus, as condições de curto-circuito são de assimetria igual a zero com uma característica rápida de crescimento inicial da corrente. Para este ângulo de atraso, a sobreposição é muito pequena para um valor particular de corrente. 


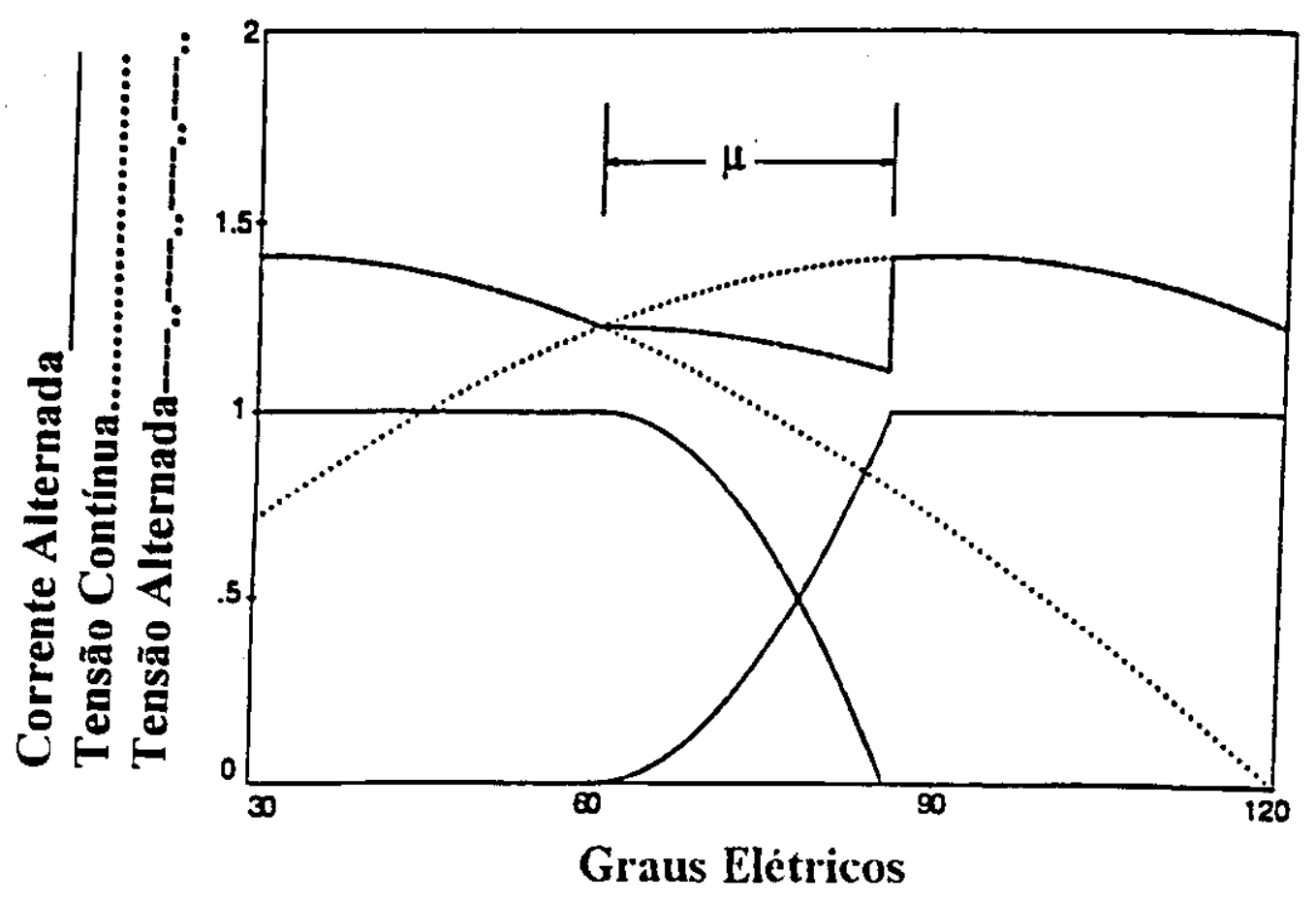

Figura 3.2.3.1 - Sobreposição na comutação para $\alpha=0^{\circ}, \mu=25^{\circ}$

\subsection{FONTES HARMÔNICAS [21], [22], [23], [24]}

Os geradores utilizados nos sistemas de energia são projetados para produzir uma tensão senoidal, de tal modo que, para objetivos práticos, pode-se considerar a forma de onda de tensão gerada como puramente senoidal. Desta forma, todas as distorções consideradas significativas ocorrem na transmissão e na distribuição entre os geradores e as cargas.

De um modo geral, costuma-se dividir as cargas geradoras de harmônicos em três grupos básicos:

(I) - Cargas de Conexão Direta ao Sistema: 
. motores de corrente alternada;

transformadores alimentadores;

. circuitos de iluminação com lâmpadas de descarga;

. fornos a arco,

. etc

(II) - Cargas Conectadas Através de Conversores:

. motores de corrente contínua controláveis;

- retificadores controlados;

. motores de indução controláveis;

- inversores auto-controlados;

- retificadores não controlados de grande potência;

- ciclo conversor;

. etc.

(III) - Reguladores:

freqüência;

todos os sistemas de controle que não envolvem variação de

- fornos de indução controlados por reatores saturados;

- cargas de aquecimento controladas por tiristores;

- velocidade dos motores CA controlado por tensão por estator. 
As cargas denominadas "cargas residenciais", podem tomar-se bastante significativas em virtude do grande número que são usadas simultaneamente e por períodos relativamente grandes. Neste grupo podem ser incluídos os pequenos motores de corrente alternada, controlados ou não, usados em:

\author{
. compressores de refrigeradores \\ . ventiladores \\ . bombas elétricas \\ ferramentas elétricas
}

As diversas cargas do sistema que são capazes de gerar harmônicos são rapidamente discutidas a seguir:

\title{
A. Geradores
}

Função: é uma máquina elétrica que converte energia mecânica em energia elétrica e as formas de onda das tensões produzidas pelos geradores são usualmente bastante próximas do aspecto senoidal.

Características dos harmônicos: um gerador de corrente alternada pode ser considerado como uma fonte de tensões harmônicas equilibradas de seqüência zero, ou seja, os harmônicos gerados são predominante os de ordem $3(180 \mathrm{~Hz}$, para uma forma de onda de $60 \mathrm{~Hz}$ ) e seus múltiplos (360 $\mathrm{Hz}, 540 \mathrm{~Hz}$, etc).

Causa: a origem destes harmônicos pode ser explicada em termos da distribuição do fluxo magnético na máquina. Em substituição ao desejado fluxo perfeitamente senoidal, sabe-se que a distribuição do fluxo magnético 
no entreferro (intervalo radial entre as partes ferromagnéticas do rotor do gerador) para um alternador é do tipo ilustrado na figura 3.3.1

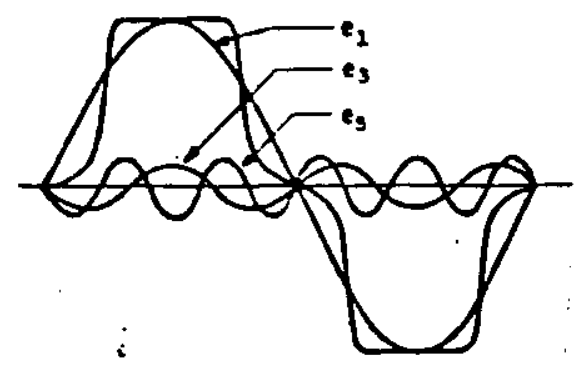

Figura 3.3.1 - Distribuição do fluxo magnético

Analisando a forma de onda do fluxo magnético pela série de Fourier, verifica-se que a mesma pode ser considerada como a composição de uma componente fundamental, na qual são superpostos diversos componentes harmônicos de ordem ímpar. Então, a cada componente de fluxo estará associada uma correspondente tensão.

Deve-se ainda observar que os harmônicos de ordem diferente de três, ou seus múltiplos, constituirão um sistema equilibrado de tensões harmônicas. Entretanto, o $3^{\circ}$ harmônico, e múltiplos deste, formarão um sistema de tensões de seqüência zero.

Valores típicos: para estes harmônicos [21] tem-se:

$$
\begin{aligned}
& 7,5 \% \text { para o } 3^{\circ} \text { harmônico } \\
& \text { 1,5\% para o } 5^{\circ} \text { harmônico } \\
& 0,7 \% \text { para o } 7^{\circ} \text { harmônico }
\end{aligned}
$$




\section{B. Transformadores}

Função: são transdutores de energia elétrica, estáticos, que transferem energia elétrica sem mudança na freqüência.

Causa: podem ser considerados como geradores de tensões e/ou de correntes harmônicas, que aparecem devido à distorção magnética e a componente harmônica dos fluxos induzindo força eletromotriz em seus enrolamentos. Deve ser ressaltado que o projeto econômico dos transformadores exige que seu núcleo, normalmente aço-silício com grãos orientados, trabalhe na parte não linear da curva de saturação, resultando em apreciável saturação. Nestas condições, a corrente de magnetização não é uma onda senoidal e sua forma depende da caracteristica (curva B-H, figura 3.3.2) do circuito magnético do transformador. A forma de onda da corrente é aquela mostrada na figura 3.3.2.b. Observa-se que, apesar do fluxo ser senoidal, a corrente é uma onda distorcida.

Característica dos harmônicos: a análise desta onda de corrente mostra que ela contém componentes harmônicas impares de valores consideráveis, estando a componente de $3^{\circ}$ harmônico representada na figura 3.3.2.b.

Valores típicos: [21] dos harmônicos são:

$$
\begin{aligned}
& 45 \% \text { para o } 3^{\circ} \text { harmônico } \\
& 15 \% \text { para o } 5^{\circ} \text { harmônico } \\
& 3 \% \text { para o } 7^{\circ} \text { harmônico }
\end{aligned}
$$

Estes valores são expressos em porcentagem do valor da onda fundamental da corrente total de excitação, a qual é praticamente constante e independente da carga. 


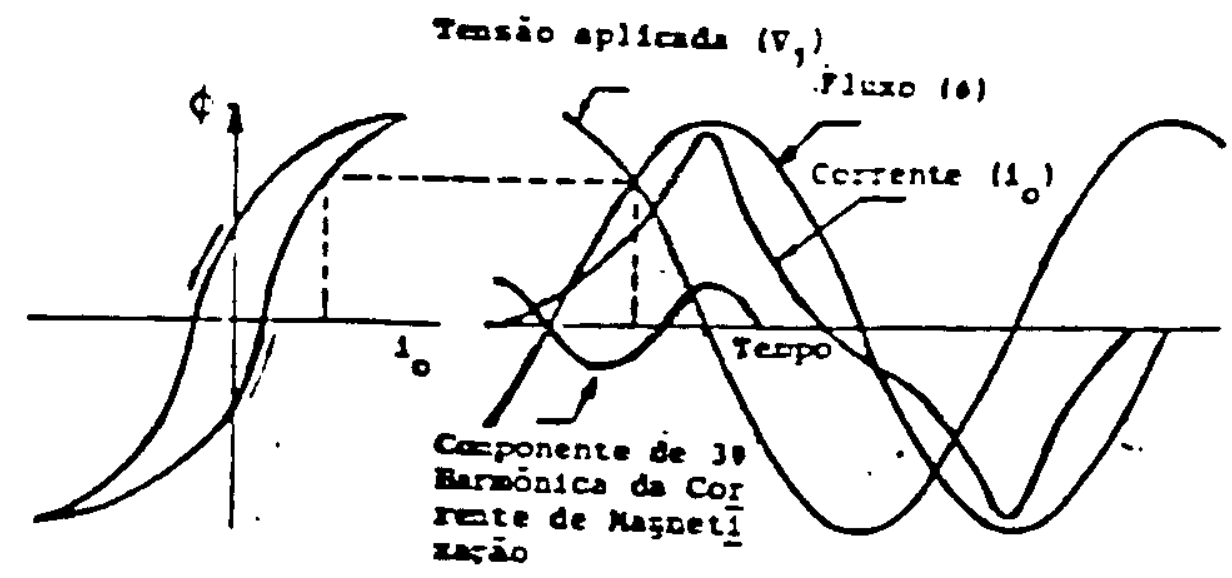

a) Curva B-H do transformador

b) Onda de tensão de fluxo de corrente

Figura 3.3.2 - Formas de onda da corrente de magnetização, da tensão aplicada, do fluxo, (atrasado $90^{\circ} \mathrm{em}$ em relação à tensão) e do $3^{\circ}$ harmônico compo nente da corrente.

C. Compensadores Estáticos de Energia Reativa

Fuņ̣ão: são dispositivos elétricos que funcionam sem carga mecânica, fornecendo ou absorvendo potência reativa.

É fato conhecido que os estudos do fluxo de potência dos sistemas elétricos devem ser feitos com balanço de potência ativa e reativa ao longo do sistema. Desse modo, a componente reativa da corrente circulando através das impedâncias do sistema é, em grande parte, responsável pela regulação de tensão nos terminais de carga. Quando o valor desta componente se torna razoavelmente alto, a queda de tensão pode ser inconveniente, ou mesmo proibitiva, para a operação satisfatória da instalação. 
Dentre os vários sistemas de compensação estática utilizados para balancear esta energia reativa, pode-se citar as seguintes formas dinâmicas [21]:

. reator a núcleo saturado

. reator controlado por tiristores

capacitores chaveados a tiristores

. e a combinação destas formas dinâmicas

Sob o ponto de vista de geração de harmônicos, pode-se dizer que somente os dois primeiros introduzem harmônicos no sistema elétrico de alimentação. Sendo $K=1,2,3, \ldots$. e $P$ o número de pulsos da instalação, tem-se que o primeiro tipo gera harmônicos de ordem:

$$
\begin{aligned}
& n=(2 K P \pm 1) \\
& n=(6 K P \pm 1) \\
& n=(12 K P \pm 1)
\end{aligned}
$$

O segundo tipo é composto de um reator chaveado por meio de tiristores e inclui um banco de capacitores.

Característica dos harmônicos: para um reator chaveado por meio de tiristores incluindo um banco de capacitores, pode-se afirmar que aparecem, por fase, principalmente os harmônicos de $3^{\mathrm{a}}, 5^{\mathrm{a}}, 7^{\mathrm{a}}$ ordens.

Valores típicos: não excedem os percentuais típicos [21] de $[13,5 \%]$, $[5,8 \%]$ e $[2,5 \%]$ da fundamental, respectivamente. De uma forma geral, os harmônicos que podem aparecer, por fase, são de ordem: $n=(2 \mathrm{~K} \pm 1)$. 


\section{Fornos a Arco}

Os fornos a arco, muito utilizado para fundição de sucatas, tiveram nos últimos anos uma tendência, principalmente nas indústrias de maior, porte, de um crescimento substancial. Isto deve-se, dentre outros fatores, ao fato de que o processo metalúrgico empregado é mais simples e também, à utilização de energia elétrica como alternativa energética, por ser mais atrativa e de menor custo.

A operação dos fornos a arco é caracterizada principalmente através das conduções elétricas em arcos (plasma), a não linearidade do processo conduz ao aparecimento de distúrbios, tais como flutuações de tensão e geração de correntes harmônicas. Devido ao fato que este tipo de equipamento permite uma variação aleatória da corrente, torna-se muito dificil a previsão determinística da sua composição harmônica. Assim, a referência [23] fornece resultados estatísticos obtidos nos niveis harmônicos. A tabela 3.3.3 fornece de forma resumida as ordens e os niveis de harmônicos de corrente produzidos por uma unidade constituída por um forno a arco.

\begin{tabular}{|r|l|l|}
\hline HARMÓNICO & AMPLITUDE & NIVEL \\
\hline DE ORDEM & MÉDIA & MÁXIMO \\
\hline "N" & $(\%)$ & $(\%)$ \\
\hline 2 & 3 a 5 & 30 \\
\hline 3 & 6 a 10 & 20 \\
\hline 4 & 2 a 6 & 15 \\
\hline 5 & 2 a 10 & 12 \\
\hline 6 & 2 a 3 & 10 \\
\hline 7 & 3 a 6 & 8 \\
\hline 9 & 2 a 5 & 7 \\
\hline
\end{tabular}

Tabela 3.3.3 - Ordens e níveis médios de harmônicos, produzidos por fornos a arco ( $\%$ da fundamental) 
E. Ponte Trifásica Totalmente Controlada [25], [24], [26], [27], [28],[29]

Trata-se de um equipamento estático, que tem por objetivo transformar uma tensão alternada em contínua, sendo formada basicamente por seis tiristores. Devido à característica de operação, este equipamento pode gerar correntes harmônicas nas ordens $n=6 \mathrm{~K} \pm 1$, onde $\mathrm{K}=1,2,3, \ldots$

As correntes assim definidas por componentes harmônicas características ocorrem somente em condições ideais de operação. Entretanto, como estas condições são dificeis de acontecer na prática, as anomalias que ocorrem na operação do sistema conversor podem levar à geração de outras ordens harmônicas; tais como, as componentes pares e as múltiplas de 3 .

Dentre as causas e efeitos sobre a geração de harmônicos nãocaracterísticos pode se citar:

- erros no sistema de disparo [26]

- desequilíbrios da tensão c.a. de alimentação [27]

- distorções na tensão de alimentação [28]

- desequilíbrios entre as impedâncias do sistema c.a. [29].

- desequilibrios do circuito da própria ponte retificadora

F. Ponte Trifásica Semi-Controlada [30]

A sua característica de operação é muito semelhante à da ponte totalmente controlada, diferenciando apenas no número de tiristores utilizados. A ponte semi-controlada é formada por apenas três tiristores, sendo os outros três substituídos por diodos, característica esta que não pernite o controle total. Apesar desta economia no número de tiristores e no 
sistema de controle, tal equipamento possui uma grande desvantagem, que é a de produzir niveis das correntes harmônicas maiores, que aquelas dos conversores convencionais (controlados e não controlados), além de gerar outras ordens harmônicas.

As ordens dos harmônicos gerados por tal equipamento são previamente expressos por $\mathrm{n}=3 \mathrm{~K} \pm 1$, o que implica no aparecimento dos componentes de ordem par.

G. Regulador CA, Ciclo-Conversor e Inversor com Comutação Forçada [30]

Estes são equipamentos estáticos, de uso mais restrito e menores potências, porém que também geram harmônicos devido a característica não-linear. Normalmente, para o sistema $\mathrm{CA}$ estas cargas são vistas como um retificador (ciclo e inversor) e não alteram o exposto anteriormente. $O$ caso do regulador foge a esta condição.

H. Aparelhos de som e Televisores, Lâmpadas Fluorescentes e Dimers.

Estes são cargas normalmente instaladas nos consumidores residenciais, e que tomam uma importância relevante na geração de harmônicos, pois produzem um efeito combinado de várias instalações de pequeno porte, operando com características não-lineares.

3.4 Efeitos dos Harmônicos em Equipamentos

\subsubsection{Introdução}

No tocante aos problemas causado pelos harmônicos, além dos já citados em sistemas de comunicações telefônicas, destacam-se outros sobre 
a rede e os equipamentos de potência e eletrônica, abordados nas referências [33], [34], [35], [36], [37], [38], [39], [40], [41], [42].

De forma geral, os efeitos das distorções podem originar problemas que podem ser divididos em três grupos:

. solicitação do isolamento associada à distorção de tensões;

. solicitação térmica, devido à circulação de correntes harmônicas;

. operação indevida de diversas naturezas.

Nos dois primeiros grupos encontram-se além de outros, diminuição da vida útil de transformadores, máquinas rotativas e banco de capacitores.

No último grupo estariam enquadrados os problemas mais diversos, os quais poderiam refletir numa operação normal ou mesmo errônea de uma dado equipamento ou sistema, ou na sua falha por completo. Nesta categoria, estariam agrupados efeitos como: torques oscilatórios nos motores C.A., falhas de diversos equipamentos a estado sólido, etc.

Embora tais tópicos devam fazer parte integrante de uma investigação conjunta entre efeitos e limites permissíveis, é conveniente mencionar que este aspecto foi esquecido pelos pesquisadores brasileiros, nos anos passados. Neste sentido ressalta-se a necessidade de que isto seja considerado no presente de forma prioritária e que a interação entre empresas de energia, indústrias e instituições de ensino venham a explorar, obter métodos para simulação e experimentos, obter limites de tolerância, avaliar efeitos sobre a vida útil de equipamentos, etc. 


\subsubsection{O estado do conhecimento}

A fim de se tentar resumir o estado do conhecimento dos efeitos dos harmônicos em sistemas de potência nos equipamentos, chegou-se a algumas conclusões. Uma delas é que geralmente os fenômenos que ocorrem devido a presença de harmônicos nos equipamentos são: sobrecarga térmica, disrupção e estresse em dielétricos. Os efeitos quantitativos são referenciados quando possivel, entretanto vários efeitos somente poderão ser qualitativamente descritos. Os equipamentos analisados são: acionadores de motores com velocidade variável, capacitores, circuitos de proteção, fusíveis, cabos,. equipamentos eletrônicos, iluminação, medidores, relês de proteção, máquinas rotativas, telefones e transformadores.

\section{A. Acionadores de motores com velocidade variável}

Os Acionadores de motores com velocidade variável (A.S.D's) são conversores eletrônicos que permitem a operação dos motores em corrente contínua ou corrente alternada, com a variação de velocidade. Na literatura conhecida os A.S.D's são discutidos somente como cargas geradoras de harmônicos (não-lineares) e não como cargas sensiveis às distorções harmônicas. Entretanto, na prática, estes equipamentos são vulneráveis a uma grande variedade de distúrbios e os problemas necessitam serem documentados. No entendimento de pesquisadores destes equipamentos, existe uma vulnerabilidade à distorção harmônica na tensão, de modo similar aos equipamentos eletrônicos que serão discutidos a diante. 


\section{B. Capacitores}

$O$ uso de capacitores em forma de shunt para melhorar o fator de potência e a tensão têm uma significativa influência nos níveis harmônicos. Os capacitores não geram harmônicos, mas fornecem laços (loops) na rede de distribuição de energia elétrica, que podem provocar condições para ressonâncias. Se a rede de distribuição, ressoa perto da freqüência presente na corrente de carga ou na tensão do sistema devido a inserção de capacitores sintonizados, serão produzidos valores elevados de tensão ou corrente para aquela freqüência. A freqüência de ressonância de um sistema de baixa tensão com um banco de capacitores pode ser encontrado em

$$
\mathrm{n}=(\mathrm{Qs} / \mathrm{Qc})^{1 / 2} \text { (fórmula preliminar) }
$$

onde n é a ordem do harmônico para o qual a ressonância pode ocorrer, Qs é o curto-circuito disponível em Potência Aparente (kVA), e Qc é a taxa em Potência Reativa (kVAr) do banco de capacitores.

Em várias instalações de baixa tensão podem ser seguidas as orientações abaixo:

1. Se a Potência Aparente (kVA) da carga produzindo harmônicos é menor que $10 \%$ da Potência Aparente $(\mathrm{kVA})$ do transformador, os capacitores podem ser instalados sem problemas de ressonância.

2. Se a Potência Aparente (kVA) da carga produzindo harmônicos é menor que 30\% da Potência Aparente (kVA) do transformador e a Potência Reativa do capacitor (kVAr) é menor que $20 \%$ da Potência Aparente (kVA) do transformador, os capacitores podem ser instalados sem problemas de ressonância. 
3. Se o Potência Aparente (kVA) da carga produzindo harmônicos é maior do que $30 \%$ da Potência Aparente (kVA) do transformador, os capacitores devem ser instalados com filtros.

$\mathrm{O}$ efeito das componentes harmônicas causa aquecimento adicional e estresse elevado no dielétrico dos capacitores. A norma ANSI/IEEE 181980 fornece as limitações de tensão, corrente e potência reativa para banco de capacitores que podem ser usados para determinar o nivel harmônico máximo permitido.

Esta norma indica que o capacitor pode ser operado continuamente dentro das seguintes limitações, incluindo as componentes harmônicas:

\section{$110 \%$ da tensão eficaz \\ $120 \%$ da tensão de pico \\ $180 \%$ da corrente eficaz \\ $135 \%$ da potência reativa}

Quando um harmônico predomina (o que ocorre frequentemente), a figura 3.4.1 oferece um meio de determinar a máxima corrente harmônica permitida, para uma dada tensão fundamental, com as limitações fornecidas pela norma ANSI/IEEE 18 - 1980.

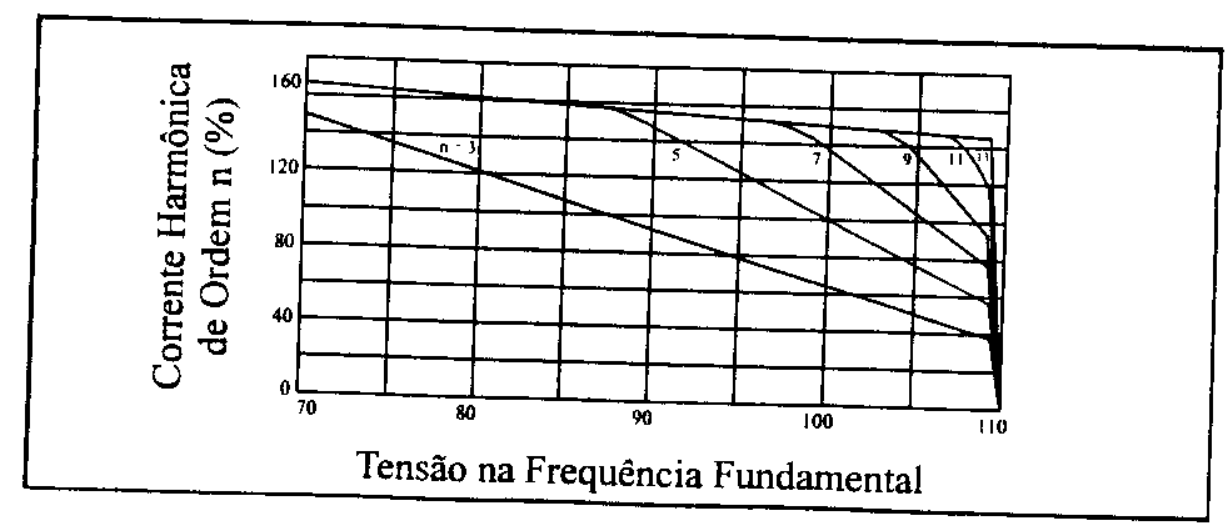

Figura 3.4.1 - Máxima Corrente permissível para tensão na frequiência fundamental 
Apesar desta tentativa de superdimensionar os capacitores para condições anormais, tais como os harmônicos, vários problemas com os harmônicos aparecem primeiro no banco de capacitores ou nos fusíveis de proteção, que se rompem, ou ainda nas unidades de capacitores que apresentam falhas.

A razão para os problemas nos capacitores é que este componente é uma parte do laço ressonante e a corrente e a tensão que serão amplificadas pela ressonância, se tomarão muito maiores que os valores locais.

Se os harmônicos de corrente estão acima do limite permitido, uma ou mais das seguintes correções podem ser realizadas:

1. A realocação dos capacitores para outras partes do circuito pode reduzir a sobrecorrente devido a ressonância. As cargas geradoras de harmônicos e os bancos de capacitores, não podem dividir o mesmo transformador.

2. Para um banco de capacitores da concessionária conectados em estrela, a conexão do neutro para o terra pode ser removida para prevenir os harmônicos de terceira ordem que podem fluir através dos capacitores. (Deve ser observada a isolação do banco de capacitores e taxa de chaveamento da carga pode estar inadequada se o neutro é desconectado.)

3. Se as correções acima falharem, pode ser necessário inserir-se un reator sintonizado. A função do reator é ajustar a freqüência de ressonância acima da freqüência harmônica da tensão ou da corrente (tipicamente a $5^{\mathrm{a}}$ ou a $7^{\mathrm{a}}$ harmônica). Considerações muito criteriosas devem ser feitas para permitir o aumento da tensão ou corrente na carga sobre o capacitor, como resultado da inserção do reator.

A impedância capacitiva diminui com o aumento da freqüência. A corrente no capacitor será: 


$$
\mathrm{In}=\mathrm{n}(\mathrm{Vn})
$$

onde In é a corrente harmônica percentual, $\mathrm{n}$ é o número do harmônico, e Vn é a tensão harmônica aplicada. Por exemplo, se uma tensão sobre um capacitor tem $15 \%$ de componente de $7^{\mathrm{a}}$ harmônica, a corrente no capacitor será $105 \%$. Isto demonstra porque fusíveis rompendo-se aleatoriamente em bancos de capacitores é frequentemente um sintoma de problemas com harmônicos. O limite de corrente, ainda que $180 \%$ do seu valor nominal, pode ser baixo, pois a tensão média individual nas unidades de capacitores, são frequentemente protegidas com $125 \%$ a $165 \%$ do valor de suas correntes nominais. Os capacitores de baixa tensão são protegidos com $200 \%$ dos seus valores nominais.

Os capacitores instalados nos bancos de filtros permitem controlar a distorção harmônica e conjuntamente, possibilita os benefícios associados com a correção do fator de potência. Nestas aplicações, os capacitores devem ter as especificações citadas acima. A inserção de reatores, eventualmente pode aumentar a tensão no capacitor, pois o capacitor deve cancelar a pequena queda de tensão introduzida através do reator. Como resultado, a tensão nominal dos capacitores nos bancos de filtros, são usualmente especificados num valor que é pelo menos $10 \%$ maior do que a tensão nominal do sistema. Se o filtro entra em ressonância perto da freqüência harmônica do sistema, este dispositivo pode cancelar correntes harmônicas de cargas distantes (como sendo um circuito derivativo de baixa impedância) e a corrente que carrega capacitivamente os seus condutores, pode fazer com que seja necessário aumentar substancialmente 0 dimensionamento dos valores nominais dos componentes dos filtros. 


\section{Fusiveis e Circuitos de Proteção}

Existem algumas evidências de que a distorção harmônica da corrente pode afetar a susceptibilidade de interrupção dos circuitos de proteção. A corrente na carga pode ser distorcida e baixos níveis de falhas podem conter altas porcentagens de correntes distorcidas. As correntes de falha de níveis elevados não serão influenciadas pelas correntes distorcidas na carga.

Quando a distorção está presente na carga, pode resultar em elevados valores de derivadas da corrente (di/dt) na passagem da forma de onda pelo zero (zero-crossing), maiores do que para uma forma de onda senoidal, fazendo com que o desligamento ocorra com maior dificuldade.

Lembo e D'Onofrio [44] descrevem várias falhas em redes de $15 \mathrm{kV}$ devido a correntes harmônicas. As correntes com 50\% de distorção harmônica limitaram o funcionamento das bobinas (indutores) dos circuitos de proteção. Além disso, as interrupções prolongadas também retardaram a dissipação de correntes de falha e causaram reignição após rápidos desligamentos. Os interruptores a vácuo são menos sensíveis aos harmônicos de corrente do que protetores magnéticos a ar.

Brozek [45] descreve como a distorção harmônica afeta a sensibilidade à corrente dos protetores termo-magnéticos. O mecanismo instantâneo de alguns protetores é uma solenóide que dissipa energia adicional, devido a perdas ocasionadas por frequiencias maiores do que a fundamental. Este aquecimento aumenta a temperatura do dispositivo térnico e reduz o ponto de disparo. Para a freqüência de $300 \mathrm{~Hz}$, o ponto de disparo de um sinal com $225 \mathrm{~A}$, num circuito de proteção, pode ser reduzido entre $10 \%$ e $20 \%$.

Como os fusiveis tem atuação térmica, eles são dispositivos inerentes a sobrecorrentes de valores eficazes [45]. A ligação em alguns fusiveis, nas empresas concessionárias de distribuição de energia elétrica, consiste de 
várias fitas metálicas que são susceptíveis ao efeito pelicular, aquecendo-se devido a correntes harmônicas. Entretanto, os problemas relatados com fusiveis devido a harmônicos podem, eventualmente, ser mensuráveis.

Dependendo da forma de onda e do processo de medição, um amperímetro pode indicar as correntes acima e abaixo do valor eficaz. Se uma corrente distorcida é medida, com outro aparelho, que não seja um amperímetro que mede valor eficaz, pode parecer que o fusivel de proteção comporta-se indevidamente. Alguns testes feitos por um fabricante de fusiveis têm mostrado que até $415 \mathrm{~Hz}$ não existe nenhuma mudança nas suas características de operação.

D. Condutores

Existem dois mecanismos nos quais as correntes harmônicas podem causar aquecimento nos condutores. O primeiro mecanismo é devido a correntes de redistribuição dentro do condutor e incluem o efeito pelicular e o efeito de proximidade.

O efeito pelicular é devido a blindagem da parte interna do condutor pela camada externa. Sendo a corrente concentrada na camada externa, a resistência efetiva do condutor é aumentada. O efeito pelicular aumenta com a frequiência da corrente e com o diâmetro do condutor.

$\mathrm{O}$ efeito de proximidade é devido ao campo magnético dos condutores que distorce a corrente de distribuição nos condutores adjacentes. Em volta dos cabos o efeito de proximidade é muito menos pronunciado do que o efeito pelicular [46].

As tubulações metálicas também contribuem para o efeito de proximidade. Os autores Arrillaga [42] e Rice [47], apresentam fórmulas e tabelas para os valores de resistências do condutor em corrente altemada ou 
em valores eficazes devido ao efeito pelicular e o efeito de proximidade. Por exemplo, a razão entre a resistência em corrente contínua e a resistência em corrente alternada em função do $5^{\circ}$ harmônico de corrente $(300 \mathrm{~Hz})$ nos condutores imediatamente próximos aos de bitola 4/0 AWG é 1,33 [47].

$O$ segundo mecanismo causa correntes elevadas e anormais no condutor neutro dos sistemas de distribuição trifásicos, a quatro fios, que alimentam cargas monofásicas. Algumas cargas tais como as fontes de alimentação chaveadas, produzem correntes de $3^{\circ}$ harmônico $(180 \mathrm{~Hz})$ de valores significativos.

As correntes trifásicas balanceadas na frequiência fundamental (60 $\mathrm{Hz}$ ), farão com que não exista nenhuma corrente no neutro do sistema. Entretanto, em circuitos trifásicos, as correntes de $3^{\circ}$ harmônico, somadas, ao invés de cancelarem as correntes no condutor neutro, podem ser muito maiores do que 1,7 vezes as correntes de fase de cargas de conversores. Como este condutor normalmente é dimensionado, com a mesma bitola dos condutores que são alimentados pelas fases, então o condutor neutro pode ser sobrecarregado.

O problema ocorre mais comumente em instalações comerciais onde o sistema de distribuição trifásico alimenta uma grande quantidade de equipamentos eletrônicos de escritórios que são na sua grande maioria cargas monofásicas. Um estudo das correntes do condutor neutro existentes em centros de processamento de dados com recomendações corretivas são apresentados por Gruzs [48].

A correção mais comum é dimensionar o condutor neutro para ser pelo menos duas vezes a ampacidade do condutor da fase. 


\section{E. Equipamentos Eletrônicos}

Existem vários mecanismos pelos quais a distorção harmônica afeta os equipamentos eletrônicos. As múltiplas tensões com a passagem pelo zero, "zero crossing", como resultado da distorção harmônica é a primeira a ser considerada. É muito comum a utilização em circuitos eletrônicos do uso da técnica de cruzamento da tensão pelo zero, "zero crossing", na freqüência fundamental de potência $(60 \mathrm{~Hz})$, para aplicações temporizadas.

Entretanto, a distorção harmônica causa mais cruzamentos pelo zero do que

a freqüência fundamental, podendo interromper o funcionamento do equipamento. Um exemplo cotidiano é o relógio digital doméstico que avançará rapidamente o horário na presença de cruzamentos pelo zero adicionais provenientes da distorção harmônica. Qualquer dispositivo que é sincronizado com o cruzamento pelo zero deve ser considerado vulnerável a interrupção pela distorção harmônica.

Os semicondutores são freqüentemente chaveados na tensão zero para reduzir a interferência eletromagnética e a corrente de partida. Os múltiplos cruzamentos podem mudar o tempo de chaveamento do dispositivo e interromper o funcionamento do equipamento. Os pesquisadores Girgis e outros descrevem o efeito dos harmônicos em relês de estado sólido em impressoras eletrofotográficas [49]. Eles recomendam uma janela mais larga quando do cruzamento pelo zero da tensão ou um chaveamento aleatório (não sincronizado) a fim de minimizar os efeitos dos harmônicos.

As fontes de alimentação eletrônicas utilizam o pico de tensão da forma de onda para manter os capacitores de filtro carregados totalmente. Dependendo da freqüência dos harmônicos e da relação de fase com a fundamental, a distorção na tensão harmônica pode aumentar ou achatar o pico da forma de onda. Conseqüentemente, a fonte de alimentação estará 
efetivamente funcionando com uma tensão de entrada acima ou abaixo do valor correto ainda que a tensão eficaz de entrada esteja dentro do valor nominal. Com distorções severas, a operação do equipamento pode ser interrompida. Uma forma de onda moderadamente achatada pode reduzir a tensão eficaz de operação até o ponto em que o equipamento toma-se vulnerável às depressões na tensão secundária. $O$ fator de crista da forma de onda deve indicar se a forma de onda está anormal.

O fator de crista é a divisão do pico da forma de onda pelo valor eficaz e vale $2 \frac{1}{2}$ (raiz de 2) para uma onda senoidal perfeita. Subtensões devido a formas de onda achatadas muito comumente causam interrupções. Um fabricante de computadores limita o fator de crista em $2 \frac{1}{2} \pm 0,1$.

As ranhuras (notches) na forma de onda da tensão também podem interromper as operações dos equipamentos eletrônicos. Essas ranhuras que podem ser visualizadas na figura 3.4.2 são produzidas pela comutação de semicondutores de potência em conversores e são quantificados pela taxa de tensão $(\mathrm{dV} / \mathrm{dt})$ e o produto tensão-tempo.

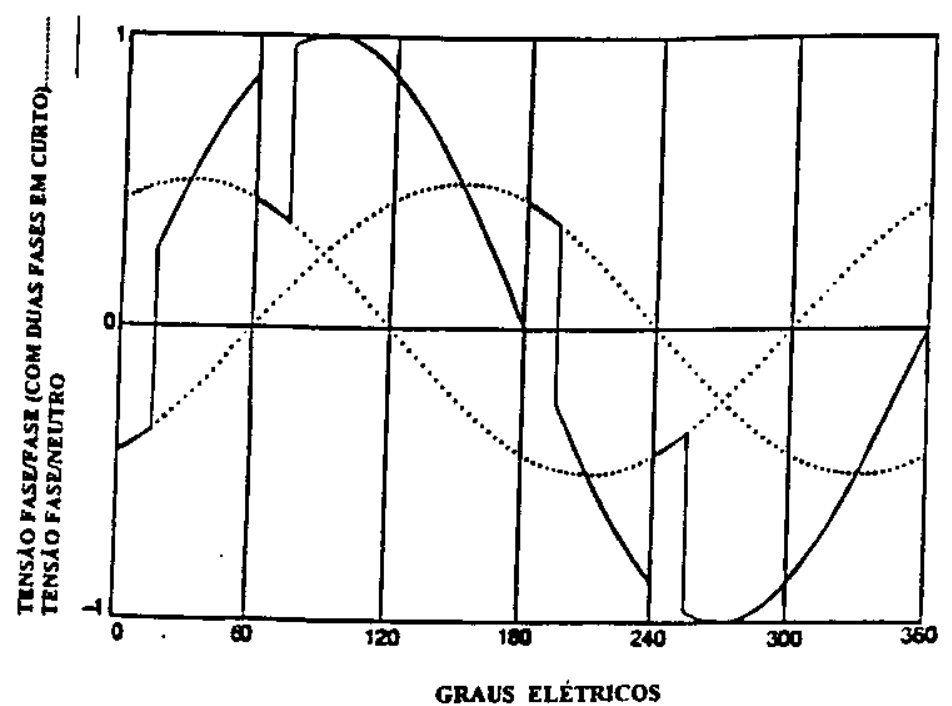

Figura 3.4.2 - Forma de Onda de Tensão com ranhura (notches) 
Uma forma de onda de tensão com ranhura pode cruzar a tensão em zero volt e afetar os equipamentos sensiveis que operam utilizando a técnica de cruzamento pelo zero, como já foi explicado anteriormente. Para valores elevados da derivada da tensão (dV/dt), a ranhura é vista como uma mudança na tensão através da rede de alimentação fazendo com que a fonte de alimentação emita um ruído na sua freqüência natural.

Como Ludbrook explica [50] a ranhura amplificada pela ressonância da fonte de alimentação, pode então interromper a operação normal dos equipamentos. É possível que uma taxa elevada de mudança na tensão associada com a ranhura possa provocar um acoplamento entre a fonte de alimentação e os circuitos digitais e causar um estado de mudança que interrompa a operação. Uma elevada $\mathrm{dV} / \mathrm{dt}$ pode causar um falso disparo e condução dos tiristores em circuitos de potência. Uma impedância, tal como um transformador ou reator, vista de um equipamento gerador de formas de onda de tensão com ranhuras reduzirá a tensão $\mathrm{dV} / \mathrm{dt}$ de outras cargas e diminuirá a excitação ressonante do sistema. A norma IEEE 519-1981 [51] fornece os limites para as ranhuras.

Os harmônicos fracionários e os sub-harmônicos podem afetar os monitores de vídeo e televisores. Os harmônicos fracionários são freqüências que não são integrais múltiplas da freqüência fundamental e subharmônicos são freqüências abaixo da fundamental. Os harmônicos fracionários produzem uma modulação em amplitude da freqüência fundamental. Fuchs [52], tem encontrado que até mesmo 0,5\% de un harmônico fracionário (referido à tensão nominal) produz ciclos periódicos de aumento e redução de imagem nos tubos de raios catódicos. 


\section{F. Iluminação}

As lâmpadas incandescentes terão uma perda definitiva de vida quando operadas com tensões distorcidas, pois as lâmpadas são sensiveis às variações de tensão.

Se o valor de tensão eficaz está acima da tensão nominal devido à distorção harmônica, a elevação de temperatura do filamento reduzirá a vida útil da lâmpada. Kaufman apresenta uma expressão em [53] e relata que para uma valor eficaz de tensão $105 \%$ acima do valor nominal, em operação contínua, a vida útil da lâmpada diminui $47 \%$.

Afora o ruído audível, não existe nenhum efeito conhecido da distorção harmônica na tensão sobre a iluminação de descarga. As lâmpadas de descarga tais como as de sódio de baixa pressão, alta pressão metal halide ou fluorescentes, necessitam de reatores indutivos cuja função é limitar a corrente em série. Os capacitores são frequentemente adicionados para corrigir o fator de potência para perto do valor unitário. Os reatores com lâmpadas fluorescentes duplas utilizam o deslocamento de fase da corrente para melhorar o fator de potência, sem o uso de capacitores. Nas instalações em geral, o capacitor junto com o reator indutivo e a lâmpada podem apresentar um problema de ressonância. Entretanto, a frequiência de ressonância da maioria das lâmpadas, é na faixa de $75 \mathrm{a} 80 \mathrm{~Hz}$ e não pode interagir com a fonte de alimentação.

\section{G. Medidores}

Os voltímetros e amperímetros modernos são relativamente imunes à influências na distorção da forma de onda. Em tais medidores, a entrada de tensão ou da corrente, é processada usando um multiplicador eletrônico. As técnicas de multiplicação mais comumente utilizadas são: transcondutância 
variável, logarítmica e antilogarítmica, divisão de tempo, térmica, e amostragem digital. Todas estas técnicas podem ser configuradas para responderem aos valores eficazes de tensão ou de corrente, independentemente da amplitude ou da fase do harmônico, enquanto os harmônicos estiverem dentro da largura de faixa de operação do instrumento e o fator de crista da forma de onda não é excessivamente elevado.

Os resultados dos testes realizados para voltímetros e amperímetros modernos que medem valores eficazes, usando um sinal senoidal de $60 \mathrm{~Hz}$, gerado por um circuito "chopperizado" (os disparos que sincronizam as fases de tensão são simultâneos) indicaram valores menores que $0,2 \%$ devido a sinais não-senoidais [54].

Os ângulos de disparo do circuito "chopperizado" senoidal, foram variados de $0^{\circ}$ até $135^{\circ}$ para simular aplicações cotidianas. Os valores correspondentes do fator de distorção e do fator de crista são mostrados na tabela 3.4.3.

\begin{tabular}{|c|c|c|}
\hline & PARÂMETRO \\
\hline ÂNGULO DE & FATOR DE & FATOR DE \\
\hline DISPARO & DISTORÇÃO & CRISTA \\
\hline$\left(^{\circ}\right)$ & D.F. & C.F. \\
\hline 0 & 0 & 1,41 \\
\hline 45 & 0,26 & 1,48 \\
\hline 90 & 0,65 & 2,00 \\
\hline 135 & 1,31 & 4,69 \\
\hline
\end{tabular}

Tabela 3.4.3 - Fator de Distorção e Fator de Crista para vários ângulos de disparo de um circuito "chopperizado" senoidal, $60 \mathrm{~Hz}$. 
Os medidores que respondiam a valores médios e que foram calibrados em valores eficazes e os medidores que respondiam a valores de pico e foram calibrados em valores eficazes não apresentaram um comportamento adequado na presença de sinais distorcidos. Por exemplo, com uma forma de onda senoidal de $60 \mathrm{~Hz}$ cujo ângulo de disparo seja $45^{\circ}$, um medidor de valor médio indicará um valor eficaz por volta de $13 \%$ menor do que o valor eficaz verdadeiro. Sendo assim, um amperimetro pode indicar, erroneamente, um condutor sobrecarregado, mesmo que este dispositivo esteja operando dentro do seu valor nominal.

Um wattímetro ideal ou um medidor de energia deveria indicar a potência ativa proporcional a corrente e a tensão. Porém, existem erros que resultam da característica de freqüência dos canais de tensão e de corrente do medidor e das não-linearidades. A linearidade pode ser degradada quando o fator de potência é baixo e as formas de onda têm fatores de crista elevados.

Em wattímetros modernos, a multiplicação eletrônica da tensão e da corrente ocorre utilizando-se técnicas como multiplicação e divisão no tempo, amostragem e multiplicação digital e multiplicação translinear. Todas estas técnicas são capazes de excelentes performances. Em testes com uma forma de onda senoidal de $60 \mathrm{~Hz}$ com o ângulo de disparo variando de $0^{\circ}$ a $90^{\circ}$, os erros devido a sinais não-senoidais foram menores do que $0,1 \%$. [55].

O medidor indutivo a disco de Watt-hora é o mais comum medidor utilizado comercialmente. Seus registros estão sujeitos a erros devido a sua freqüência característica e as não-linearidades. Em testes realizados com uma forma de onda senoidal de $60 \mathrm{~Hz}$ com as formas de onda de tensão e de corrente com distorção harmônica, os erros podem chegar à $(-20 \%)$, portanto, menor do que o valor real, para um ângulo de disparo de $90^{\circ}$. 
Com uma forma de onda de tensão não-distorcida e uma corrente distorcida, os erros atingiram à $(+5 \%)$, portanto maior do que o valor real para um ângulo de disparo de $90^{\circ}$ [56]. Deve-se evitar as aplicações em que os medidores indutivos de Watt-hora sejam submetidos a situações em que os sinais são altamente distorcidos, porque ocorrem erros nos registros e a possibilidade de falha por ressonância mecânica encontram-se na faixa entre 400 e $1000 \mathrm{~Hz}$ [55].

Um medidor de Watt-hora por amostragem calcula a energia de amostras digitais de tensão e corrente. Como em todos os medidores por amostragem, a largura de faixa do medidor é limitada pela freqüência de amostragem. Os medidores comerciais de Watt-hora por amostragem, fornecem essencialmente uma resposta em freqüência plana para valores acima de $1200 \mathrm{~Hz}$ ( $20^{\circ}$ harmônico). Um conversor de 12 bits fornece no bit menos significativo o valor equivalente a $0,024 \%$ do fundo de escala. Nos testes simulando condições de campo, com uma corrente com um fator de distorção de $88,4 \%$ e uma tensão com $4,9 \%$ de fator de distorção os erros nos registros de um medidor de Watt-hora foram menores do que $1 \%$.

\section{H. Relês de Proteção}

As formas de ondas distorcidas afetam o desempenlıo dos relês de proteção, podendo causar a operação indevida ou ainda a falha completa destes dispositivos, quando solicitados. Em vários casos, a distorção na forma de onda da corrente na carga, tem pouco efeito sobre a corrente de falha. Entretanto, para baixas amplitudes de falha, a carga pode significar uma grande parte da corrente de carga e a distorção na forma de onda pode tornar-se um fator importante. 
Ainda assim, os relês podem funcionar corretamente, mesmo na presença de correntes distorcidas na carga.

Cada relê tem um desempenho diferente na presença de formas de ondas distorcidas. Os relês de mesmo tipo, mas de fabricantes diferentes apresentam respostas muito diferenciadas para o mesmo tipo de distorção. Os relês de mesmo tipo e modelo do mesmo fabricante podem apresentar respostas diferenciadas para a mesma distorção.

As distorções podem causar falhas no disparo dos relês de proteção quando estes deveriam operar, ou ainda disparos indevidos quando estes não deveriam estar operando. A variação do ângulo de fase entre a fundamental e a componente harmônica de uma determinada forma de onda de tensão ou corrente, pode alterar significativamente a resposta do relé. Para os relês de entrada dupla, o desempenho pode ser afetado pela relação de fase entre os respectivos harmônicos nas entradas.

Vários estudos concluiram que é muito dificil prever o desempenho dos relês de proteção sem uma avaliação. Estes estudos tem levado em consideração relês de proteção dos tipos eletromecânicos, elétricos e eletrônicos, mas não existe nenhuma informação sobre os novos relês digitais [57], [58], [59], [60], [61], [62], [63].

\section{Máquinas Rotativas}

As tensões não-senoidais aplicadas em máquinas elétricas podem causar superaquecimento, torques pulsativos ou ruído. Por outro lado, nas aplicações em que é usada a alimentação da rede diretamente, os acionadores de motores com velocidade ajustável, alimentados por inversores, podem produzir significativas distorções na tensão. 
O superaquecimento dos rotores dos motores tem sido o principal problema associado à distorção na tensão [64], [65], [66], [67], [68], [69], [70], [71], [72], [73], [74]. As perdas nas máquinas elétricas são dependentes do espectro de freqüência da tensão aplicada.

As perdas por dispersão e no núcleo podem tornar-se significativas em um motor à indução com um rotor oblíquo alimentado por um inversor, produzindo harmônicos em alta freqüência [56], [72], [74]. Um aumento na temperatura do motor causará a redução da vida útil do motor. Os motores monofásico são os mais afetados.[52], [65], [66]. O aumento da temperatura não é uniforme através do motor; pontos aquecidos aparecem perto dos condutores e dentro de partes do núcleo de ferro. Se os harmônicos estão variando no tempo, o motor pode tolerar elevados níveis de pico de distorção sem aumento de temperatura ou aquecimentos pontuais [93]. Isto é possível porque a constante de tempo térmica do motor é muito maior do que o período de variação dos harmônicos.

Vários fatores de perdas podem ser definidos para avaliar-se o peso dos tipos de perdas no motor através do espectro total dos harmônicos. Os autores Murphy e Egan [68], avaliaram algumas estratégias para os inversores configurados em modulação pelo comprimento do pulso (P.W.M.) usando um fator de comparação, L, que elimina o efeito pelicular.

$$
\mathrm{L}=\Sigma\left(\mathrm{V}_{\mathrm{n}} / \mathrm{f}_{\mathrm{n}}\right)^{2} \quad \mathrm{n}=2,3,4 \ldots \ldots
$$

onde $V_{n}$ é a enésima tensão harmônica aplicada e $f_{n}$ é a enésima freqüiência harmônica. Embora esta aproximação possa ser uma grande simplificação das perdas harmônicas e poderia ser solução quando avalia-se diferentes configurações P.W.M.

Boys e Walton, [69], propõem que se some uma terceira harmônica ao sinal de referência do P.W.M. a fim de alterar o espectro harmônico dos 
inversores senoidais configurados em P.W.M. e assim reduzir as perdas do motor.

Connors [71] enfatiza que as perdas harmônicas também possuem influência sobre as caraterísticas dos motores. A impedância de fuga do motor aumentará linearmente com a frequiência harmônica. Para reduzir-se as correntes harmônicas de um inversor, configurado como uma fonte de alimentação de tensão, é necessário uma grande indutância de fuga.

Por outro lado, um inversor configurado como uma fonte de alimentação de corrente, injetará corrente harmônicas dentro do motor e portanto, uma pequena indutância de fuga é necessária para reduzir-se as tensões harmônicas.

Os torques pulsativos são produzidos pela interação entre o intervalo formado pelo fluxo de ar (principalmente na componente fundamental) e o fluxo produzido pelas correntes harmônicas no rotor [68], [78], [79]. Os motores de indução com velocidade fixa tem sido tradicionalmente projetados para operarem em velocidades aproximadamente de 30 a $40 \%$ acima da primeira velocidade mecânica critica. No entanto, para os acionadores de motores com velocidade ajustável é necessária uma análise da velocidade de ressonância mecânica para se evitar qualquer dano devido a amplificação dos torques pulsantes [68], [70], [78], [79], [80].

As referências [81], [82] e [83], concluem que os ruídos audiveis são produzidos pela diferença entre os tempos das freqüências harmônicas. Entretanto, altas freqüências harmônicas inaudiveis podem contribuir também para ruídos audíveis. 


\section{J. Equipamentos de Telecomunicações}

A superposição das linhas telefônicas com as linhas dos sistemas elétricos de potência, cria oportunidades para que exista interferência na freqüência de potência com as linhas de comunicação telefônica. Assim como a sensibilidade da audição humana e o pico de resposta do telefone é perto de $1 \mathrm{kHz}$, as freqüências harmônicas nos sistemas de potência podem representar problemas maiores do que a freqüência fundamental. As interferências podem ser expressas por vários tipos de medidas diferentes discutidas em [42] e [51]. Uma das medidas é o fator de influência de telefone (F.I.T.) que incorpora a freqüência, amplitude e um fator de peso para a frequêencia. Uma medida comum é o produto IT que é o produto da corrente eficaz e o F.I.T.. Um produto IT de menos do que 10000 não poderia causar problemas enquanto que um produto acima de 25000 provavelmente causará problemas de interferências nas linhas telefônicas. Existem 4 (quatro) mecanismos de acoplamento da linha de alimentação de potência com a linha telefônica. Um deles é a indução em laço, que é o campo magnético que induz uma tensão na linha de alimentação de potência formando um laço com os dois condutores telefônicos. Uma prática padrão é separar-se os condutores de potência ou trançar os pares telefônicos limitando este mecanismo.

O segundo mecanismo é similar ao primeiro, exceto pelo fato de que o laço é formado entre o condutor telefônico e o terra. O caminho através do qual o terra é criado, por suas conexões em oposição aos terminais do circuito. Como a área do laço pode ser muito grande, este mecanismo é tipo mais comum de interferência. $O$ terceiro mecanismo é o acoplamento capacitivo entre o condutor de potência e o condutor do telefone. A capacitância formada pelo inter-condutor e o condutor para o terra, formam um divisor de tensão para o potencial do condutor de potência. 
Os condutores de sistemas monofásicos e a redução da reatância capacitiva aumentam o nível de interferência. A blindagem dos condutores telefônicos é eficaz na eliminação do acoplamento capacitivo.

O último mecanismo é o acoplamento condutivo no qual o potencial do terra local cresce devido ao aumento da potência do neutro. Este aumento de potência é então aplicado no fio terra do condutor telefônico, criando um potencial entre o ponto de terra que foi elevado e o ponto distante do terra no circuito telefônico. Uma conexão ineficaz no condutor neutro pode causar um crescimento anormal no potencial de terra local, resultando neste tipo de interferência.

Onde forem aplicadas as técnicas de atenuação discutidas acima sem sucesso, ou não houver possibilidades de sua aplicação, os harmônicos podem ser reduzidos com a instalação de filtros. O comitê do IEEE [84] e Arrillaga [42] discutem os mecanismos e as técnicas de atenuação em grandes detalhes.

\section{K. Transformadores}

O efeito primário dos harmônicos em sistemas de potência sobre os transformadores é o aquecimento adicional provocado pelas perdas causadas pelo conteúdo harmônico da corrente na carga. Outros problemas incluem possiveis ressonâncias entre a indutância do transformador e a capacitância do sistema, pressão na isolação mecânica (nos fios e nas lâminas) devido a ciclos térmicos e possíveis pequenas vibrações no núcleo [66].

O aquecimento adicional causado pelos harmônicos do sistema requer uma capacidade de dissipação na carga para manter a temperatura do transformador dentro do seu valor nominal ou então o uso de 
transformadores especialmente projetados para correntes de carga nãosenoidais. A vida útil dos transformadores será reduzida como resultado de sua operação acima de valores de temperaturas nominais.

As componentes de perdas primárias são: a fiação, perdas por efeito joule, perdas por correntes de fuga e perdas parasitárias do fluxo eletromagnético em áreas tais como: a fiação, o núcleo, etc. As perdas devido ao efeito joule serão devido ao aquecimento no condutor e ao efeito pelicular. As perdas por correntes de fuga na fiação aumentarão com o quadrado da corrente da carga e o quadrado da freqüência. Outras perdas parasitárias também aumentarão com a freqüência, porém com uma potência ligeiramente menor do que 2 (dois) [85].

Vảrias normas do IEEE fornecem orientações sobre 0 dimensionamento dos transformadores [86], [87], [88]. Essas orientações sobre as cargas são baseadas nos limites do fator distorção da corrente de carga de 0,05 por unidade como está redigido na norma IEEE/ANSI C57.12.00-1987 [89] e C57.12.01-1989 [90].

A norma IEEE/ANSI C57.110-1986 [85], reconhece que as correntes de carga, em vários casos, excedem o fator de distorção no limite de 0,05 por unidade. Esta norma enfatiza dois métodos para determinar a capacidade do transformador com correntes de carga não-senoidais com perda de sua expectativa normal de vida. Ambos os métodos requerem conhecimento das características da corrente de carga. O primeiro método requer que os dados do projeto do transformador sejam detallados e o segundo método confianos dados disponíveis nos relatórios de testes de certificação.

Ambos os métodos são baseados na premissa que todas as perdas parasitárias resultam nas correntes de fuga e estas perdas aumentam com o 
quadrado da corrente e da frequiência. As perdas por unidade da corrente de fuga são expressas como sendo:

$$
P_{e c}=P_{e c-r} \sum I_{n}^{2}{ }_{n}^{2} \quad n=1,2,3,4 \ldots \ldots
$$

onde:

$\mathrm{P}_{\mathrm{ec}}=$ perdas na fiação por corrente de fuga ( por unidade do valor nominal das perdas $I^{2 *} R$ )

$\mathrm{P}_{\mathrm{ec}-\mathrm{r}}=$ perdas na fiação por corrente de fuga em valores nominais da carga e da freqüência (por unidade do valor nominal das perdas $I^{2 *} R$ )

$I_{n}=$ Valor eficaz da corrente do harmônico de ordem n ( por unidade do valor nominal da corrente eficaz da carga).

n $=$ ordem do harmônico.

Hwang tem mostrado que a equação acima é válida para harmônicos de ordem baixa, até o nono harmônico. Entretanto, para o décimo harmônico até o vigésimo quinto harmônico, as perdas variam com n para uma potência de 1,94 a 1,98. Isto aumentaria o caráter conservador dos resultados obtidos com os métodos na norma.

As normas de corrente esboçam os valores nominais de sobretensões nos transformadores sobre bases de valores eficazes em regime permanente. A máxima sobretensão é 5\% do valor nominal da carga e 10\% para do valor nominal sem carga [89]. Estes limites incluem qualquer contribuição resultante da distorção harmônica na forma de onda.

As cargas conectadas a transformadores configurados em delta, podem nos iludir por causa da circulação de correntes harmônicas triplas. As correntes de carga harmônicas triplas e balanceadas $\left(3^{a}, 6^{a}, 9^{a}\right.$, etc.) circularão num transformador configurado em delta e não aparecerão nos 
condutores primários. Conseqüentemente, as medições de corrente no primário não refletirão a verdadeira corrente de carga do transformador.

As cargas eletrônicas monofásicas são ricas em correntes harmônicas triplas e os transformadores trifásicos alimentando estas cargas são susceptiveis a esta condição. As especificações nominais dos transformadores estão sendo desenvolvidas para poderem incorporar uma grande quantidade de cargas harmônicas. Os laboratórios Underwriters estão investigando um fator para os transformadores de potência tipo seco, baseados na norma UL 1561. Este fator é definido como sendo o fator $\mathrm{K}$ por Dini [92]. Por exemplo, os transformadores que encontram os requisitos de testes para um fator $\mathrm{K}$ de quatro serão capazes de serem carregados com cargas nominais dentro de limites de temperatura para cargas harmônicas que produzem quatro vezes as perdas por correntes parasitas. Elevados valores de fator $\mathrm{K}$ indicam o aumento da capacidade em termos de correntes harmônicas.

\subsection{Limites para Harmônicos em Sistemas Elétricos de Potência}

A preocupação com os efeitos causado por harmônicos, levaram vários países a estabelecerem, ao longo dos anos, recomendações ou guias [19], [20], relativos ao controle de harmônicos, apresentando sempre em comum, efetivamente, os seguintes objetivos:

. preservar o padrão de suprimento de energia elétrica; . manter as distorções das ondas de tensão e corrente dentro de níveis toleráveis pelo sistema de potência e seus componentes; - garantir a operação adequada de equipamentos; 
evitar interferências, etc.

Para atender a esses objetivos, os critérios de limitação harmônica, adotados por diferentes países, são fundamentados em experiências próprias e raramente baseadas em estudo e compreensão detalhadas do comportamento do sistema. Estes critérios são divididos basicamente em três grupos:

. limites para a distorção de tensão harmônica total e/ou para os harmônicos de tensões individuais;

. limites para as correntes harmônicas injetadas no sistema;

limites para as tensões e correntes harmônicas.

A experiência do Brasil com respeito às recomendações e limites é baseada nos relatórios elaborados pelo Grupo Coordenador de Operaçãu Interligada (GCOI) da Eletrobrás e é fundamentada em experiências de outros países, basicamente Inglaterra e Nova Zelândia, e em séries históricas de medidas realizadas ao longo de vários anos.

A recomendação brasileira que atualmente está em vigor, sugere limites harmônicos globais, vide tabela 3.3.1, e por consumidor, vide tabela 3.3.2. Nesse limites existem valores para tensões menores a $69 \mathrm{kV}$, ou valores maiores ou iguais a $69 \mathrm{kV}$.

Os limites globais não podem ser excedidos em nenhum ponto do sistema elétrico de potência das concessionárias e os limites por consumidor devem ser analisados no ponto de acoplamento comum (P.A.C.) entre o consumidor e as concessionárias. 

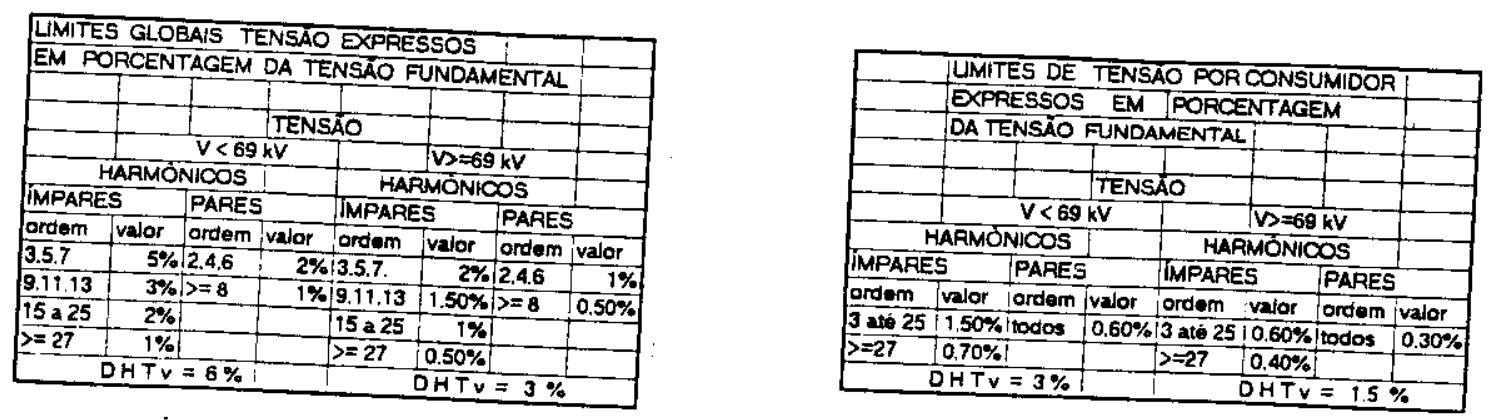

Tabela 3.3.1

Tabela 3.3.2

No caso de vários consumidores ligados a um mesmo barramento, os limites de harmônicos devem ser divididos entre os diversos consumidores conectados àquele P.A.C., em proporção às demandas máximas de cada um.

Com o objetivo de controlar o grau dos distúrbios que podem ser originados pelos harmônicos, os órgãos competentes que legislam sobre o fornecimento energético, tem procurado investigar, estudar e determinar tais fontes, já existentes ou ainda a serem injetadas no sistema, para que sejam minimizadas. Uma compilação de vários resultados apresentados na literatura clássica, é rapidamente apresentada e discutida a seguir. 


\section{MEDIÇÕES DAS COMPONENTES HARMÔNICAS [19], [20], [31]}

Considerando que um dado sistema apresente cargas não-lineares já instaladas, a avaliação efetiva das componentes harmônicas é obtida pela medição direta. Os critérios de medição utilizados nos dias de hoje pelas concessionárias brasileiras são fundamentados nas recomendações práticas e experiências de outros países, conforme descrevem as referências:

. Limits for harmonics in the United Kingdom

Electricity Supply System - G. 5/3.

. Limitation of Harmonic Levels - New Zeland Gazette of 3rd December 1981.

Measuring Voltage and Current Harmonics on Distribution Systems - USA, IEEE Transactions on Power Apparatus and Systems, July 1981.

Os equipamentos de instrumentação utilizados para o propósito da medição são discutidos nestas recomendações, sendo rapidamente descritos a seguir. As discussões consideram os diversos equipamentos existentes no passado e os empregados nos dias atuais.

4.1 Métodos Simples para a Constatação de Correntes e Tensões Harmônicas

A primeira informação sobre a existência de tensões e correntes harmônicas pode ser obtida por meio da visualização das formas de onda, através de osciloscópios. Este processo mostra a distorção na forma de onda fundamental, no entanto, não permite uma análise detalhada dos níveis dos diversos harmônicos. Assim consiste em um método para simples informação do estado geral da forma de onda. 
4.2 Medição através de Analisadores de Harmônicos e de Espectros

Face às necessidades da análise individual das componentes harmônicas, utilizou-se por muitos anos, a técnica de selecionar a freqüência, correspondente à onda distorcida, através de circuitos sintonizados. Estas análises eram então realizadas, para todas as freqüências, com um voltímetro seletivo constituído de um filtro passa-faixa, com o ajuste das faixas de freqüência nas freqüências harmônicas, e um medidor de tensão RMS (valor eficaz). Dentro do exposto, estes analisadores de onda apresentam como desvantagens uma baixa precisão para as componentes harmônicas de pequenas amplitudes e a incapacidade de medir várias componentes ao mesmo tempo.

Este processo de medição foi então substituído pelos equipamentos denominados de "Analisadores Harmônicos", constituídos de vários circuitos já sintonizados (filtros passa-faixa). Entretanto, permanecia ainda o problema da sensibilidade destes circuitos quanto a pequenas variações da freqüência fundamental, durante o período de amostragem do sinal. Um outro fator agravante ocorria quando da variação rápida do espectro de freqüência, incidindo em informações irreais, ao considerá-las em regime permanente. Além destes problemas, destacam-se outros associados aos filtros analógicos, como:

faixa de passagem

. seletividade

tempo de resposta

. envelhecimento

temperatura 
. verificação e recalibração regulares.

Devido a estes inconvenientes, os desenvolvimentos prosseguiram e atualmente os instrumentos disponíveis para a medição de harmônicos, dentro das mais modernas técnicas de engenharia, podem ser agrupados em duas categorias: os analisadores de harmônicos e os analisadores de espectro. Tais equipamentos podem empregar, em sua concepção, tanto técnicas analógicas quanto digitais.

Os analisadores de espectro cobrem toda uma faixa de freqüência e fornecem a amplitude das componentes de um sinal, em todas as freqüências dentro da faixa especificada.

Os analisadores harmônicos medem as amplitudes do sinal apenas nas frequiencias harmônicas, fornecendo um espectro de saída que é um subconjunto do espectro que seria produzido por um analisador de espectro, cobrindo apenas a faixa de freqüências contendo os harmônicos desejados.

Seu princípio de funcionamento é basicamente o mesmo dos analisadores de espectro, mas com a adição de algum meio de isolar e identificar as frequiências harmônicas.

Fundamentalmente, existem duas formas, bastante distintas, para a construção de um equipamento com estas características: a analógica e a digital (utilizando-se ou não de microprocessadores).

Atualmente, analisadores modemos para medidas em tempo real são construídos através de microprocessadores, proporcionando informações dos níveis de tensões e correntes harmônicas e outras como:

hora de medição

distorção harmônica total

. programação automática de intervalos de medição

ângulo de fase 
. variação de freqüência

. composição da forma de onda distorcida

· potência harmônica

. alarme quando a distorção ultrapassa níveis recomendados citam-se:

Dentre os instrumentos mais modernos utilizados nos dias de hoje

. NOWA - 1 AC POWER LINE HARMONIC ANALYSER

(CANADÁ)

.HP 3582 A Spectrum Analyser (ESTADOS UNIDOS)

. PQ NODE BMI (ESTADOS UNIDOS)

. POWER MEASUREMENT LTD. - 3720 ACM (CANADÁ)

. QUASAR (ITÁLIA)

\section{REGISTRADOR DESENVOLVIDO NO IEE [43]}

\subsection{Histórico}

Em meados de 1988, o IEE-USP desenvolveu com recursos próprios, um equipamento para monitoração de grandezas elétricas que recebeu o nome de Registrador de Curvas de Carga Trifásico (R.C.C. - versão 1.0).

A finalidade deste equipamento era realizar levantamento de Curvas de Carga de consumidores e elaborar estudos junto às concessionárias de Energia Elétrica e consumidores que solicitassem ao IEE este serviço possibilitando assim substituir os registradores gráficos da instituição que eram obsoletos. 
Inicialmente houve um contato com o Banco Banespa que solicitou os serviços do IEE/USP para realizar medições de Curvas de Carga no seu sistema de NO-BREAKS.

Antevendo o potencial de tal prestação de serviços, o IEE, resolveu investir no desenvolvimento de uma segunda versão (R.C.C. - versão 1.5) que contemplava mais recursos tecnológicos e procurava facilitar a operação do usuário.

Isto resultou em várias consultas à Seção Técnica de Desenvolvimento de Hardware (atual Seção Técnica de Sistemas Eletrônicos), que propôs em meados de 1990 a elaboração de um Projeto junto a Agência Financiadora de Estudos e Projetos (FINEP), para obter-se financiamento e desenvolver um equipamento mais completo, com um maior número de canais trifásicos e que possibilitasse o cálculo, por fase, da distorção harmônica total.

Este projeto abria definitivamente a possibilidade de se realizar um estudo em conjunto com as concessionárias de energia elétrica e empresas privadas. Inclusive una das condições para que a FINEP aprovasse o projeto seria através de uma carta formal à instituição, de uma empresa privada, demonstrando interesse pelo projeto. Essa empresa foi a Consip Engenharia S/A.

Com a aprovação do projeto pela FINEP em outubro de 1990, iniciouse efetivamente a implementação do hardware do protótipo para que se pudesse testar o software residente (firmware) do equipamento que estava sendo desenvolvido em paralelo.

Após vários testes no protótipo, chegou-se a uma primeira versão do equipamento em abril de 1991. A primeira versão foi ao campo, fez várias medições para instituições públicas tais como: Hospital Universitário (H.U.USP), COPESP (Ministério da Marinha), Faculdade de Medicina da 
Universidade de São Paulo (FM-USP), tendo operado por mais de 1000 (mil) horas continuamente sem apresentar qualquer problema de funcionamento.

Atualmente o IEE/USP trabalha em conjunto com a C.P.F.L. a fim de melhorar o desempenho do R.C.C. 2.0 no que diz respeito ao cálculo da distorção harmônica individual, ou seja, por harmônico. Este novo desenvolvimento consiste em conseguir-se detetar o fluxo dos harmônicos com precisão até o $40^{\circ}$ harmônico de $60 \mathrm{~Hz}$, ou seja, $2400 \mathrm{~Hz}$. Também foi desenvolvido um protocolo de comunicação entre o R.C.C. e um notebook para facilitar a retirada dos dados em campo.

\subsection{Princípio de Funcionamento}

O equipamento é dotado de quatro microcontroladores 8031 ligados em rede, através de uma configuração em estrela. Desta forma existe uma CPU central controlando três CPU's locais, compondo um sistema capaz de monitorar até 32 canais trifásicos simultaneamente. Cada uma das três CPU's é responsável por uma das fases a serem monitoradas pelo sistema global. Uma destas CPU's controla, portanto, 32 pontos de leitura de tensão e corrente, com precisão de 12 bits.

A CPU central possui as seguintes funções:

- monitoração do teclado e display.

- responsabilidade na orientação das CPU's locais.

- controle de informações.

- armazenamento de dados.

- comunicação com o meio externo.

- relógio de tempo real. 
As CPU's locais executam as seguintes tarefas:

- Obtenção dos valores de tensão e corrente.

- cálculo de valores eficazes.

- determinação de fator de potência, distorção harmônica e espectro de amplitudes.

A necessidade de execução de um processamento paralelo das três fases é consequiência direta da intenção de se produzir um sistema veloz. Assim, a cada instante de amostragem, três valores de tensão e corrente são amostrados e tratados. Cada processador local irá tratar o seu respectivo par de dados (tensão-corrente), armazenado momentaneamente em circuitos "sample-hold". Através deste método, o sistema precisa de apenas 3 segundos para aferir todos os dados de um trifásico qualquer.

Através de um teclado de fácil acesso, o usuário tem disponiveis todos os recursos do equipamento. Existe um menu de seleção capaz de acionar as funções a seguir:

- implementação da data e hora vigente, auxiliada por um algoritmo de consistência de dados capaz de impedir a entrada de dados incoerentes.

- seleção do canal a ser visto no display, com seus respectivos valores eficazes e fator de potência.(medição simples)

- ativação dos módulos de cálculo de distorção harmônica, análise de espectro e transmissão de dados via interface serial à um notebook.

As tensões e correntes de um trifásico possuem seus valores reduzidos por componentes analógicos antes de serem digitalizadas, através de Transformadores de Corrente e de Potencial (TC e TP). Além disso, os sinais são tratados por um módulo analógico, responsável pela proteção do sistema e pela preparação dos dados de entrada para o processo de digitalização, através do uso de filtros seletivos. Ainda, este grupo de 
circuitos transforma os níveis de corrente de entrada em valores compativeis de tensão, a partir do uso de resistores padronizados e de um amplificador de ganho programável (de valores 1, 2, 10 e 100), controlado por software.

A monitoração de tensões e correntes feita pelo sistema é periódica, com intervalos definidos pelo usuário via teclado. Os valores aferidos e calculados são armazenados pelo processador central em um banco de até $4 \mathrm{Mb}$ de memórias RAM estáticas. Quando este banco é preenchido, existe a necessidade de transferência de dados, pois o processador central irá inserir novos dados no lugar dos antigos, ocasionando sua perda.

Para executar a transferência de dados, o sistema é dotado de uma interface serial do tipo RS232C, capaz de enviar suas informações por algum computador que venha a armazená-las. Para uma melhor compreensão desses dados, foi produzido um programa PC-compatível de forma a produzir gráficos contendo as curvas de carga dos 32 canais e respectivas análises harmônicas.

O sistema foi totalmente implementado em linguagem Assembly compatível com o microcontrolador utilizado, exceto o algoritmo da Transformada Rápida de Fourier e a Interface Homem-Máquina, desenvolvidos em linguagem de alto nível $(C)$.

\subsection{Descrição Funcional}

O Registrador de Curvas de Carga (R.C.C. - versão 2.0) utiliza o conceito de processamento paralelo de informações, ou seja, as três fases são medidas simultaneamente, para que se possa obter o Potência Trifásica Real, vide figura 5.3. 


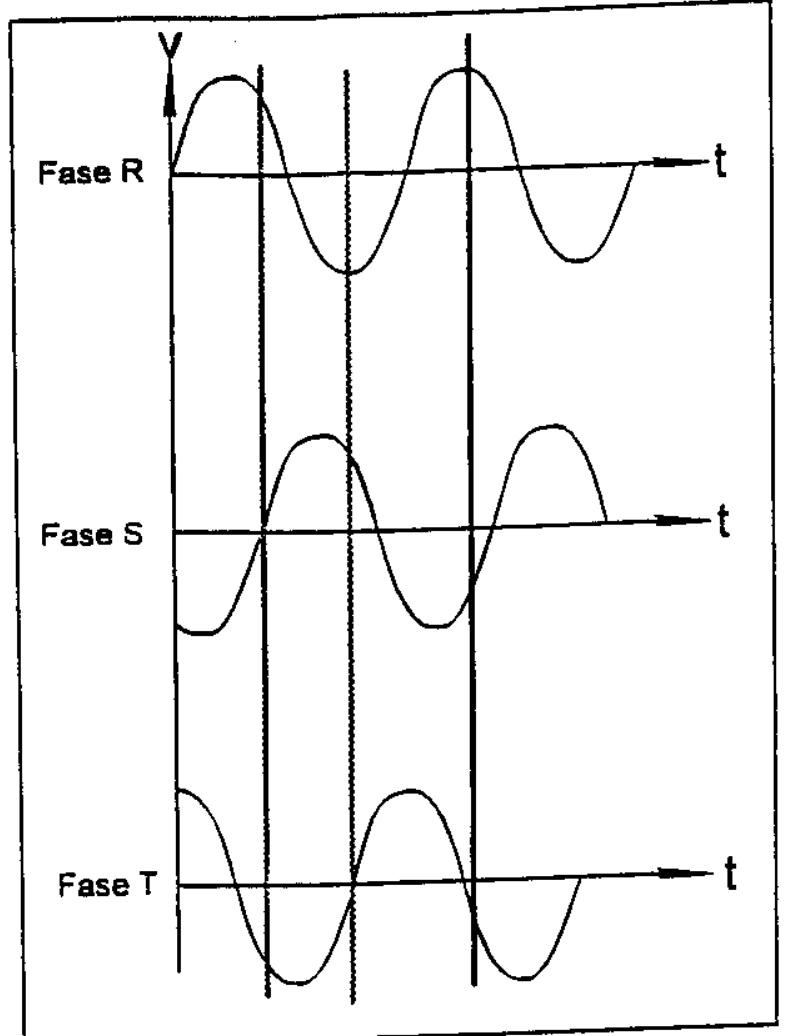

Figura 5.3 - Forma de Onda de um Trifásico em Sincronismo

\subsubsection{Hardware}

A figura 5.3.1 mostra o diagrama em blocos do equipamento, onde se destaca a interligação feita entre as CPU's Locais e a CPU Central via interface serial e também a topologia de medição onde se percebe a simultaneidade dos sinais de entrada sendo medidos em paralelo. 


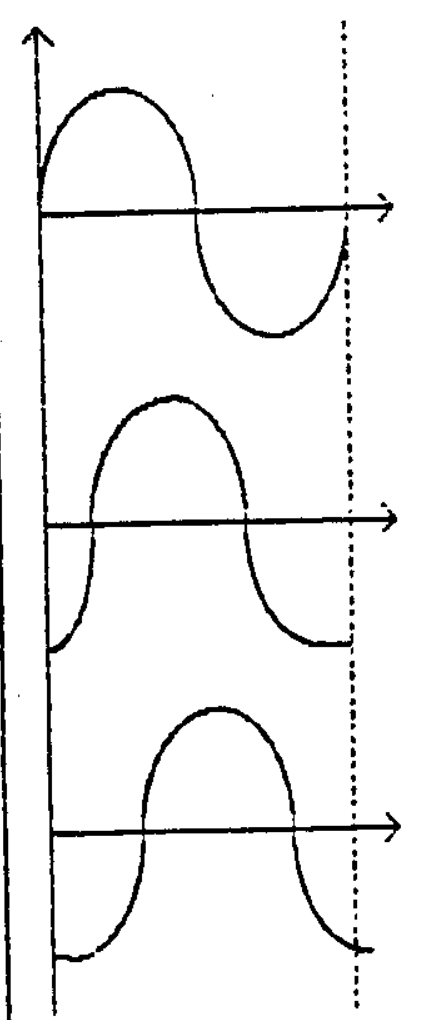

\section{FASES}

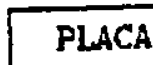
ANALOCIC

$\mathbf{R}$
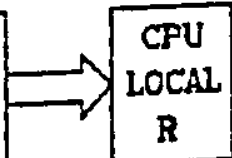

32 FASES

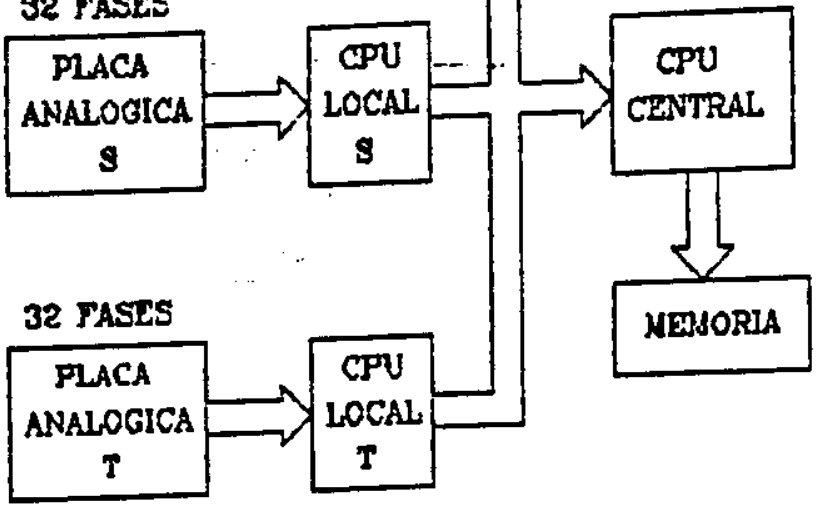

RSTRUTURA NULTIPROCTSSADA (LGADA EM ESTREHA)

Figura 5.3.1 - Diagrama em Blocos do R.C.C.

O Hardware está dividido em 5 (cinco) partes principais, sendo que 2 (duas) são puramente analógicas e 2 (duas) são puramente digitais e uma delas é híbrida (parte digital, parte analógica) que foram assim denominadas: sensores, condicionamento de sinal dos sensores, aquisição de dados, processamento e transmissão dos dados e armazenamento digital.

\subsubsection{Sensores}

São utilizados dois tipos de sensores:

\section{A. Tensão}

São os transformadores de potencial (TP's) com saída em $115 \mathrm{~V}$ que alimentam diretamente o equipamento na sua entrada de tensão. 
O R.C.C. deve ser programado conforme a relação de transformação dos TP's, para que se possa efetuar a leitura da tensão eficaz diretamente no display do equipamento.

B. Corrente

São os transformadores de corrente (TC's) com saída em 5 A que alimentam diretamente o equipamento na sua entrada de corrente.

O R.C.C. deve ser programado conforme a relação de transformação dos TC's, para que se possa efetuar a leitura da corrente eficaz diretamente no display do equipamento.

\subsubsection{Condicionamento do Sinal dos Sensores}

É realizado externa e internamente ao R.C.C.: externamente existem 2 (dois) transdutores dentro do bastidor do equipamento que são responsáveis pela transdução do sinal dos sensores de tensão e corrente, a saber:

\section{A. Transdutor Tensão-Tensão:}

Atenua o sinal de tensão da saida dos TP's $(115 \mathrm{~V})$ para un nível compatível com a entrada do equipamento $(5 \mathrm{~V})$, através de um divisor resistivo.

B. Transdutor Corrente-Tensão:

Transforma o sinal de corrente da saida dos TC's (5A) para um nivel compatível com a entrada do R.C.C. ( $5 \mathrm{~V})$, através de um circuito ativo.

Internamente existe uma placa cuja função é proteger o sistema de entrada contra surtos de tensão ou correntes elevadas.

A figura 5.3.1.2 mostra o circuito de interligação entre os sensores e os transdutores na entrada do equipamento. 


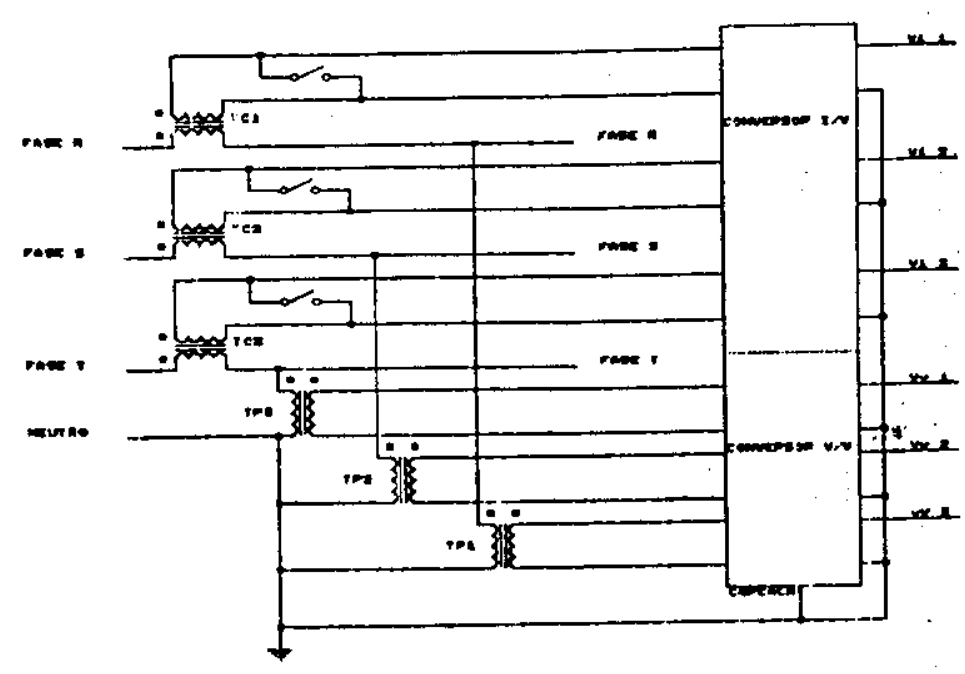

Figura 5.3.1.2 - Circuito de Interligação Sensores - Transdutores

\section{Placa de Proteção}

Seus componentes principais são varistores e diodos zeners cuja função é proteger o sistema de entrada contra surtos de tensão e/ou correntes elevadas. A figura 5.3.1.2 (a) detalha o circuito.

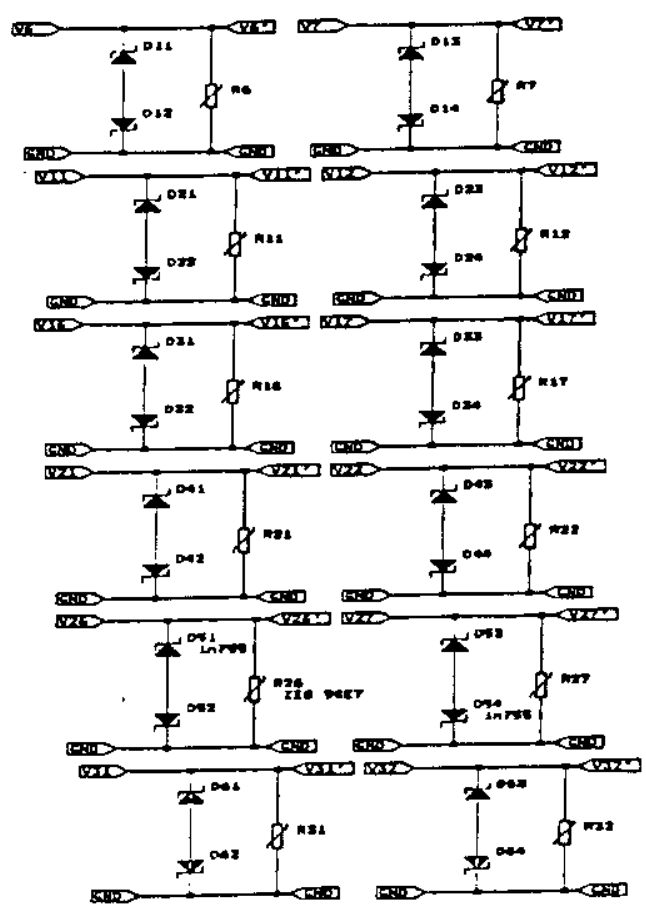

Figura 5.3.1.2 (a) - Placa de Proteção 


\subsubsection{Aquisição de Dados}

\section{A. Multiplex}

É responsável pela aquisição dos dados a serem tratados. Esta placa está dividida em duas partes. Numa das partes está localizada a placa de proteção e na outra parte localiza-se a área de multiplexação. Esta solução foi encontrada para se evitar que os vários sinais de tensão e de corrente provenientes das entradas trifásicas e que serão multiplexados, não transitem pelo barramento digital. Cada fase $\mathrm{R}, \mathrm{S}, \mathrm{T}$ possui duas placas de proteção e cada placa de proteção possui 2 (dois) circuitos integrados multiplex (4067). A figura 5.3.1.3 detalha os circuitos.

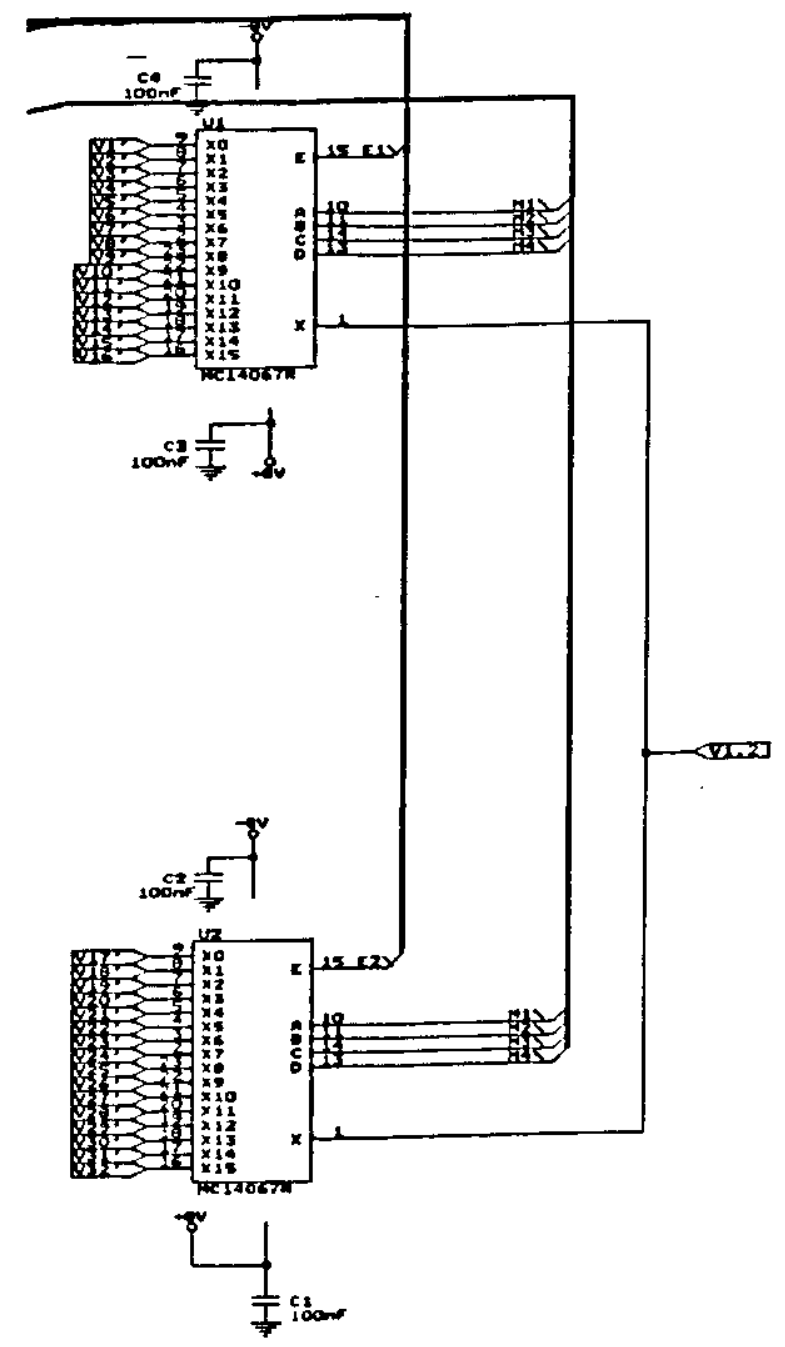

Figura 5.3.1.3 - Multiplex 


\subsubsection{Placa Analógica}

É responsável pela isolação, amostragem e retenção (sample and hold), conversão analógica para digital (A/D) do sinal de entrada, controle de ganho da corrente, filtragem do sinal em $60 \mathrm{~Hz}$, deteção da passagem pelo zero do sinal de tensão (zero crossing detector), chaveamento dos circuitos de amostragem e retenção e sinais de controle para o conversor A/D e interface com o microprocessador. A figura 5.3.1.4 mostra o diagrama em bloco dos circuitos.

O R.C.C. foi projetado para a medição de até 32 canais trifásicos. O sistema conta com 3 placas analógicas. Cada placa analógica é responsável pela conversão de 64 sinais relativos à fase a qual estiver conectada $(R, S$, ou $\mathrm{T}$ ), sendo 32 sinais relativos à tensão e 32 sinais relativos à corrente. Como cada placa analógica tem apenas um conversor $\mathrm{A} / \mathrm{D}$, é necessário a multiplexação dos sinais de entrada. Esta multiplexação é feita na placa multiplex/proteção. Cada placa de proteção tem capacidade para 32 sinais de entrada, sendo portanto, necessárias duas placas para cada placa analógica ( 1 placa com sinais de tensão, outra com sinais de corrente).

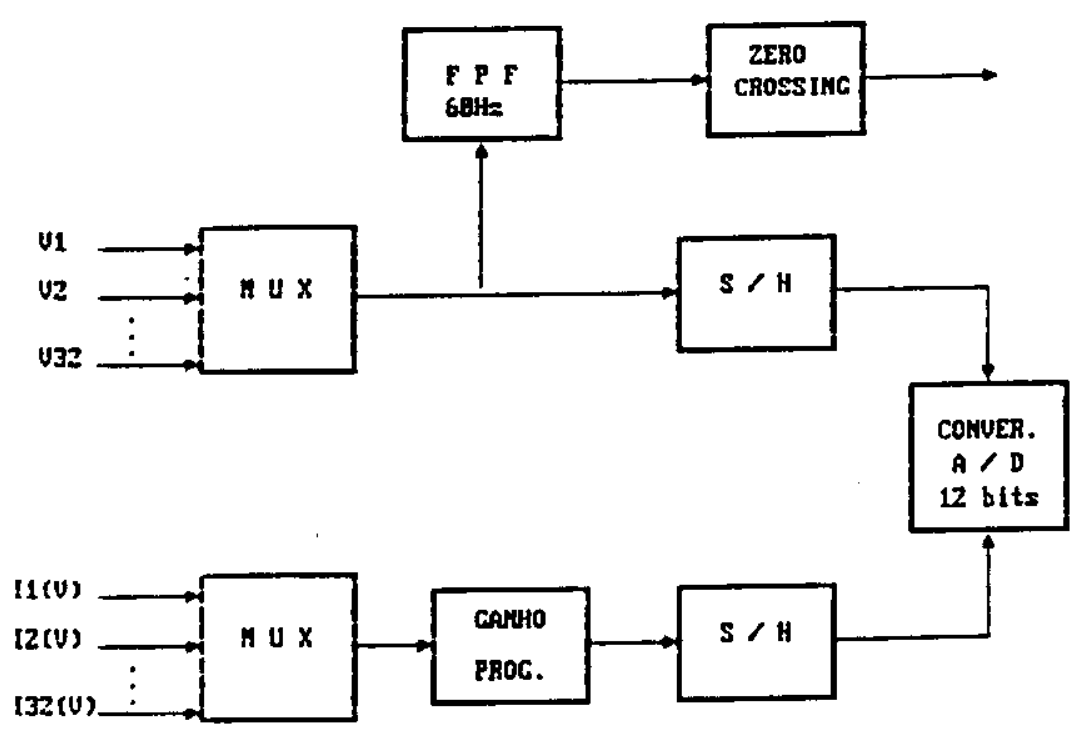

Figura 5.3.1.4 - Diagrama em Blocos da Placa Analógica 
5.3.1.5 Processamento e Transmissão dos Dados

\subsection{Placa CPU}

\section{A. Local}

Esta placa é responsável pelo controle da placa analógica, isto é, selecionar os canais elétricos, selecionar o ganho do amplificador do canal de corrente, amostragem e conversão do sinal e por fím, cálculos para obtenção dos valores eficazes, determinação do fator de potência e análise harmônica, além de se comunicar pela interface serial interna com a CPU Central. A figura 5.3.1.5.1 mostra o diagrama em blocos da CPU Local.

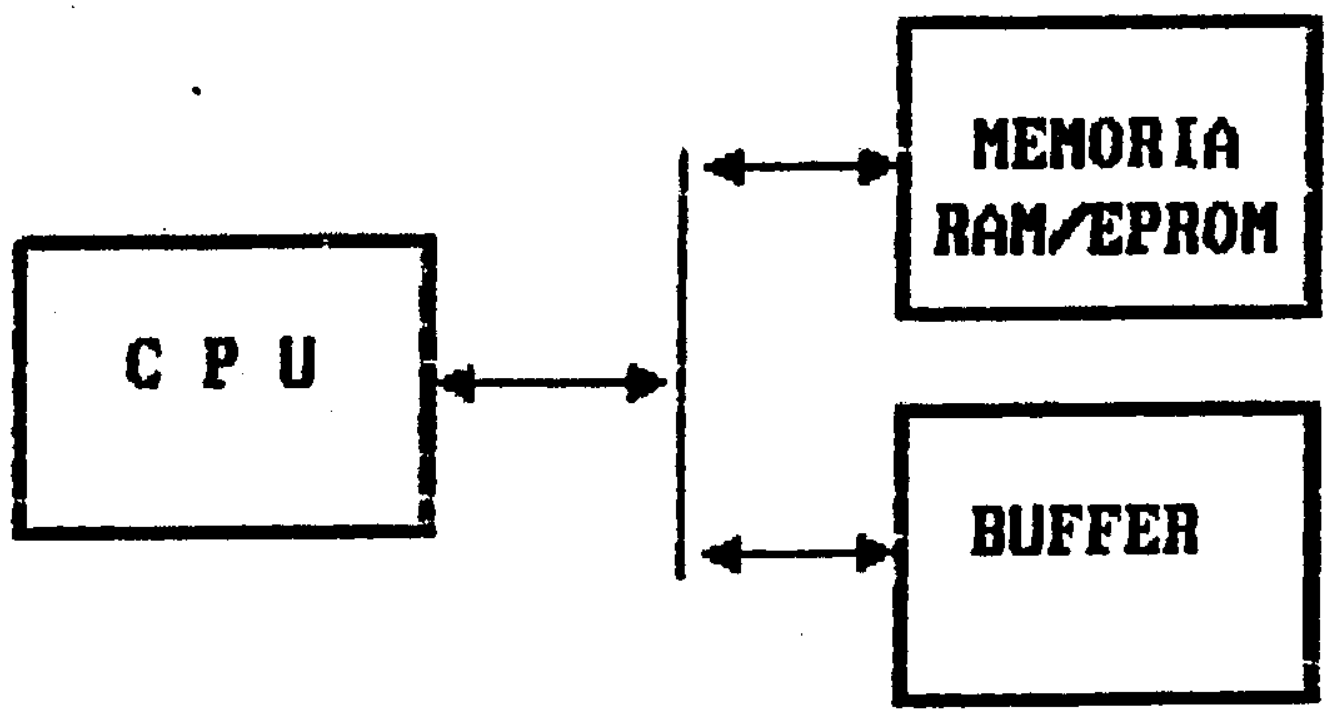

Figura 5.3.1.5.1 - Diagrama em Blocos da CPU Local 
B. CPU Central

É responsável pela monitoração do teclado e display, comando das CPU's Locais, controle de informações do sistema, armazenamento dos dados, comunicação com o meio externo, controle do relógio de tempo real. A figura 5.3.1.5.2 mostra o diagrama em blocos da CPU Central.

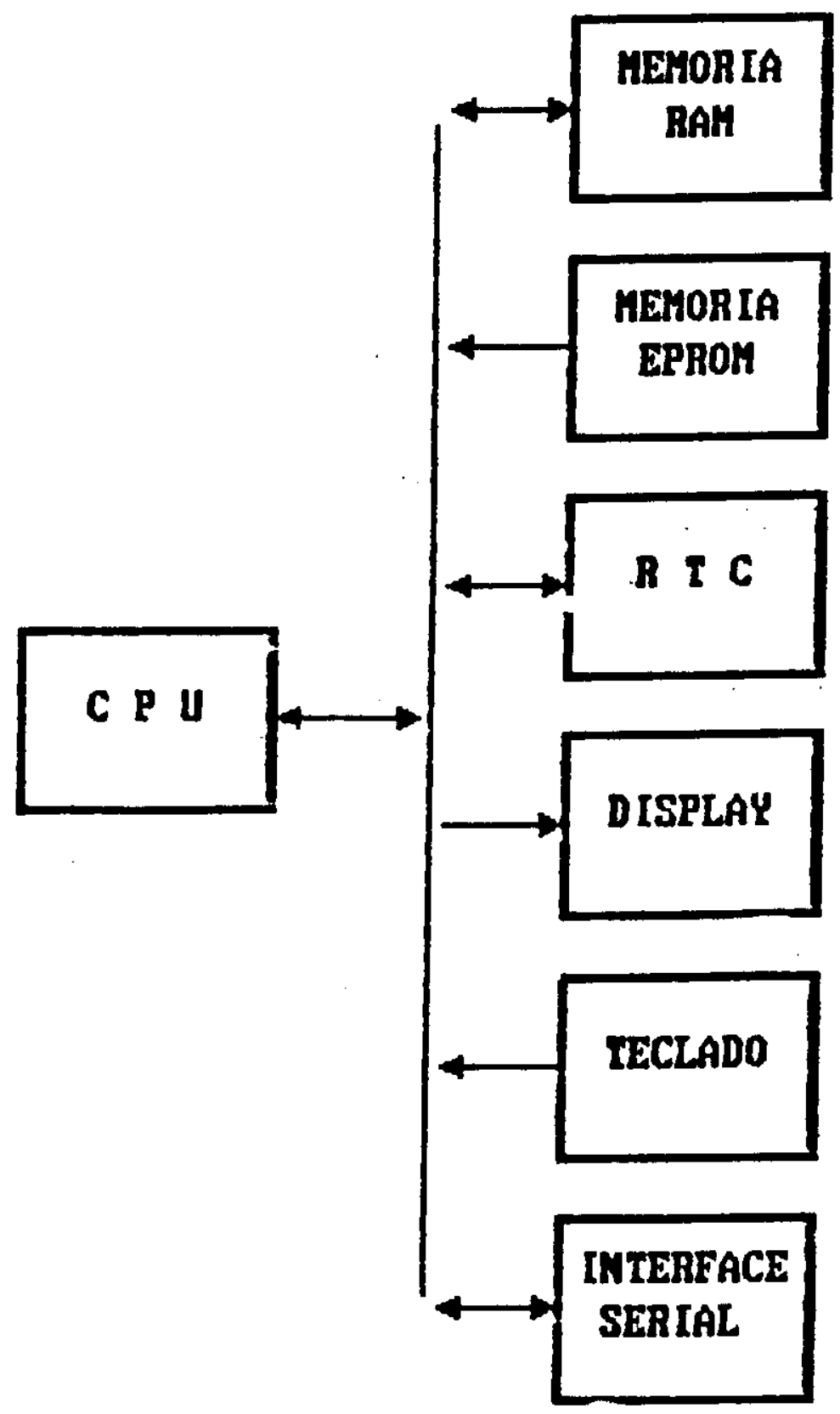

Figura 5.3.1.5.2 - Diagrama em Blocos da CPU Central 


\subsubsection{Armazenamento dos Dados}

\subsection{Placa de Memória}

A Placa de memória é utilizada pela CPU Central como um banco de armazenamento de dados. Cada placa possui 512 Kbytes de capacidade de armazenamento de dados, sendo que as memória são R.A.M's (memórias de acesso aleatório) estáticas alimentadas por baterias de lítio. Mesmo com a queda na energia que alimenta o R.C.C., os dados armazenados na memória permanecem intactos. A figura 5.3.1.6.1 ilustra o diagrama em blocos da placa de memória.
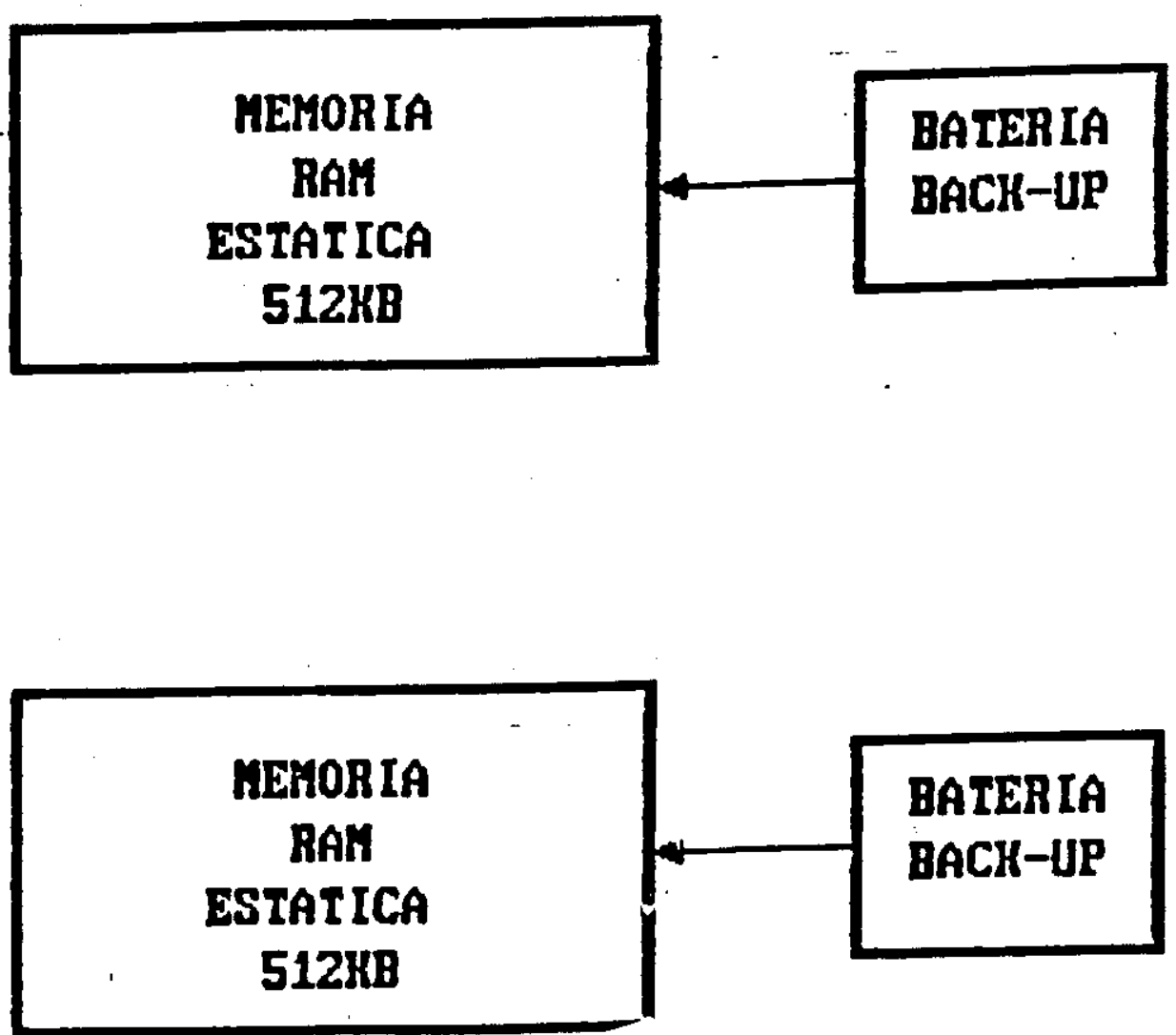

Figura 5.3.1.6.1 - Diagrama em blocos da Placa de Memória 


\subsubsection{Software}

A figura 5.3.2 apresenta um esquema simplificado do sistema de controle onde tem-se módulos distintos para o controle, interface com o usuário, amostragem, cálculos, etc. Estas funções são realizadas pelo conjunto de microprocessadores localizados na CPU Central e Local.

- Controle Principal: realizado na CPU Central, é responsável pelo gerenciamento do sistema completo, desde a realização de tarefas às CPU's locais até o gerenciamento do banco de memória e interface com o usuário.

- Controle Local: realizado nas CPU's Locais, é responsável pelo controle dos sensores de medição, digitalização dos sinais e cálculos.

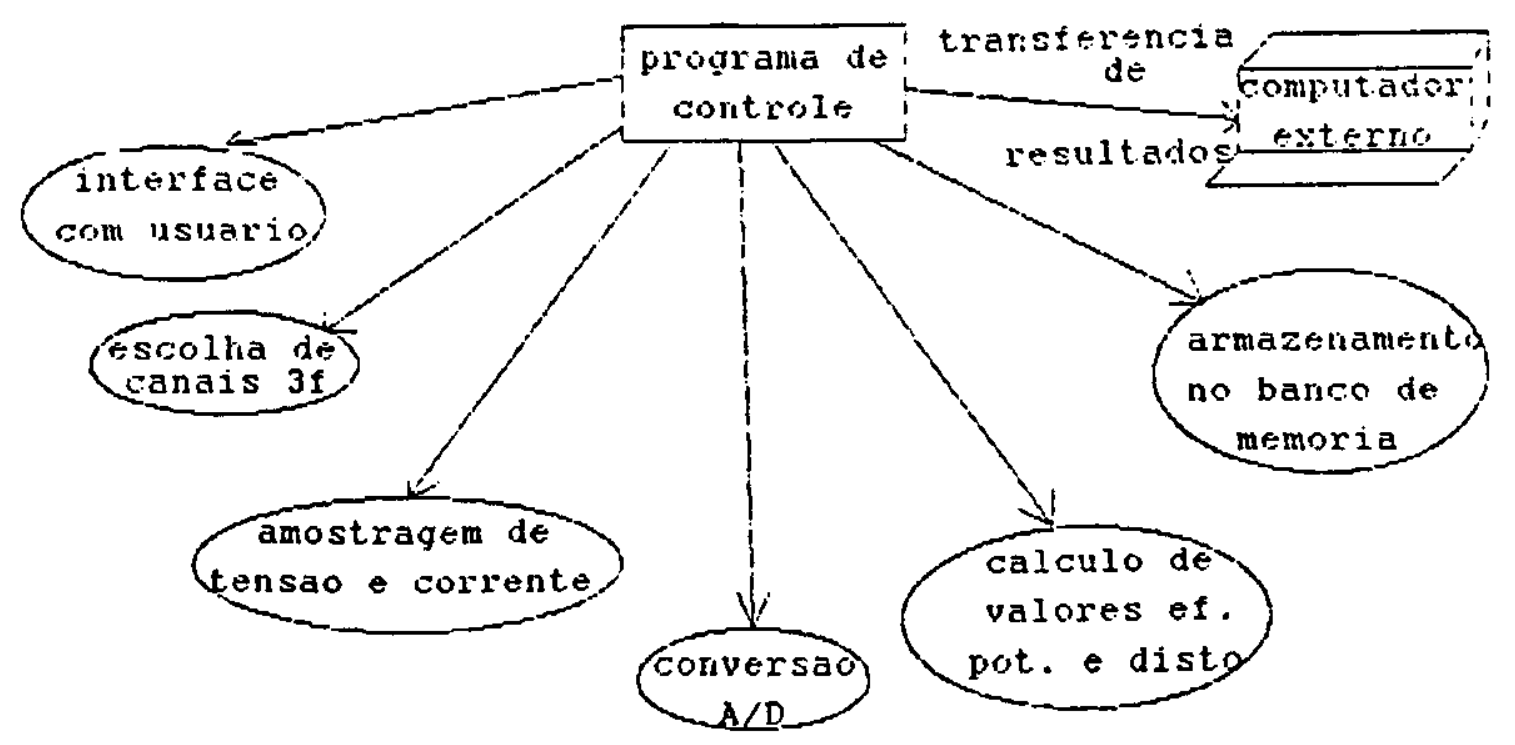

Figura 5.3.2 - Estrutura Simplificada do Programa de Controle 


\subsubsection{CPU Central}

É responsável, como já foi dito, pelo gerenciamento do sistema como um todo, controlando os dispositivos de entrada e saída: porta serial, porta paralela, display, teclado, relógio de tempo real, banco de memórias, placas de CPU's Locais. A figura 5.3.2.1 mostra o diagrama em blocos do software da CPU Central.

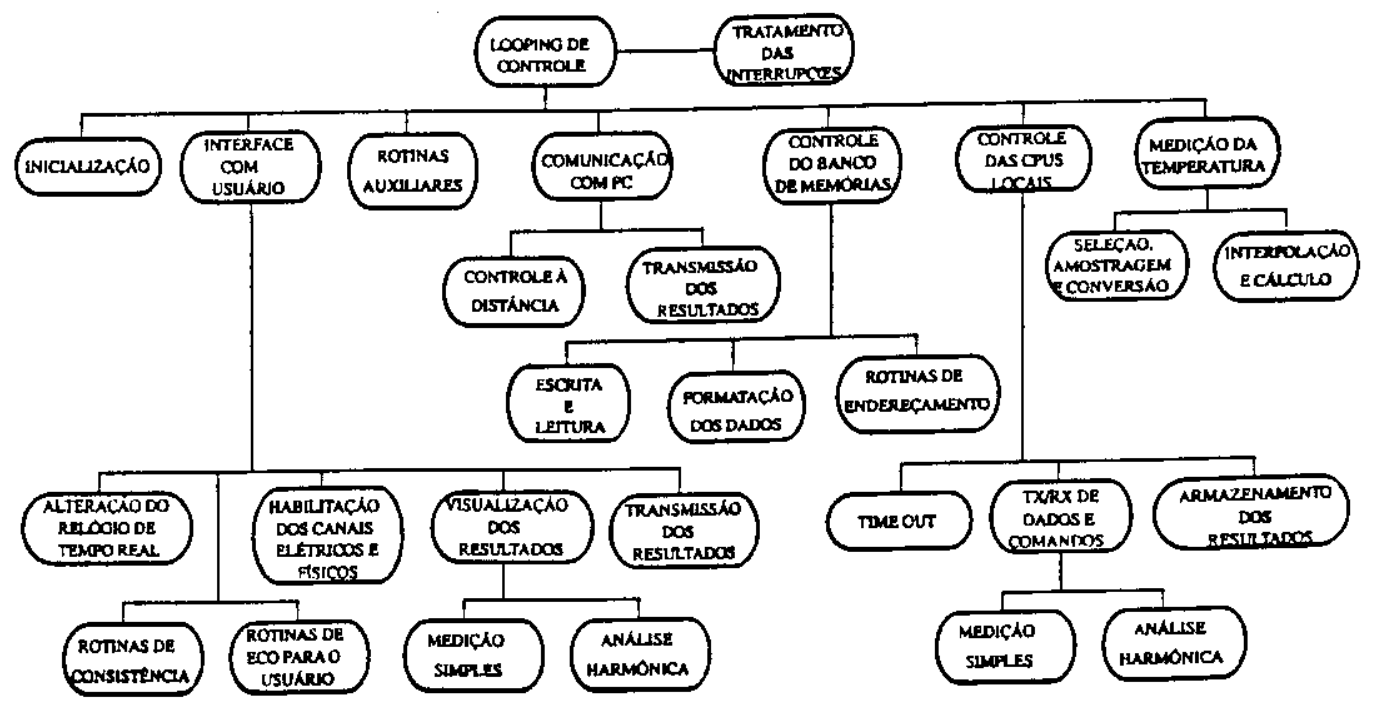

Figura 5.3.2.1 - Diagrama em blocos do software da CPU Central 


\subsubsection{Módulo de Controle}

O módulo de controle baseia-se numa variável de estado para seleção das operações a serem executadas. Num primeiro instante, quando o sistema é ativado (power on), um estado de inicialização é ativado para que as portas de entrada e saída sejam programadas. Além disto, as variáveis de controle do sistema são recuperadas da memória não volátil disponivel no relógio de tempo real - preservação da programação anterior. A integridade do banco de dados também é garantida através da preservação de ponteiros na RAM não volátil.

A inicialização compreende, ainda, a reprogramação do último passo de medição selecionado bem como os canais habilitados, permitindo, assim, quue seja retomado o estado de medição automaticamente.

Uma vez inicializado o sistema, os novos estados são atingidos através de interrupções do usuário (via teclado), do modo automático de medição (via timer interno) ou através do microcomputador externo (via interface serial). Os estados disponiveis são os seguintes:

- Programação e Resultados: Tratamento das interrupções do usuário (via teclado) através das quais permite a seleção de novos parâmetros, tais como passo de medição (ver item reprogramação) e visualização dos resultados da última medição efetuada. A interface com o usuário é do tipo amigável, apresentando as opções no display para que o usuário escolha através de setas (segue a filosofia das janelas de exibição/extração);

- Medicão automática: Este estado é acionado pelo timer interno de modo a efetuar medições periódicas. É solicitado um tipo de medição e cálculos às CPU's escravas, selecionando o periodo de execução e recolhendo os 
resultados para o banco de dados. O acesso às CPU's é feito através da porta serial interna, com endereços para cada CPU;

- Controle a distância: Este estado é acionado pela serial externa, passando o registrador ao atendimento dos comandos do microcomputador externo. Assim, é possível a alteração de parâmetros, medição e transmissão contínua dos canais selecionados (permite monitoração) e retirada dos resultados contidos no banco de dados.

Interface Serial Interna - Controle das CPU's Locais

O microcontrolador utilizado, família INTEL MCS-51, possui uma interface serial que pode ser utilizada no padrão RS 232 (até 4800 bps) ou num protocolo interno, aqui operado na freqüência de $375 \mathrm{KHZ}$. Utilizando este segundo modo, a CPU mestre pode acessar todas as placas simultaneamente ou cada uma em particular - no pedido de medição, o acesso é feito ao grupo de escravas, enquanto que nos pedidos de resultados o endereçamento é individual, evitando a colisão dos dados.

A troca de mensagens (comandos/resultados) é temporizada de modo que a CPU mestre não permaneça indefinidamente alocada na comunicação com as escravas em caso de falha em algumas delas.

Interface Serial Externa - Controle à Distância

Como interface serial externa é utilizada a pastilha Intel 8251 interface de comunicação programável, operando a 9600 bps. A atualização das variáveis de estado quanto à solicitação de controle a distância é feita via interrupção por parte desta interface. 
O controle a distância compreende a possibilidade de se efetuar a programação do aparelho (ver item programação), contínuo (monitoração) e retirada dos resultados armazenados no banco de memórias.

As mensagens trocadas seguem o mesmo formato utilizado na comunicação interna, contendo um campo com a identificação da mensagem (comando ou resultado) e comandos auxiliares (número do canal, resultados, etc.).

\subsubsection{CPU Local}

É responsável pelo interfaceamento e controle da placa analógica, ou seja, a seleção dos canais de medição, programação do amplificador de corrente, amostragem e conversão do sinal e cálculos para obtenção dos valores eficazes e análise harmônica. A figura 5.3.2.3 apresenta o diagrama em blocos completo do software da CPU Local.

O R.C.C. possui 3 CPU's locais e uma CPU central. O software das CPU's locais é idêntico no que diz respeito às operações executadas, mas difere quantos aos endereços de acesso. Assim cada placa de CPU Local deve ser configurada conforme a fase a ser medida (R, S, ou T).

\subsubsection{Módulo de Controle - CPU Local}

O módulo de controle, assim como ocorre na CPU central, baseia-se numa variável de estado para seleção das operações a serem executadas. A inicialização consiste na programação da placa analógica no modo repouso, canais de corrente e tensão desabilitados, sample $\&$ hold desabilitado; conversor A/D no modo resultados e amplificador de ganho programável com ganho 1 . 


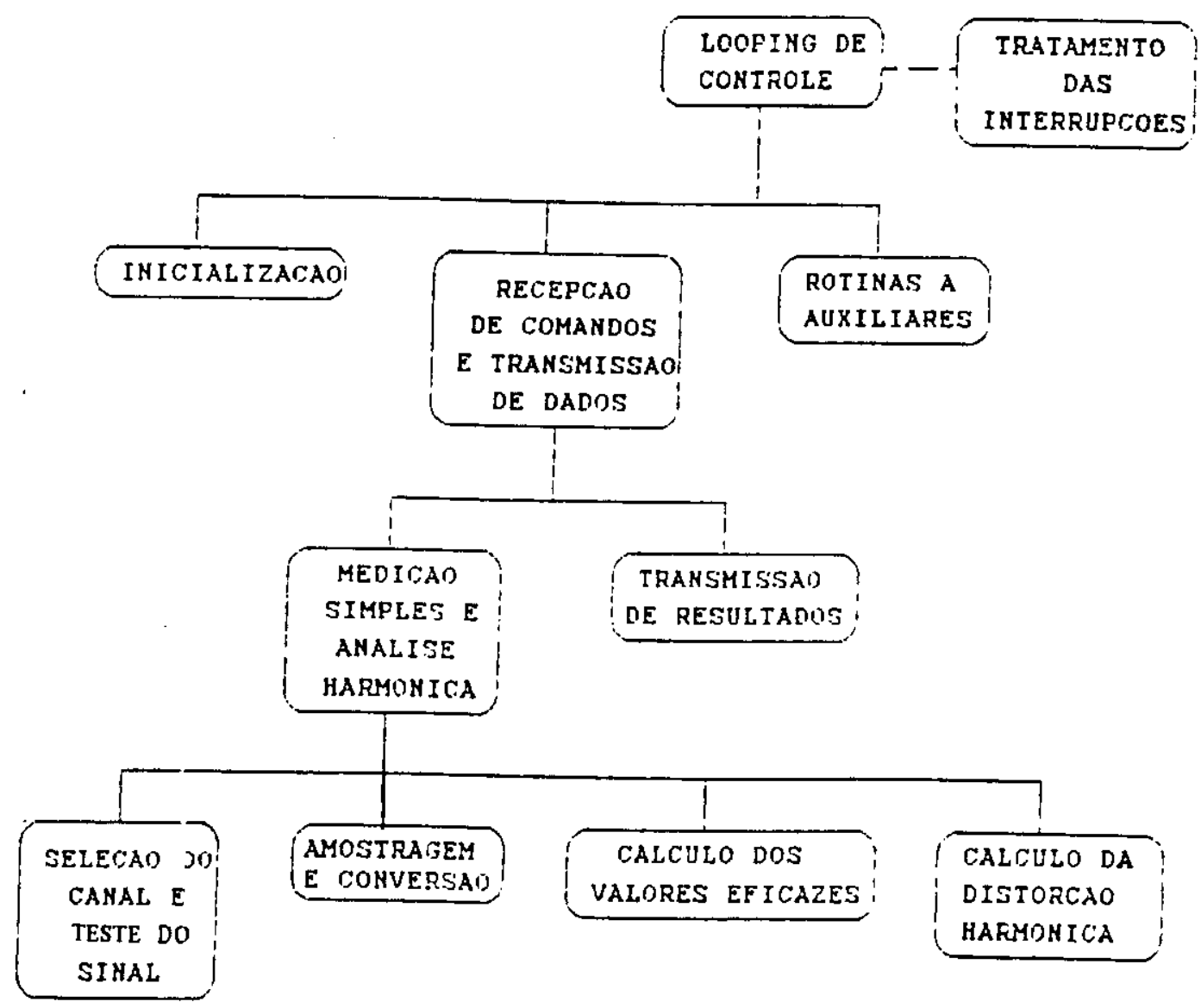

Figura 5.3.2.3 - Diagrama em blocos do software da CPU Local 
Além da placa analógica, são inicializadas as variáveis de estado - atualização via serial.

Após a inicialização, o módulo de controle aguarda solicitação da CPU Central para que seja realizada uma determinada operação. Esta solicitação ocorre via rede interna, sendo que os estados disponiveis são:

- Medição-Simples: teste do sinal, aquisição de dados e cálculo dos valores eficazes do canal elétrico previamente selecionado. Após o cálculo, aguarda comando da CPU Central para transferência dos resultados;

- Análise Harmônica: teste do sinal, aquisição de dados e cálculo da distorção total com a amplitude das 40 primeiras harmônicas. Assim como na medição simples, aguarda comando para transmissão dos resultados;

- Seleção dos Canais: habilitação prévia do próximo canal a ser medido de modo a obter-se uma estabilização do sinal;

- Reset_Local: utilizado quando a cpu central deseja que a última operação requisitada seja desconsiderada.

\subsubsection{Amostragem e Conversão A/D}

A medição é realizada nas 3 fases de um canal simultaneamente, uma fase em cada módulo local. Além disto, a tensão e a corrente também são medidas simultaneamente, utilizando-se dois circuitos de amostragem. Uma vez amostradas a tensão e a corrente, é feita a conversão da tensão enquanto é armazenado o resultado da última conversão de corrente. Ao término da conversão de tensão, é feita a conversão da corrente enquanto esta última tensão convertida é armazenada, deste modo, obteve-se uma otimização no desempenho aproveitando-se o tempo de conversão, que seria 
perdido para o armazenamento, o custo deste melhor desempenho está na complexidade da rotina de aquisição e na leitura de uma amostra inválida que deve ser desprezada.

Atualmente, a taxa de amostragem gira em torno de 13.000 amostras por segundo.

A medição é feita em apenas um ciclo do sinal de entrada, baseada nas transições pelo zero (monitoradas por interrupção) de modo a monitorar variações na freqüência. Existe, ainda, um dispositivo de time out para que não seja ultrapassado um limite máximo de $48 \mathrm{~Hz}-\mathrm{Ta}<=$ $20,8 \mathrm{~ms}$.

A medição só ocorre quando da existência de sinal na entrada da placá analógica e, também, após a programação do amplificador de corrente. A rotina de verificação do sinal monitora um ciclo máximo de 48 $\mathrm{Hz}$ de modo que neste intervalo de tempo não ocorram mais do que duas transições (monitoradas por interrupção) - ocorrência de ruido em freqüências elevadas e, também, que a amplitude atinja um nivel mínimo para medição, entre 10 e $20 \%$ do fundo de escala.

O amplificador de corrente permanece sempre programado com o ganho 1 . Una vez que o sinal está presente, a rotina de programação deste amplificador monitora um período do sinal e escolhe o ganho segundo o valor máximo encontrado. O canal a ser medido é previamente selecionado. A seleção dos canais é feita segundo dois parâmetros: o número do canal (de 1 a 16) e o grupo (alto e baixo).Com estes dois parâmetros obtém-se os 32 canais disponíveis na CPU Central, aqui convertidos em dois grupos; 1 a 16 (grupo baixo) e 17 a 32 (grupo alto). 


\subsubsection{Cálculos - Valor Eficaz}

A operação "medição simples" disponível na CPU Central consiste no cálculo do valor eficaz da tensão, corrente e o fator de potência.

A rotina que executa estes cálculos foi desenvolvida na linguagem " $\mathrm{C}$ " de modo que execute as operações em ponto flutuante. $A$ partir do vetor de amostras (16 bits) obtido por uma rotina em assembly, é feita uma filtragem de modo a retirar o nível $\mathrm{DC}$ adicionado pelo conversor A/D - entrada em 0 a $20 \mathrm{~V}$ com sinal de -10 a $+10 \mathrm{~V}$ e, em seguida, faz-se a integração numérica ao longo do periodo, obtendo-se a tensão eficaz (V), a corrente eficaz (A) e a potência ativa (W).O fator de potência é obtido da relação [W/V.A].

As operações em ponto flutuante utilizam a representação mantissa - expoente, da seguinte forma: 1 bit de sinal, 8 bits de expoente e 23 bits de mantissa.Em função disto e das amostras serem obtidas em 12 bits os resultados finais da tensão e corrente resultam com 1 casa decimal e o fator de potência com 2 .

O armazenamento é feito em variáveis internas devido ao espaço em memória necessário, o que implica em multiplicar-se a tensão e corrente por 10 e o fator de potência por 100 - preservação das casas decimais.

\subsubsection{Cálculos - Análise Harmônica}

O RCC possui implementado em seu hardware um algoritmo escrito em linguagem $C$ capaz de calcular a Transformada Rápida de Fourier (F.F.T.). Através do método tradicional de cálculo, este algoritmo fornece ao usuário o valor de amplitude das 40 harmônicas do sinal de entrada, acrescido de sua respectiva distorção harmônica total, em valores percentuais. 
A função Análise Harmônica deve ser habilitada pelo usuário do equipamento, através do teclado acoplado ao rack. Uma vez escolhido o tamanho do passo de medição, o RCC executará o cálculo ciclicamente, armazenando os dados obtidos no seu bloco de memória.

\subsubsection{Interface Serial}

A interface serial interna é a mesma já descrita anteriormente, sendo responsável pela atualização das variáveis de estado.

A chamada "rede interna" entre os 4 microcontroladores é o meio fisico das mensagens trocadas entre as CPU's central e locais.Os comandos enviados pela central interrompem todas as 3 locais que passam imediatamente a recodificar o campo de endereço. Uma vez decodificado, a CPU local apontada por este endereço passa a aguardar, se for o caso, o restante da mensagem, enquanto que as demais ignoram os campos recebidos.

\subsubsection{Desempenho do Sistema}

\section{A. Tempo de Medição}

O registrador opera em dois modos distintos, isto é, a medição simples que requer 3 segundos por canal e a análise Harmônica que requer 20 segundos por canal.

\section{B. Autonomia do Banco de Dados}

O Banco de Dados pode contar com até 8 placas de memória onde permite uma área de $8 \mathrm{M}$ bytes. A autonomia depende do tipo de medição bem como do passo utilizado e do $\mathrm{n}^{\circ}$ de canais ativos.

Assim, uma vez escolhido o passo de medição obtém-se o $\mathrm{n}^{\circ}$ de medições por dia e, portanto, o $\mathrm{n}^{\circ}$ de bytes necessários. As tabelas 5.3.2.9 e 
5.3.2.10 mostram como são distribuídos os bytes para o tipo de medição simples e de harmônicos, respectivamente

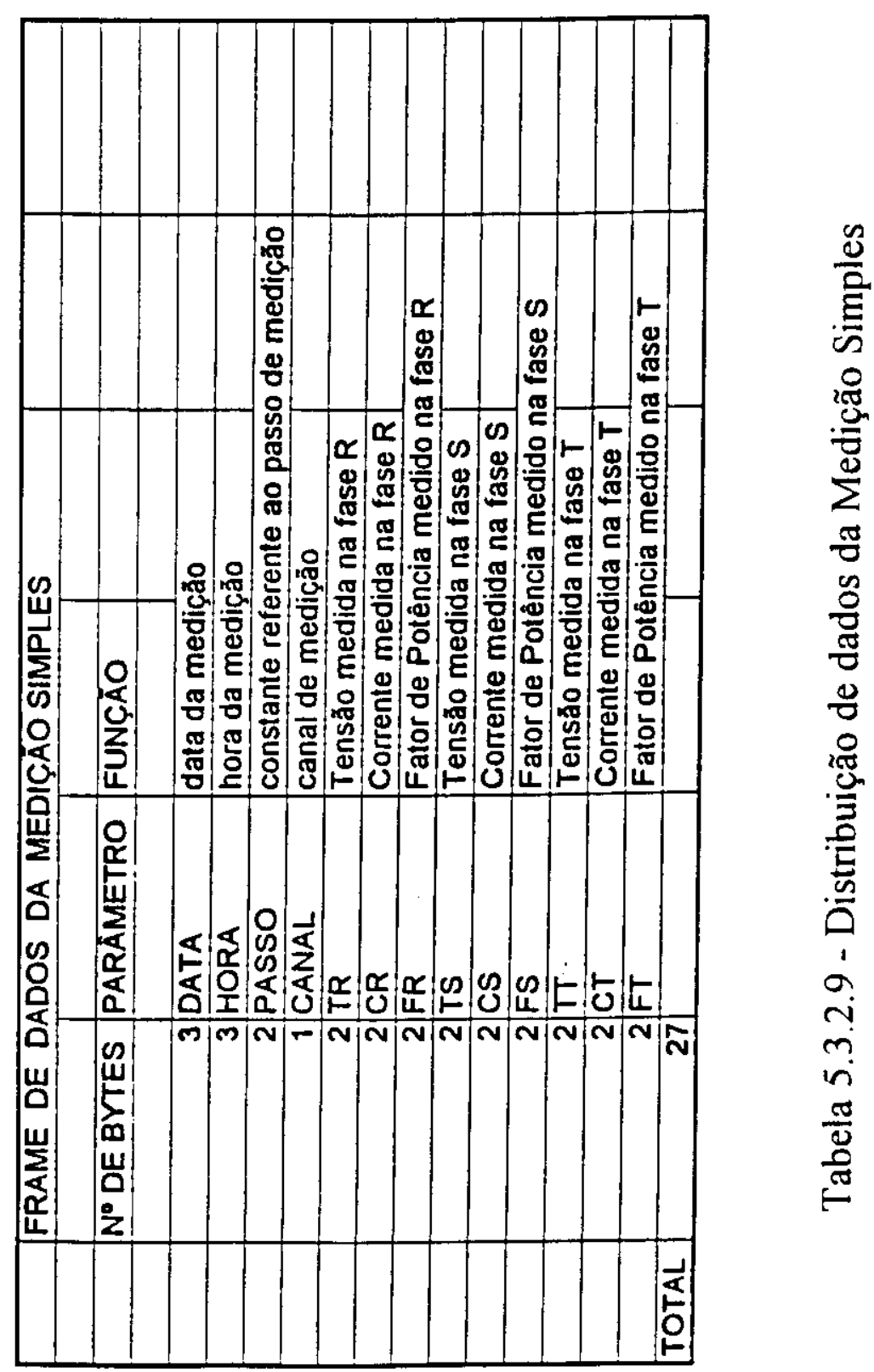




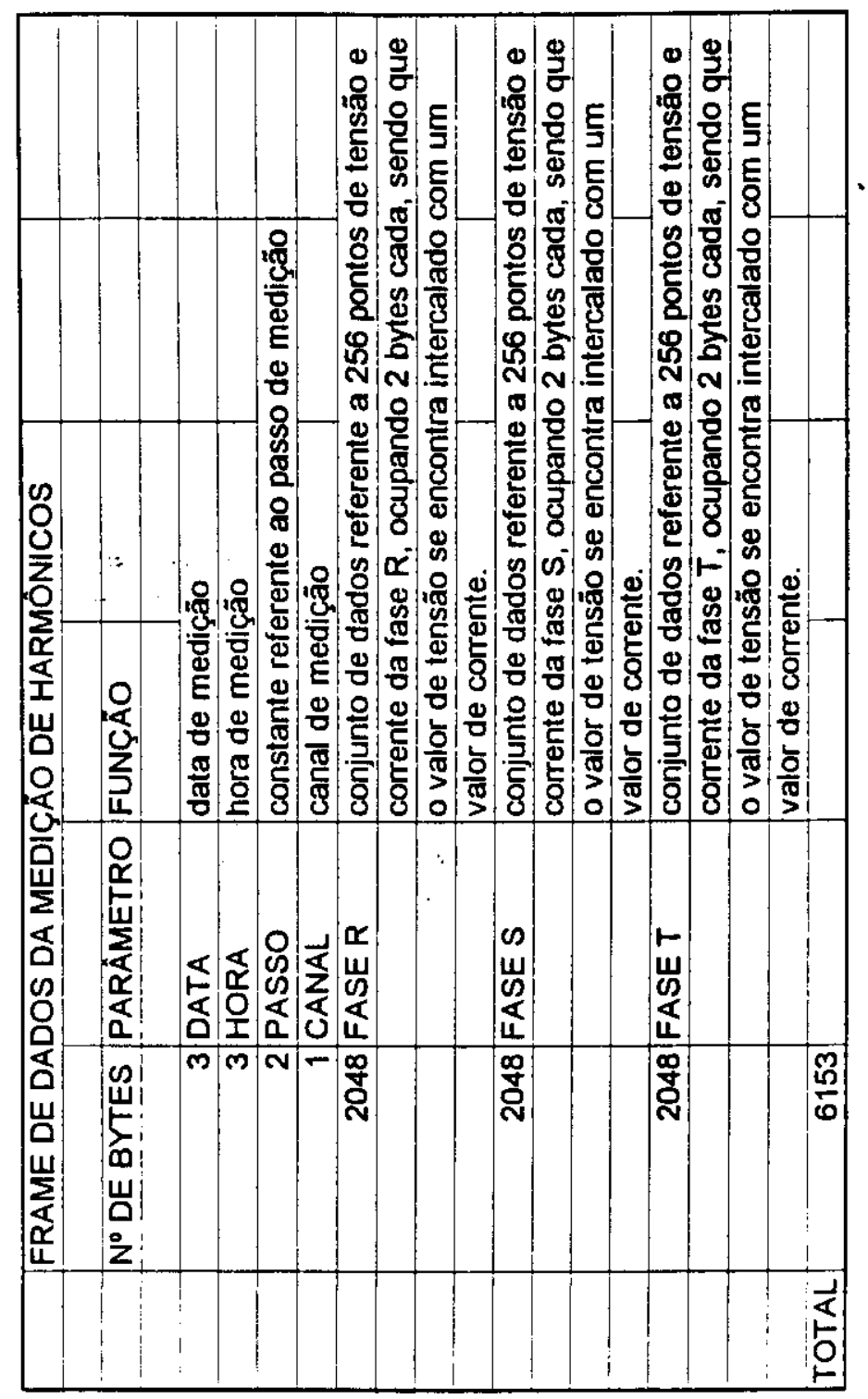

告 
A determinação do número de medições simples em função do número de horas pode ser feita como no exemplo abaixo:

Total de horas de medição $=500$ horas $\Longrightarrow 21$ dias $(500 \mathrm{~h} /(24 \mathrm{~h} / \mathrm{dia}))$

Passo de medição $=5$ minutos $\Longrightarrow 12$ medições por hora.

Número de medições $=500 * 12=6.000$

A determinação do espaço total de memória ocupada:

Número de medições * Frame $=6.000 * 27=162.000$ bytes

Caso a capacidade total da memória de dados seja de 512 kbytes, teremos então uma autonomia de memória de $512 \mathrm{k} / 162 \mathrm{k}=3,16$. Isto significa que aproximadamente $1 / 3$ (um terço) da capacidade da memória do aparelho estará ocupada.

A determinação do tempo de transmissão de dados será:

Taxa de transmissão do aparelho $=1870$ bytes $/ \mathrm{min}$

Tempo de transmissão $=162000 / 1870=86,6 \mathrm{~min}=1 \mathrm{~h} \mathrm{e} 27 \mathrm{~min}$

A determinação do número de medições harmônicas, simples em função do número de horas pode ser feita como no exemplo abaixo:

Total de horas de medição $=168$ horas $=7$ dias

Passo de medição $=1$ hora $=1$ medição por hora

Número de medições $=168 * 1=168$

A determinação do espaço total de memória ocupada:

Número de medições * Frame $=168 * 6153=1033704$ bytes

Caso a capacidade total da memória de dados seja de 2000 kbytes, ou

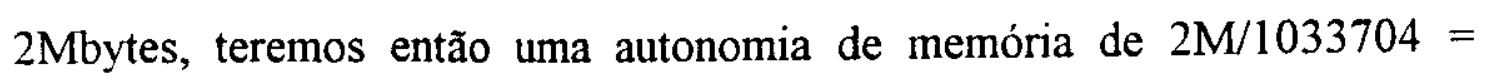
1,93. Isto significa que aproximadamente $1 / 2$ (metade) da capacidade da memória do aparelho estará ocupada.

A determinação do tempo de transmissão de dados será:

Taxa de transmissão do aparelho $=1870$ bytes $/ \mathrm{min}$

Tempo de transmissão $=1033704 / 1870=552,78 \mathrm{~min}=9 \mathrm{~h}$ e $17 \mathrm{~min}$ 


\section{Precisão dos Resultados}

A aferição do aparelho foi realizada através do levantamento de uma série de pontos para cada fase do canal 1 , visto que o circuito dos vários canais é comum para uma mesma fase. Assim, ao término do levantamento foi obtida uma curva normal de modo a atribuir uma precisão ao aparelho. Além disto, foi realizada uma aferição prévia com 1 ponto em cada fase (para o canal 1) o que implicou num erro de $0,5 \%$ da medida (tensão, corrente) e 1,0\% (potência). Foi verificada também a repetibilidade das medidas.

\section{Duração do Projeto}

A duração do projeto é dividida em 3 etapas: especificação, desenvolvimento e testes, descritas a seguir:

* Especificação: esta etapa consistiu no detalhamento da arquitetura e do software de controle, sendo concluída no periodo de outubro de 1990 a março de 1991;

* Desenvolvimento: a etapa de desenvolvimento implementou a arquitetura especificada, corrigindo as eventuais falhas e reespecificando alguns itens quando necessário. O início desta fase deu-se em janeiro de 91 , sendo que o desenvolvimento do hardware terminou em janeiro de 92 e do software foi e concluido em julho de 1992.

* Testes: a fase de teste dos módulos iniciou-se junto ao desenvolvimento, persistindo durante toda sua duração. Já os testes de integração do sistema completo, deram-se a partir de abril de 1992 sendo que no período de dezembro de 1992 a março de 1993 o equipamento 
totalizou 1190 horas de funcionamento contínuo, sem problemas de hardware ou software, para o modo de medição simples. Para o modo de medição de harmônicos, o início foi a partir de dezembro de 1993 e concluído em julho de 1994.

\subsection{Avaliação de Desempenho de Equipamentos}

As medições de correntes e tensões harmônicas são essenciais para a confiabilidade dos Sistemas Elétricos de Potência e sua rede de distribuição de energia elétrica. Para justificar este pressuposto algumas razões são apontadàs abaixo:

a. Monitorar os valores existentes de harmônicos e checá-los em relação às normas e recomendações vigentes.

b. Testar os equipamentos que geram harmônicos.

c. Diagnosticar e estabelecer situações nas quais o desempenho dos equipamentos é inaceitável para a concessionária ou para o usuário.

d. Observar os níveis existentes de tensão e corrente harmônica e planejar ao longo do tempo para qual tendência estão caminhando estes valores seja diariamente, semanalmente, mensalmente ou modelos sazonais.

e. Medir para a verificação de estudos de simulação que incluam fluxo de carga harmônico.

f. Medir tensões e correntes harmônicas com seu respectivo ângulo de fase. Tais medidas podem ser feitas com e sem una parte das cargas não-lineares conectadas, e podem ajudar a determinar o ponto de impedância harmônica para un dado local.

As técnicas para medições de harmônicos diferem daquelas utilizadas comumente em medições para sistemas elétricos de potência. 
A largura de banda da freqüência comumente utilizada para medições de tensão, corrente e potência pode ser uma banda de freqüência próxima da freqüência da rede de distribuição elétrica, $60 \mathrm{~Hz}$.

Para o estudo dos harmônicos em sistemas elétricos de potência é requerido uma maior largura de banda da freqüência, até $3 \mathrm{kHz}$.

Como já foi mencionado anteriormente, os equipamentos mais utilizados, basicamente, para a análise de tensões e correntes não-senoidais são: osciloscópios, analisadores de espectro, analisadores harmônicos ou analisadores de forma de onda, analisadores de distorção, equipamentos medidores digitais de harmônicos.

A análise digital pode ser realizada com duas técnicas básicas:

1. Através de filtros digitais: este método é similar à filtragem analógica. Os analisadores digitais de dois canais incluem filtragem digital. A faixa de freqüência é medida ajustando os filtros digitais para aquele específico valor de freqüência. Também, a largura da faixa de freqüência é ajustada para otimizar a captura de pequenos sinais harmônicos na presença de uma freqüência fundamental muito grande.

2. A Transformada Rápida de Fourier: este método verifica o desempenho da análise de espectro em tempo real e com rapidez, permitindo a avaliação de um grande número de funções e parâmetros.

Micro e mini computadores, conversores analógico-digitais multicanais são usados para aquisição de dados em tempo real. Quando a forma de onda é gravada, usando-se técnicas analógicas ou digitais em tempo real, o cálculo das componentes harmônicas via F.F.T., a conversão para unidades de engenharia, as estatísticas, o desenho e a impressão dos resultados pode ser realizada fora de tempo real em laboratórios utilizandose dos recursos disponiveis. 
São requisitos importantes para avaliação de performance dos equipamentos de medição:

. Exatidão: Frequentemente confundida com precisão (um equipamento pode ser preciso sem ser exato), a exatidão do equipamento para medições de uma componente harmônica constante (steady-state) deve ter um erro compatível com limites permissiveis. É razoável usar um instrumento com uma incerteza não maior que $5 \%$ de limite permissivel.

Por exemplo, assume-se uma tensão de $480 \mathrm{~V}$, num sistema trifásico no qual o $11^{\circ}$ (décimo-segundo) harmônico pode ser menor do que $0,70 \%$. A tensão fase-neutro $\mathrm{V}_{l l}$, é menor do que $1,94 \mathrm{~V}$. Isto indica que $\mathrm{o}$ instrumento deve ter uma incerteza menor que $\pm(0,05) \times(1,94)= \pm 0,097 \mathrm{~V}$. . Seletividade: a seletividade de um instrumento é uma indicação da sua habilidade para separar componentes harmônicos de diferentes freqüências. Uma maneira prática de garantir uma boa seletividade é definir requisitos para uma atenuação mínima para uma freqüência injetada, enquanto o instrumento é ajustado (sintonizado) para a freqüência $f_{h}-60 \mathrm{~Hz}$. A tabela abaixo dá a mínima atenuação necessária.

Mínima atenuação $(\mathrm{dB})$

$\begin{array}{ccc}\begin{array}{c}\text { Freqüência Injetada } \\ \mathrm{Hz}\end{array} & \begin{array}{c}\text { Instrumento } \\ \text { Dominio da Freqüencia }\end{array} & \begin{array}{c}\text { Instrumento } \\ \text { Dominio do Tempo }\end{array} \\ 60 & 0 & 0 \\ 30 & 50 & 60 \\ 120 \text { a } 720 & 30 & 50 \\ 720 \text { a } 1200 & 20 & 40 \\ 1200 \text { a } 2400 & 15 & 35\end{array}$


Em várias aplicações, a corrente fundamental pode ser muito grande em comparação com as correntes harmônicas. As correntes harmônicas podem ser significativamente importantes para causar sérios distúrbios, como no caso de interferências telefônicas. Em tais situações, uma faixa dinâmica é necessária para a verificação de todos os harmônicos num sistema elétrico de potência. Em quase todos os equipamentos de medição de harmônicos pode-se encontrar no mínimo $60 \mathrm{~dB}(0,1 \%$ da fundamental). Os equipamentos que alcançam a $90 \mathrm{~dB}(0,00316 \%)$ tem um custo extra.

Medida instantânea: se os harmônicos medidos variam no tempo, é necessário, suavizar a flutuação rápida das componentes harmônicas sobre o período de tempo medido. Dois fatores tornam-se importantes neste caso: a resposta dinâmica e a largura da banda de frequêencia.

a. Resposta Dinâmica: por exemplo, se é desejável a média num periodo de 3 (três) segundos, então a resposta da saída do medidor deveria ser idêntico a uma filtro passa-baixa de primeira ordem com uma constante de tempo de $1,5 \pm 0,15 \mathrm{~s}$.

b. Largura da Banda de Freqüência: a largura da banda de freqüência do equipamento afetará fortemente a leitura, especialmente quando os harmônicos estão flutuando. Recomenda-se que sejam usados os equipamentos com largura de faixa constante, para toda a faixa de frequiências. A largura de faixa deve ser de $3 \pm 0,5 \mathrm{~Hz}$ entre os pontos de $-3 \mathrm{~dB}$ com minima atenuação de $40 \mathrm{~dB}$ para a freqüência de $f \mathrm{~h}+15 \mathrm{~Hz}$. Em situações nas quais interharmônicos e transitórios estão presentes, uma largura de faixa extensa provocará grandes erros positivos.

A noção de variações de cargas suaves sobre um período de tempo pode ser aproximada com um claro entendimento do ciclo de trabalho das cargas provocadoras de distúrbios. Por exemplo, um S.C.R. acionando a 
abertura de uma escavadeira elétrica numa mina de carvão, os harmônicos somente aparecem durante o ciclo de escavação. Se tentar-se tirar a média de um evento harmônico transitório, o resultado poderia ser a perda da informação dos harmônicos. No caso da escavadeira numa mina de carvão, é essencial ter-se a habilidade para selecionar e registrar o comportamento instantâneo da corrente e da tensão durante o ciclo de escavação.

As repetições do comportamento instantâneo da corrente e da tensão durante o ciclo de escavação fornecerão uma indicação das características dos harmônicos do acionador elétrico da escavadeira. Por outro lado, muitas definições sobre harmônicos são baseados na periodicidade. Entretanto, em situações nas quais a carga monitorada contêm transitórios, é necessário utilizar-se uma "janela" para se verificar em regime permanente um ou mais ciclos e uma onda periódica.

O resultado da Transformada Rápida de Fourier (F.F.T.), para esta respectiva "janela", pode ser considerada como um valor médio dos harmônicos. Onde os harmônicos não são sempre acentuados, a média é sempre usada. Um analisador digital de sinais de dois canais, tem a vantagem de permitir a seleção de médias variando no tempo ou número de ciclos.

\subsubsection{Apresentação dos dados dos harmônicos}

Os dados medidos podem ser apresentados ou em forma de tabelas (ver tabela 5.4.1) ou em forma de gráficos.

Espectro de Corrente Harmônica

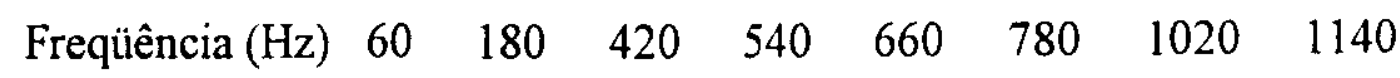

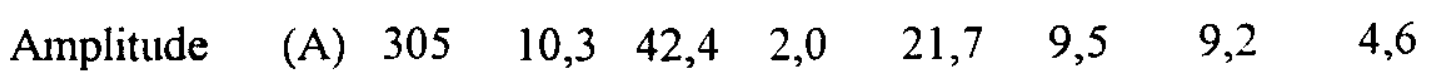

Tabela 5.4.1 - Espectro de corrente harmônica 
A saída do analisador é mostrado na figura 5.4.1.1, a tela com o espectro na figura 5.4.1.2 é dada em escala linear. As escalas logarítmicas também podem ser usadas e relevam componentes harmônicas abaixo de $5 \%$.

Os harmônicos variáveis no tempo estão convenientemente apresentados em função da frequêencia, como na figura 5.4.1.2. As estatísticas dependentes do tempo, podem ser definidas quando os harmônicos estão flutuando. Se um período de aquisição de dados Td, é subdividido em $\mathrm{m}$ sub-intervalos, o tempo total de observação será $\mathrm{mT}=\mathrm{Td}$.

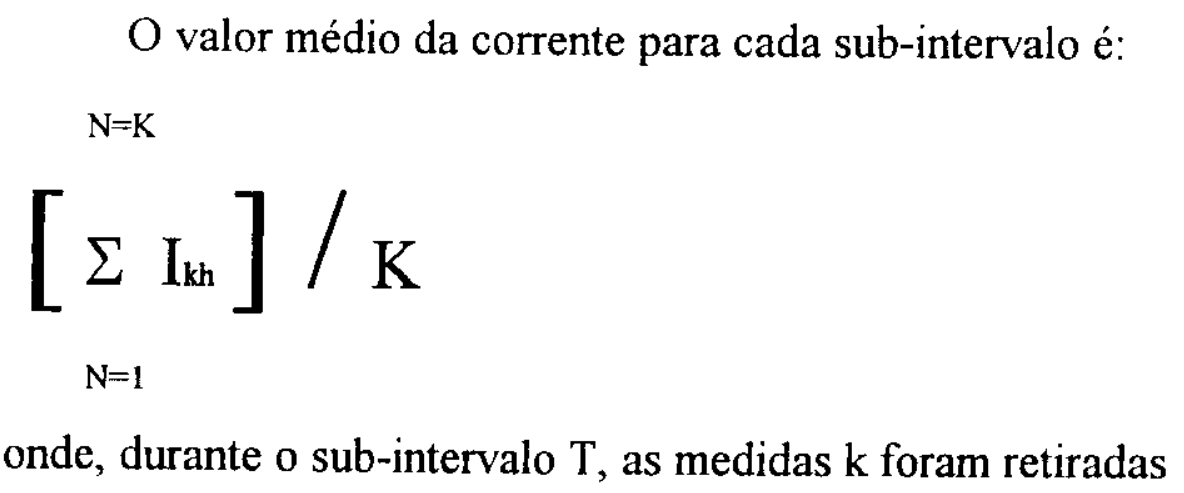

O valor eficaz é:

$$
\left[\begin{array}{ll}
\mathrm{N}=\mathrm{K} & \mathrm{I}_{\mathrm{kh}}
\end{array}\right]^{2} / \mathrm{K}
$$

$\mathrm{N}=1$

Os valores acima habilitam-nos a calcular o desvio padrão:

$$
\mathrm{I}_{\mathrm{h}}=\left(\mathrm{I}_{\mathrm{hmax}}-\mathrm{I}_{\min }\right)^{1 / 2}
$$




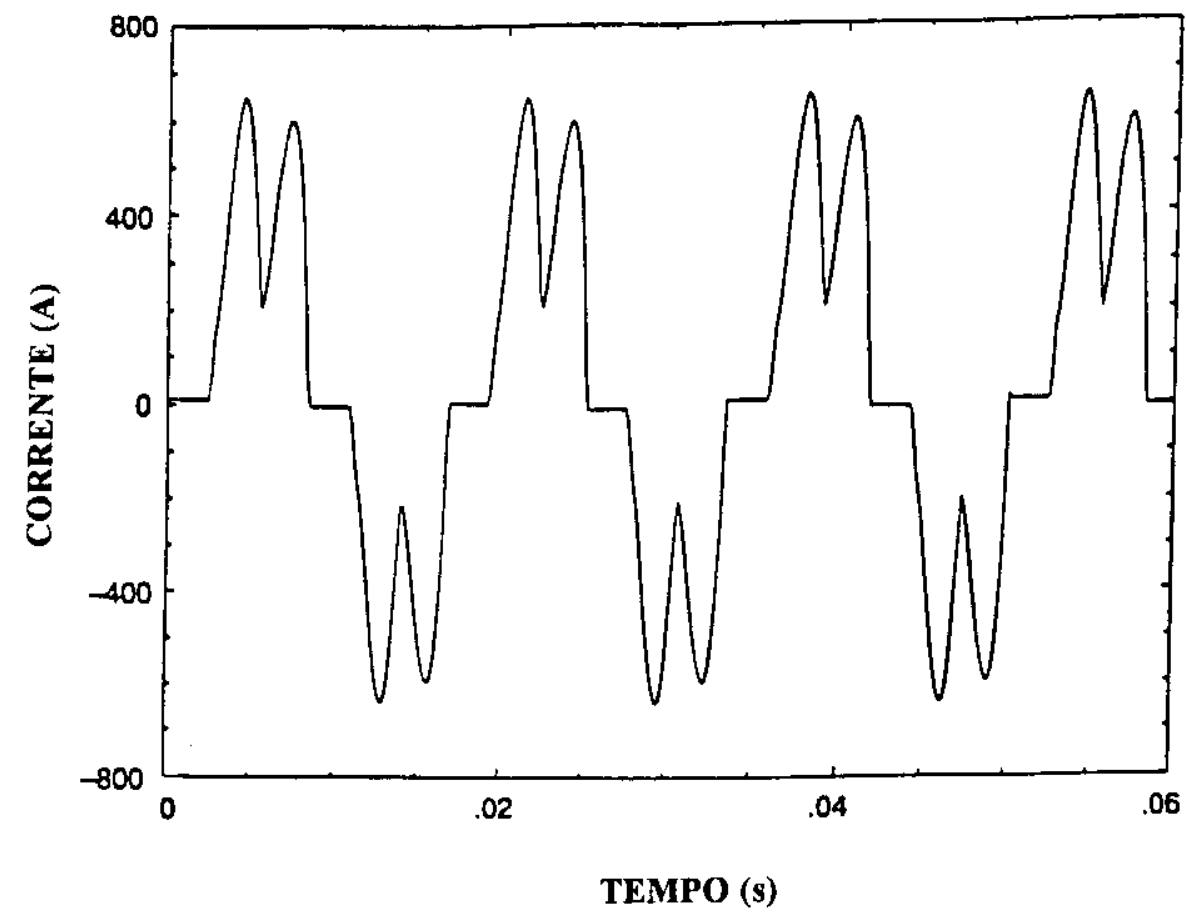

Figura 5.4.1.1 - Analisador de Espectro - No domínio do tempo

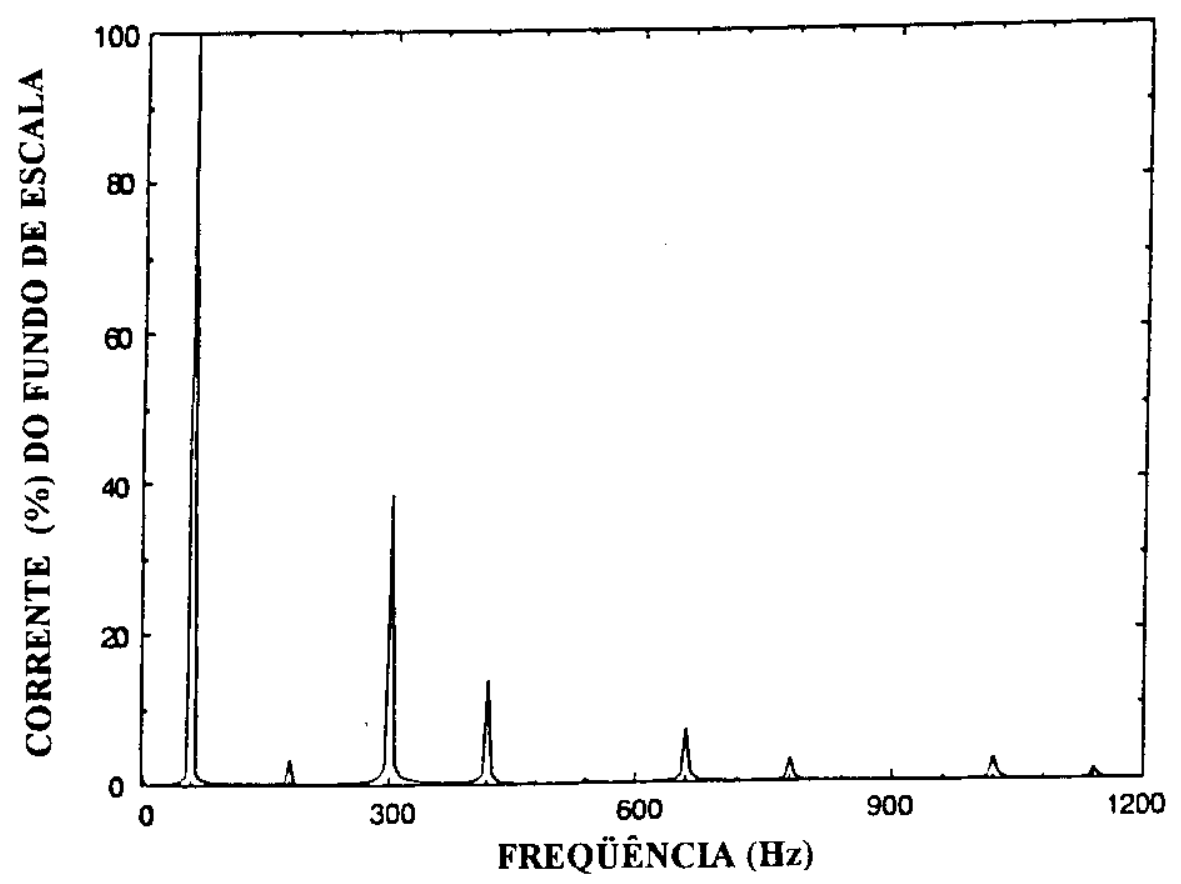

Figura 5.4.1.2 - Analisador de Espectro - No dominio da freqüência 
Os valores máximos e mínimos para cada sub-intervalo são partes do programa de aquisição de dados

Ih = máximo (Ih) sobre o $\mathrm{k}$ medido

Ih $\min =$ mínimo (Ih) sobre o $\mathrm{k}$ medido

A distribuição de probabilidades (frequentemente referida com um histograma), ver figura 5.4.1.3, são gráficos de barras com o peso de cada barra representando a freqüência relativa da quantidade de ocorrências de cada tensão harmônica.

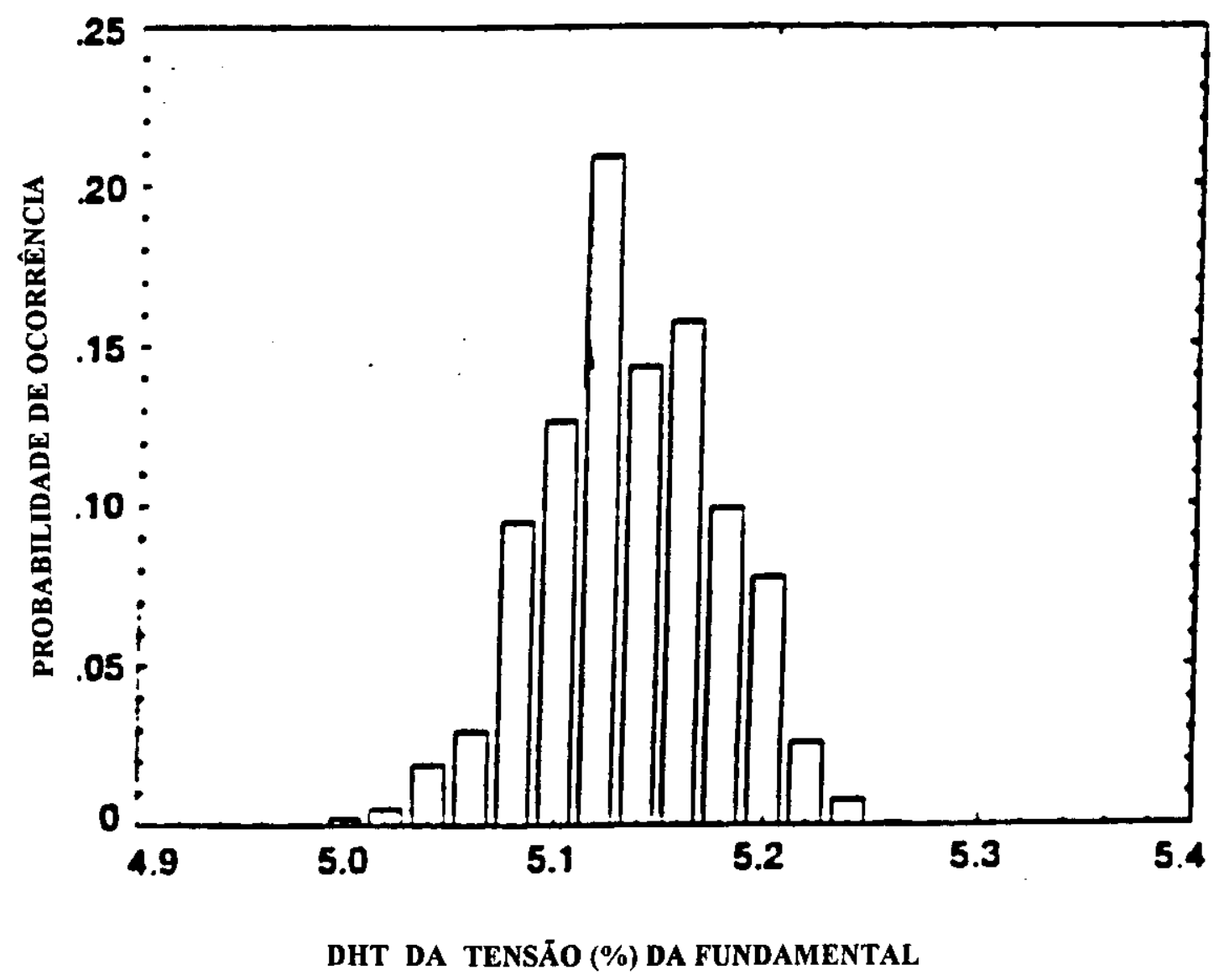

Figura 5.4.1.3 - Histograma da distorção harmônica total na tensão(D.H.T) 
Esta informação pode ser muito convenientemente mostrada na forma de uma função inversa de distribuição, ver figura 5.4.1.4. Neste formato, a informação torna-se uma poderosa ferramenta na avaliação dos efeitos dos harmônicos sobre os equipamentos tais como capacitores, motores, transformadores, etc...

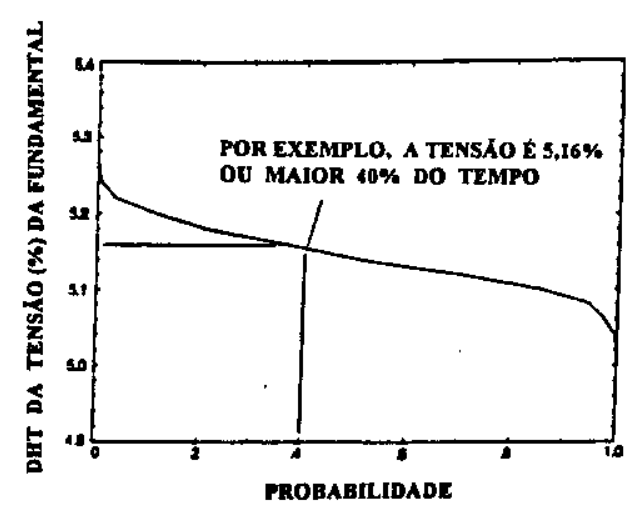

Figura 5.4.1.4 - Curva de Distribuição da Distorção Harmônica Total na tensão (D.H.T.)

\subsubsection{Avaliação do R.C.C.}

Para que se pudesse avaliar o desempenho do Registrador de Curvas de Carga (R.C.C.), foram feitos vários ensaios no Laboratório de Aferições do IEE/USP e os resultados foram acima do esperado, pois sua estabilidade, exatidão e precisão ficaram dentro de uma faixa melhor que a requerida para um equipamento de medição convencional, utilizado inclusive para faturamento, pelas concessionárias brasileiras.

Os primeiros ensaios foram realizados visando levantar a exatidão do equipamento, assim como o desvio padrão das medidas realizadas, pensando-se em levantar a precisão, no modo de medição simples, ou seja, tensão eficaz, corrente eficaz e fator de potência, tendo sido expedido pelo Laboratório de Aferições do IEE/USP, um relatório técnico oficial. Devido ao sucesso alcançado então partiu-se para o levantamento dos mesmos 
parâmetros para medição de harmônicos, tendo-se conseguido um desempenho igualmente acima do esperado.

E para validar definitivamente o equipamento foram feitos ensaios comparativos entre o R.C.C. e um equipamento italiano marca Quasar. A carga seria um conjunto de reatores eletrônicos de lâmpadas fluorescentes que testados um de cada vez produziu uma amostragem estatística que possibitou a emissão de um relatório técnico oficial. Todos os resultados mostraram que os dois equipamentos de medição, Quasar e R.C.C., estavam dentro de mesma faixa de precisão e exatidão em relação à amplitude e em relação às frequêencias dos harmônicos medidos.

Com o objetivo de verificar o que existe de mais atual em termos de equipamento de medição de grandezas elétricas em Sistemas Elétricos de Potência no mundo, foi elaborada uma tabela comparativa, tendo em vista principalmente sua adaptação do caso estudado, ou seja, medição de harmônicos numa ligação cujo primário dos transformadores de potencial fosse ligado em delta aberto e o secundário dos TP's estivesse configurado em delta, com uma das fases aterrada (no caso a fase "S"), sem deixar de considerar outros tipos de ligações mais usuais, por exemplo a ligação em estrela no primário e no secundário dos transformadores de potencial, mais úteis no caso de outras concessionárias e consumidores brasileiros. Os conceitos fornecidos por norma IEEE 519-1992 [32], também foram considerados, quando foi possível integrá-los na análise.

Foram analisados os seguintes equipamentos e modelos: PQ Node 8010, Power 3720 ACM, Quasar, R.C.C. 2.0, NOWA - 1, Siemens Qualimetre/Oscillostore P512, Alpes Multiver. A tabela 5.4.2, mostra os parâmetros analisados e os respectivos valores, que foram retirados dos manuais técnicos dos equipamentos: 


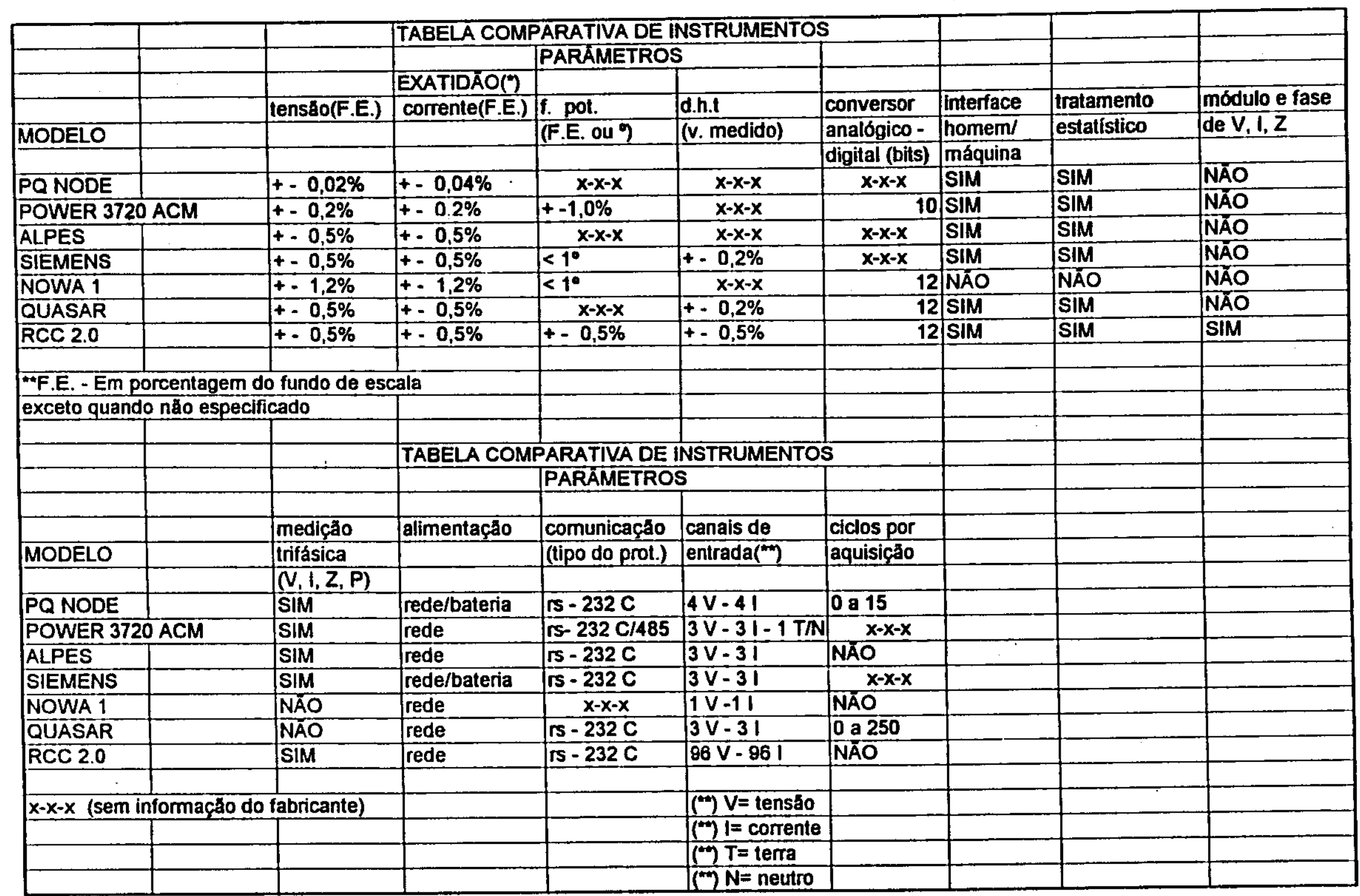

Tabela 5.4.2 - Comparação entre instrumentos de medição 
Quando são investigados alguns parâmetros importantes nos manuais técnicos dos instrumentos analisados, percebe-se que nenhum identificou-se com os publicados pela norma IEEE 519-92. Isto demonstra uma preocupante tendência da indústria internacional, em não divulgar parâmetros normalizados para a obtenção de uma avaliação comparativa do desempenho dos instrumentos entre si.

Mesmo com essa aparente dificuldade, foram selecionados, na tabela 5.4.2 alguns parâmetros de interesse nas medições em campo e posterior análise, que podem ajudar a entender as limitações de cada equipamento. Será feita uma comparação sucinta entre os instrumentos a fím de se estabelcer as melhores opções de mercado, atualmente.

- EXATIDÃO (V, I, F. P.):

Todos os equipamentos analisados, que divulgaram nos manuais técnicos seus resultados, estão dentro de valores aceitáveis para as medições em campo.

\section{- DISTORÇÃO HARMÔNICA TOTAL}

É um parâmetro fundamental na análise da distorção harmônica da corrente e da tensão, alguns aparelhos não divulgam corretamente até que harmônico a exatidão dos resultados são mantidos e não dizem se a distorção harmônica individual está disponivel à investigação. Neste item os melhores equipamentos são o Siemens (apesar de ser ainda um protótipo), o Quasar e o R.C.C., respectivamente.

\section{- CONVERSOR ANALÓGICO-DIGITAL(A/D)}

Os conversores analógicos-digitais de maior número de bits apresentam menor erro quântico. Quanto menor for seu valor, menor será o erro relativo dos parâmetros por ele convertidos. Neste item os 
equipamentos NOWA 1, Quasar e R.C.C. são os melhores, pois possuem conversores $\mathrm{A} / \mathrm{D}$ de 12 bits.

\section{INTERFACE HOMEM-MÁQUINA}

Este item foi propositalmente colocado, pois o equipamento NOWA 1, que atualmente equipa a grande maioria das concessionárias paulistas, não possui uma interface homem-máquina agradável, dificultando a análise dos dados registrados no equipamento. Os demais equipamentos, possuem este item, porém a do R.C.C. tem a vantagem de ser configurada conforme a necessidade do cliente.

\section{TRATAMENTO ESTATISTICO DOS DADOS}

É muito importante que os dados coletados em campo, sejam analisados por um programa computacional, que tenha recursos estatísticos e que possua emissão de relatórios. Novamente, o NOWA 1, é deficiente neste item, o equipamento Quasar, tem um programa estatístico de boa qualidade, porém sua interface com o usuário é pobre. O R.C.C. tem um programa estatístico que está sendo modificado para atingir uma melhor performance. O programa antigo apesar de ter uma excelente interface com o usuário, necessitava aprimorar os recursos estatísticos, pois com a inclusão da distorção harmônica individual até o $40^{\circ}$ harmônico, a quantidade de dados a serem analisados aumentou, provocando a necessidade da migração do programa computacional antigo (DOS/LABWIN), para um novo ambiente (WINDOWS/VISUAL BASIC). 


\section{- MÓdULO E FASE DE V, I, Z}

Este item também é fundamental quando se analisa o comportamento da impedância harmônica, que é uma das causas principais, da ressonância em Sistemas Elétricos de Potência. Apenas o R.C.C. divulga este parâmetro, os demais equipamentos não deixam claro se esta opção está disponível.

\section{- MEDIÇÃO TRIFÁSICA}

Quando analisa-se o comportamento de uma instalação, o consumo de Potência Ativa, Reativa e Aparente, Trifásicos, podem fornecer elementos importantes de análise do desempenho do sistema de potência ao qual estão conectados. Existem equipamentos, como o Quasar, que possuem três canais de entrada, porém não fazem a medição trifásica simultaneamente. Realizam apenas a medição monofásica, não tendo como medir um parâmetro muito importante, que é o fator de potência trifásico. O NOWA i, cuja especificação deixa claro que é um equipamento monofásico, pode apenas medir o fator de potência monofasicamente.

Os demais equipamentos, medem e calculam todos os parâmetros simultaneamente, facilitando a investigação do fator de potência trifásico da instalação e auxiliam na manutenção e no projeto de sistemas de correção deste fator.

\section{ALIMENTAÇÃO}

Poucos equipamentos, possuem a opção de dupla alimentação, a rede de corrente alternada e baterias. Devido a larga experiência em atividades de campo, e verificando a tendência internacional, chega-se a conclusão, .que um equipamento que tenha estas duas opções, ficará mais tempo em funcionamento sem ser danificado pelos distúrbios da rede de energia elétrica e sua confiabilidade será muito maior, já que possiveis flutuações na 
sua alimentação não alterarão o valor dos registros por ele realizados. Destacam-se neste item os equipamentos PQ NODE e o SIEMENS e esta vantagem é muito significativa e importante.

\section{COMUNICAÇÃO}

Todos os equipamentos atuais possuem este recurso, apenas 0 NOWA 1 é deficiente neste importante item. A vantagem deste recurso decorre da possibilidade de comunicação com o aparelho sem necessidade de deslocamentos, quando instalado em locais de dificil acesso. A interligação do R.C.C. com linha telefônica discada, privada ou celular está fortemente sendo analisada.

\section{CANAIS DE ENTRADA}

O mínimo desejável são 4 canais para tensões e 4 canais para correntes, pois na medição de sistemas trifásicos pode-se medir também o fio neutro, que constantemente é afetado pelas cargas não-lineares. Sabe-se que o custo do aumento do número de canais em relação ao custo do equipamento tem um comportamento exponencial. Portanto, deve-se especificar com segurança o número de canais desejados para não ocorrerem problemas futuros. O R.C.C. por ter sido concebido inicialmente para aplicações em sub-estações onde o número de alimentadores fosse elevado, pode medir até 32 circuitos trifásicos, totalizando 96 tensões e 96 correntes, para medições simples. Deve-se ressaltar que o elevado custo dos transdutores que compatibilizam as tensões dos transformadores de potencial (TP's) e dos transformadores de corrente (TC's), com as entradas do R.C.C., pode inviabilizar medições para um número muito grande de circuitos trifásicos, porém o equipamento foi projetado para um grande 
número de canais, estando apto a registrar os 32 circuitos trifásicos, para medições simples $(\mathrm{V}, \mathrm{I}, \cos \phi)$.

Para medições de harmônicos, apenas um circuito trifásico é possivel ser monitorado, devido a grande quantidade de memória necessária para $o$ armazenamento das amostras de tensão e de corrente do circuito trifásico.

\section{CICLOS DE AQUISIÇÃO}

Tão importante quanto o número de canais disponíveis para a medição, o número de ciclos de potência de $60 \mathrm{~Hz}$, em que são calculados todos os parâmetros relativos a instalação devem ter um destaque muito grande na especificação do equipamento a ser adquirido. Se o fenômeno a ser analisado for caracterizado pelo seu comportamento em regime permanente, pode-se obter valores de distorção harmônica elevados que não refletem o comportamento da instalação. Pode ocorrer durante a medição, instantes em que fenômenos transitórios podem estar afetando o resultado final da grandeza analisada. Se o equipamento não estiver ajustado para um número significativo de ciclos, que impeçam sua medição em momentos transitórios, como em partidas de motores, os valores medidos não traduzirão o comportamento do sistema. Para tanto, os equipamentos que possuem tais recursos são os mais vantajosos quando são realizadas medições em horários aleatórios ou instalações com o comportamento nãoconhecido. Neste item o equipamento Quasar e o PQ NODE, têm vantagem significativa sobre os demais, porque seus ciclos de aquisição são ajustáveis entre 1 e 250 e 1 e 50 ciclos, respectivamente.

Após a análise de todos os itens anteriores chega-se a conclusão que os equipamentos quando especificados devem ter o máximo possível de recursos para determinada aplicação. Por exemplo, não adianta adquirir um equipamento com um elevado número de canais de entrada, se não é 
possivel sincronizar as tensões com as correntes e extrair o fator de potência.

Para finalizar, foi tentado pesquisar a autonomia de memória dos equipamentos analisados, mas devido a falta de clareza dos manuais técnicos, não foi possivel incluí-la nesta tabela. Sabendo-se da importância desta especificação, existe um exemplo de cálculo de autonomia de memória do R.C.C., vide página 80 , que pode auxiliar o usuário quando este for adquirir um equipamento.

\section{MEDIÇÕES REALIZADAS EM CAMPO}

\subsection{Caracteristicas do Consumidor}

Foi escolhido um consumidor que fosse comprovadamente um gerador de harmônicos e que a concessionária nos ajudasse na escolla, para que ficasse claro que o consumidor já possuía um histórico de problemas em relação a distorção harmônica.

Este consumidor também deveria ter caracteristicamente um processo que não gerasse harmônicos transitoriamente e sim constantemente para que pudéssemos fazer uma melhor análise estatística do fenômeno.

O consumidor escolhido foi uma indústria metalúrgica na região de Piracicaba que tem um processo de fundição baseado num forno a indução, que é alimentado por um retificador de 6 (seis) pulsos.

A indústria metalúrgica produz em média 750 tambores de freio por dia usando um ferro tipo cinzento e em média 50 cubos de roda e algemas usando um ferro tipo nodular. A matéria prima para a produção é sobras de fundição e ferro gusa (sem manganês) que se transformará em ferro cinzento ou ferro nodular conforme o produto final. 
A produção média mensal de material derretido pelos fornos de indução é de 800.000 toneladas. O periodo de trabalho está entre 12 a 14 horas por dia (das 5:00 às 17:00 horas ou das 5:00 às 19 horas).

\subsection{INSTALAÇÃO}

Os circuitos dos fornos a indução possuem potências nominais diferentes e funcionam simultaneamente. Um forno é alimentado através de um transformador de $750 \mathrm{kVA}(500 \mathrm{~kW})$ e o outro é alimentado por um transformador de $1750 \mathrm{kVA}(1500 \mathrm{~kW})$.

As tensões de saida dos transformadores também são diferentes, o forno de indução de menor potência $(500 \mathrm{~kW})$ rebaixa a tensão de $11500 \mathrm{~V}$ para $480 \mathrm{~V}$ e o forno de maior potência $(1500 \mathrm{~kW})$ rebaixa a tensão dé $11500 \mathrm{~V}$ para $750 \mathrm{~V}$.

O diagrama esquemático da instalação é mostrado na figura 6.2.1:

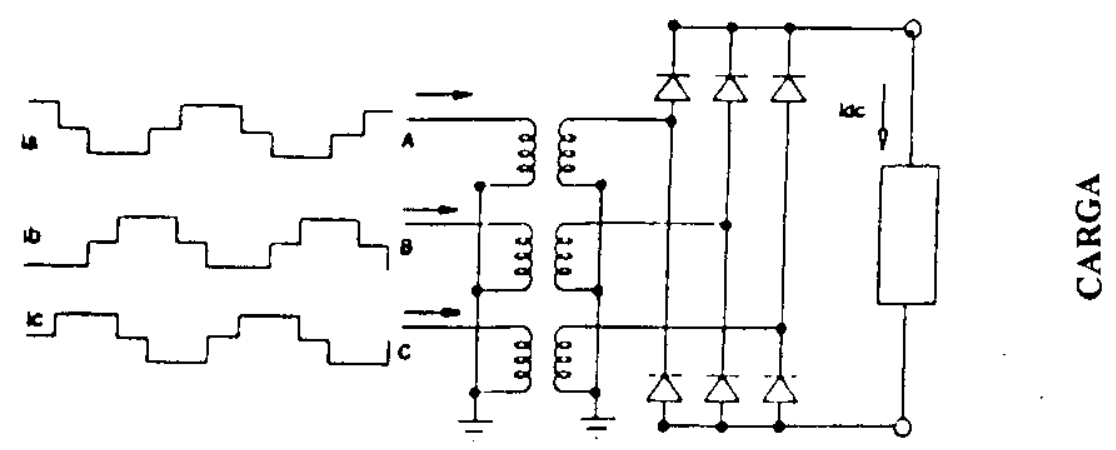

CORRENTES DE FASE

Figura 6.2.1 - Diagrama esquemático da instalação 
Houve uma atenção especial para a ligação da medição em delta aberto. Devido ao fato de não ser uma ligação convencional, causou um grande tempo investido em resolver o problema fasorial, para a determinação do fator de potência, da potência por fase e trifásica.

Após várias formulações chegou-se a algumas conclusões, que podem ser analisadas com o auxílio do diagrama fasorial da figura 6.2.2:

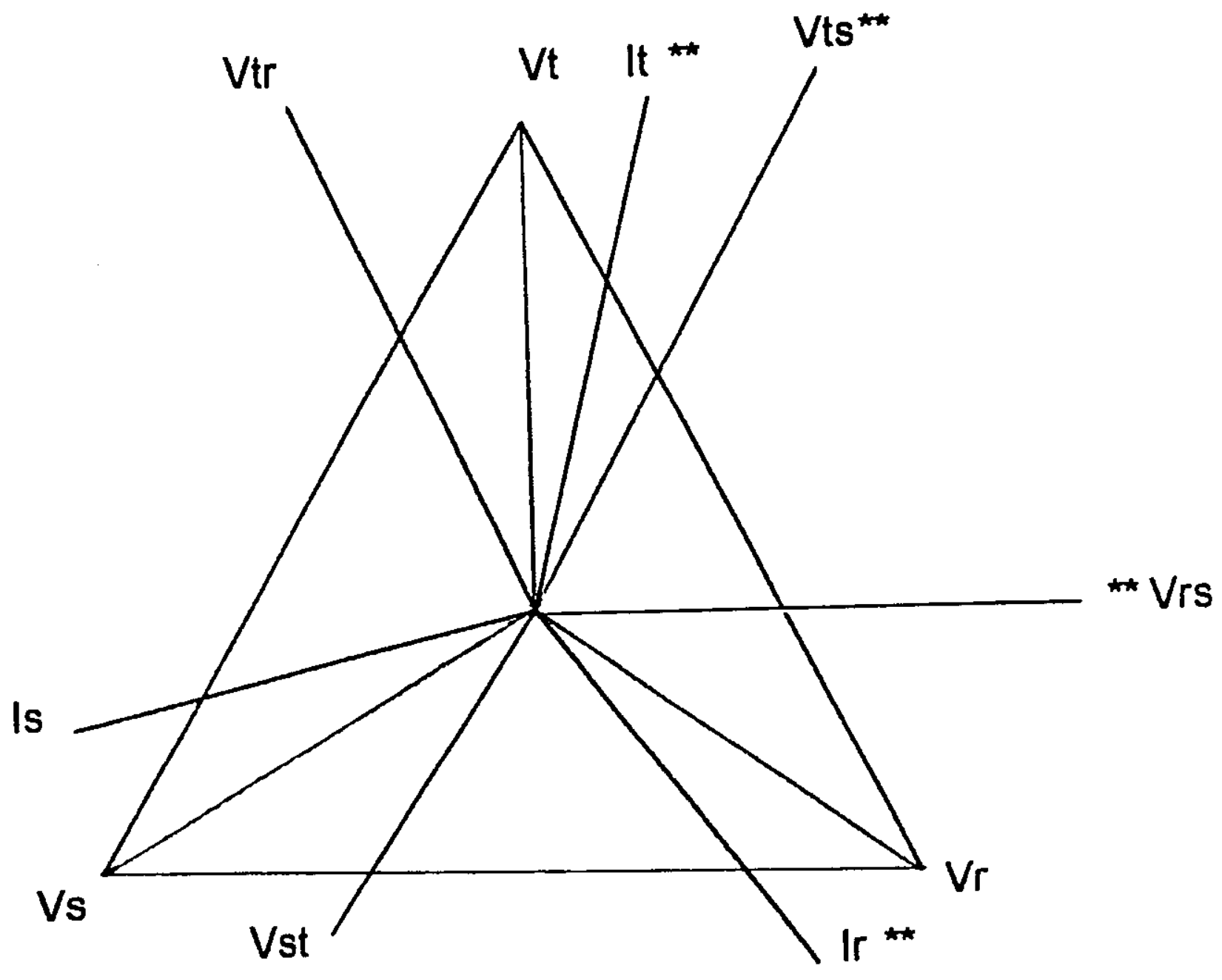

Figura 6.2.2 - Diagrama Fasorial (Ligação Medição Consumidor) ** Valores obtidos na medição 
1. Existe uma defasagem de $60^{\circ}$ entre a tensão Vrs (tensão de linha) e a tensão Vts (tensão de linha), fato que foi constatado em campo com medidas feitas por um osciloscópio.

Este valor indica que há necessidade de se calcular o fator de potência real levando em consideração esta defasagem.

2. O ângulo $\theta r$ formado entre Vrs e Ir, que foi medido em campo, precisa ser corrigido considerando que a defasagem entre Vrs e Vr (tensão de fase), é de $30^{\circ}$, para que possa representar o ângulo $\phi$ (defasagem entre $\mathrm{Vr}$ e Ir), com qual, através da expressão da potência ativa $\left(\mathrm{P}=\mathrm{Vfase}{ }^{*} \mathrm{Ifase}{ }^{*} \cos \phi\right)$, encontra-se o valor correto.

Para a fase R, a expressão que calcula o ângulo $\phi$ é: $\phi=\left(\theta \mathrm{r}-30^{\circ}\right)$, pois percebe-se que a corrente está atrasada em relação à tensão (Vrs, Ir).

Para a fase $T$, a expressão que calcula o ângulo $\phi$ é: $\phi=\left(30^{\circ}+(-\theta t)\right)$, ou seja, $\phi=\left(30^{\circ}-\theta t\right)$ pois percebe-se que a corrente está adiantada em relação à tensão (Vts, It).

3. Com a correção dos ângulos $\phi$ pode-se calcular os valores de potência da fase $\mathrm{R}(\mathrm{Pr})$, da fase $\mathrm{T}(\mathrm{Pt})$ e a potência total $(\mathrm{Pf})$.

4. Como o sistema é equilibrado a potência total (Pf) é: $\mathrm{Pf}=3 * \operatorname{Pr}$ ou $3 * \mathrm{Pt}$.

\subsection{RESULTADOS OBTIDOS}

A instalação do consumidor foi monitorada durante 15 dias consecutivos e os primeiros resultados dos dados coletados e analisados, indicam coerência em relação aos valores esperados em relação as normas [32] (página 90). O espectro de corrente de um retificador de 6 (seis) pulsos apareceu claramente nos dados analisados e os valores percentuais de 
distorção harmônica individual e distorção harmônica total também estão dentro de uma margem de erro aceitável.

A tabela 6.3.1 compara os valores medidos em campo e os valores normalizados extraidos da norma IEEE-519/92.

\begin{tabular}{|r|r|r|r|}
\hline DADOS DE MEDIÇÁO EM CAMPO & \multicolumn{2}{|c|}{ NORMA IEEE 519/92 } \\
\hline \multicolumn{2}{|r|}{ HARMÓNICOS } & \multicolumn{2}{|c|}{ HARMÓNICOS } \\
\hline ORDEM & D.H.T(i) (\%) & ORDEM & D.H.T(i) (\%) \\
\hline 1 & 0 & 1 & 0 \\
\hline 3 & 0,1 & 3 & 0 \\
\hline 5 & 15,83 & 5 & 19 \\
\hline 7 & 9,82 & 7 & 13 \\
\hline 11 & 5 & 11 & 7 \\
\hline 13 & 3,01 & 13 & 5 \\
\hline
\end{tabular}

Tabeia 6.3.1 - Valores da Norma IEEE-519/1992 x Valores Medidos

Foram realizadas 360 (trezentas e sessenta) medidas durante os 15 (quinze) dias de inedição em campo, sendo que o intervalo de medição foi de uma hora e o equipamento armazenou dados semanais e foram retirados a cada 7 (sete) dias em viagens periódicas de São Paulo a Piracicaba. Foi realizada a compilação de toda a série histórica destas 360 medidas para a obtenção de valores que possam caracterizar a assinatura espectral dos 


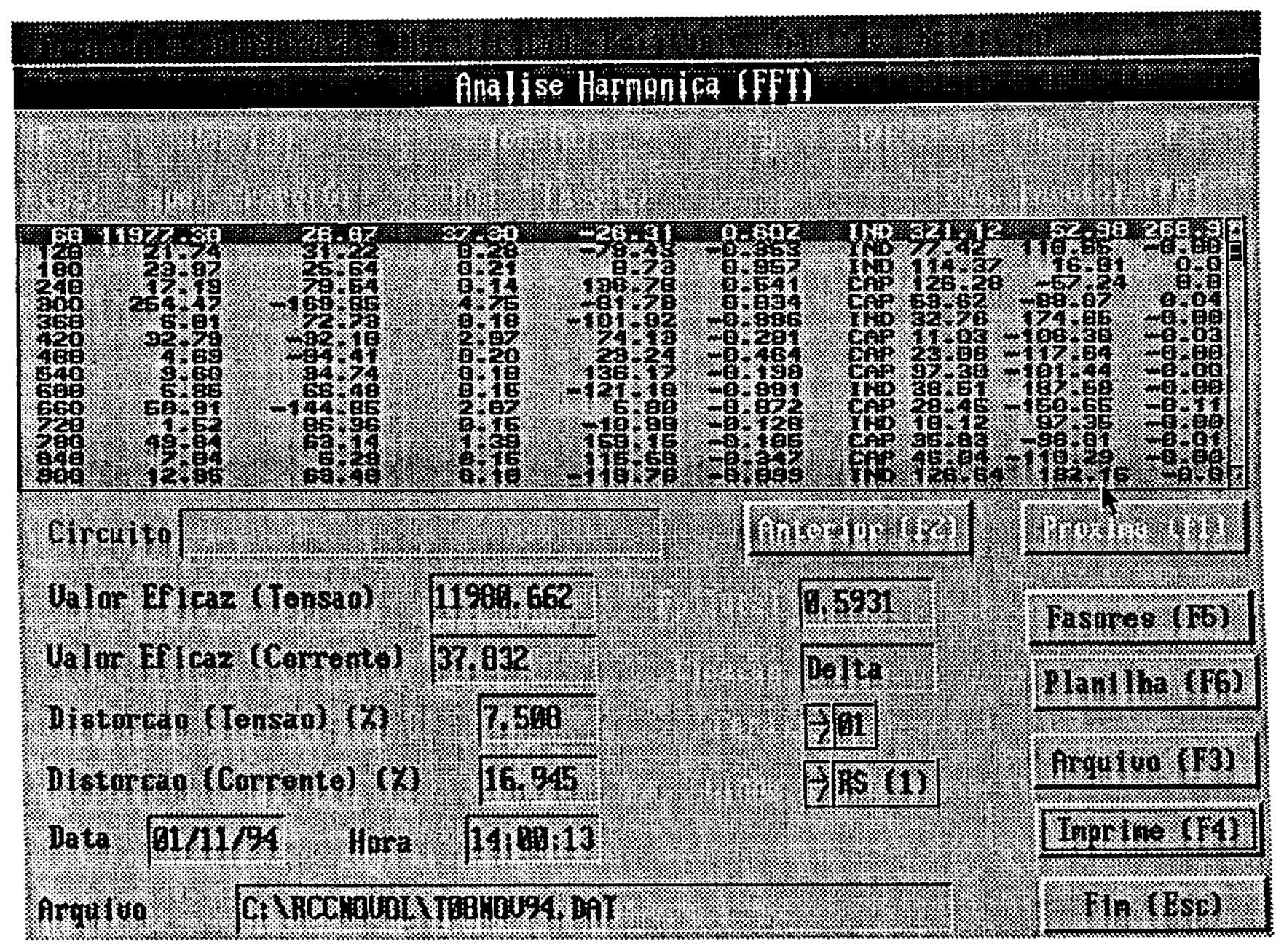

Figura 6.3.2 - Tabela de Análise de dados (IHM)

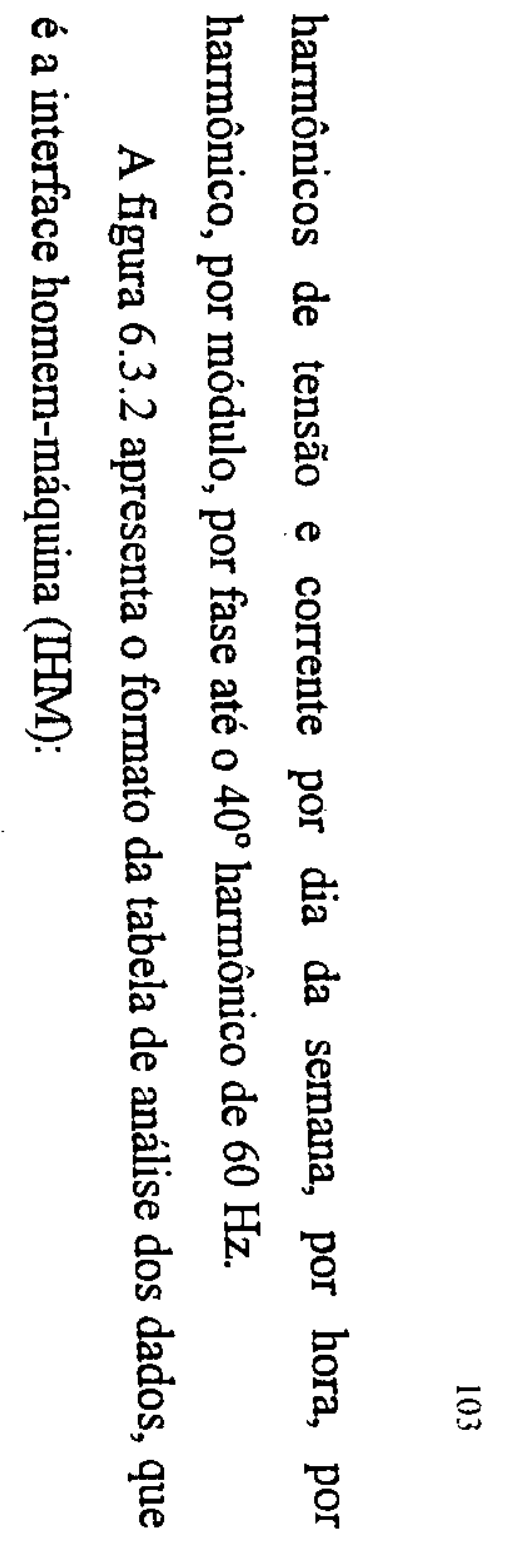


A figura 6.3.3 apresenta os valores típicos medidos em campo do espectro da corrente:

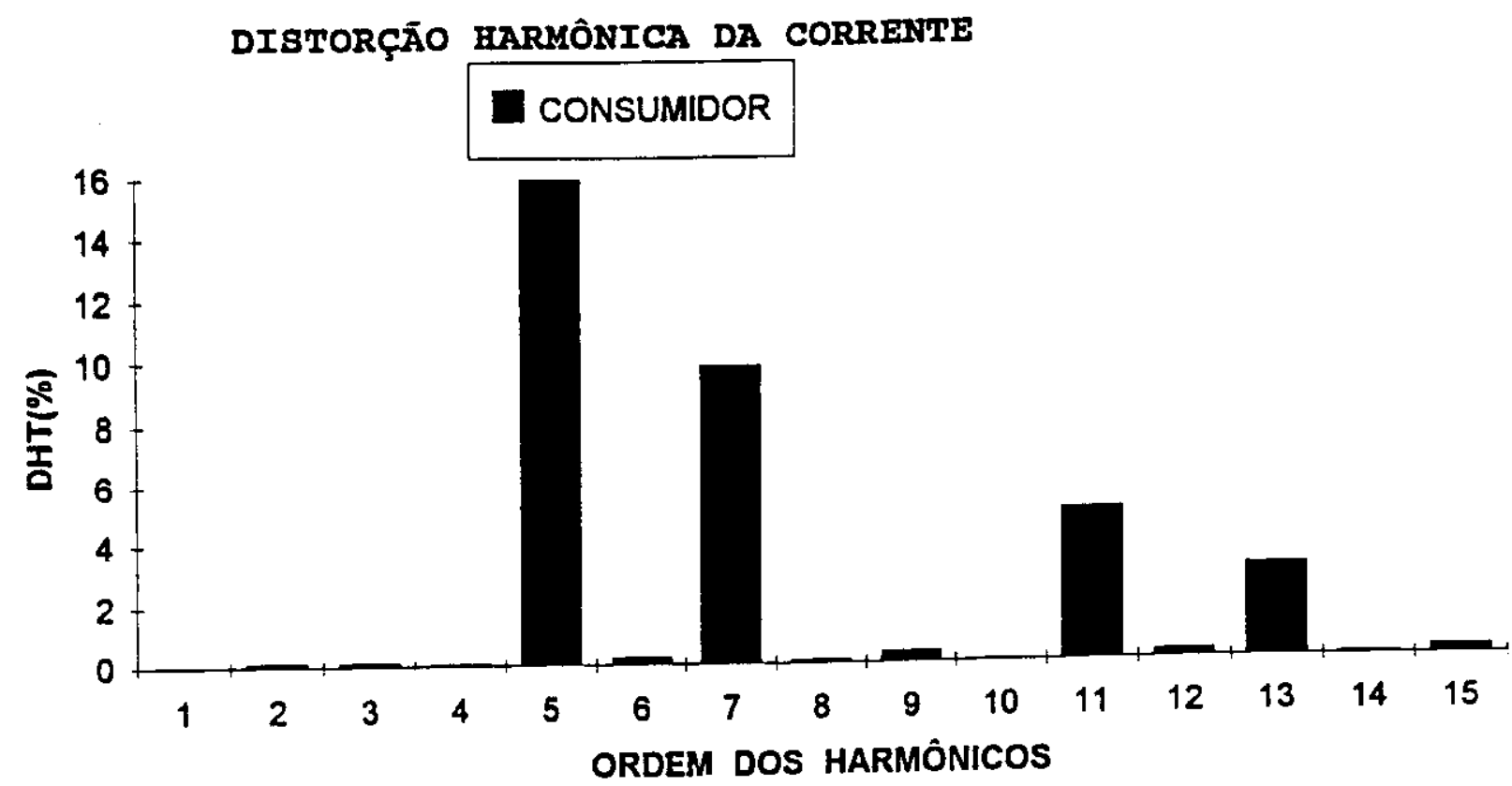

Figura 6.3.3 - Valores típicos medidos em campo do espectro da corrente

A figura 6.3.4 apresenta valores típicos medidos em campo do espectro de tensão:

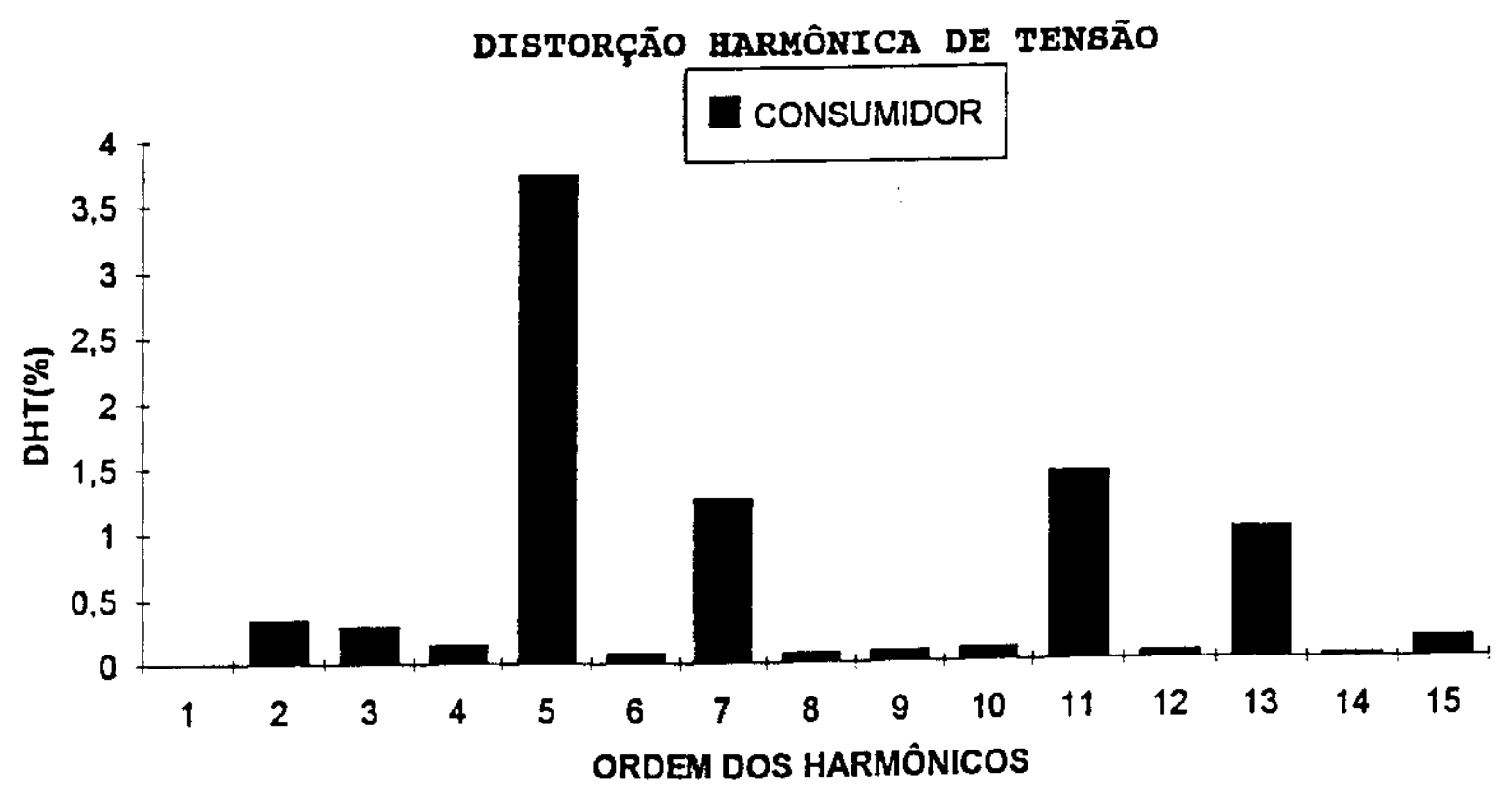

Figura 6.3.4 - Valores típicos medidos em campo do espectro de tensão 
A figura 6.3.5 apresenta valores típicos medidos em campo da impedância harmônica:

\section{IMPEDÂNCIA HARMÔNICA}

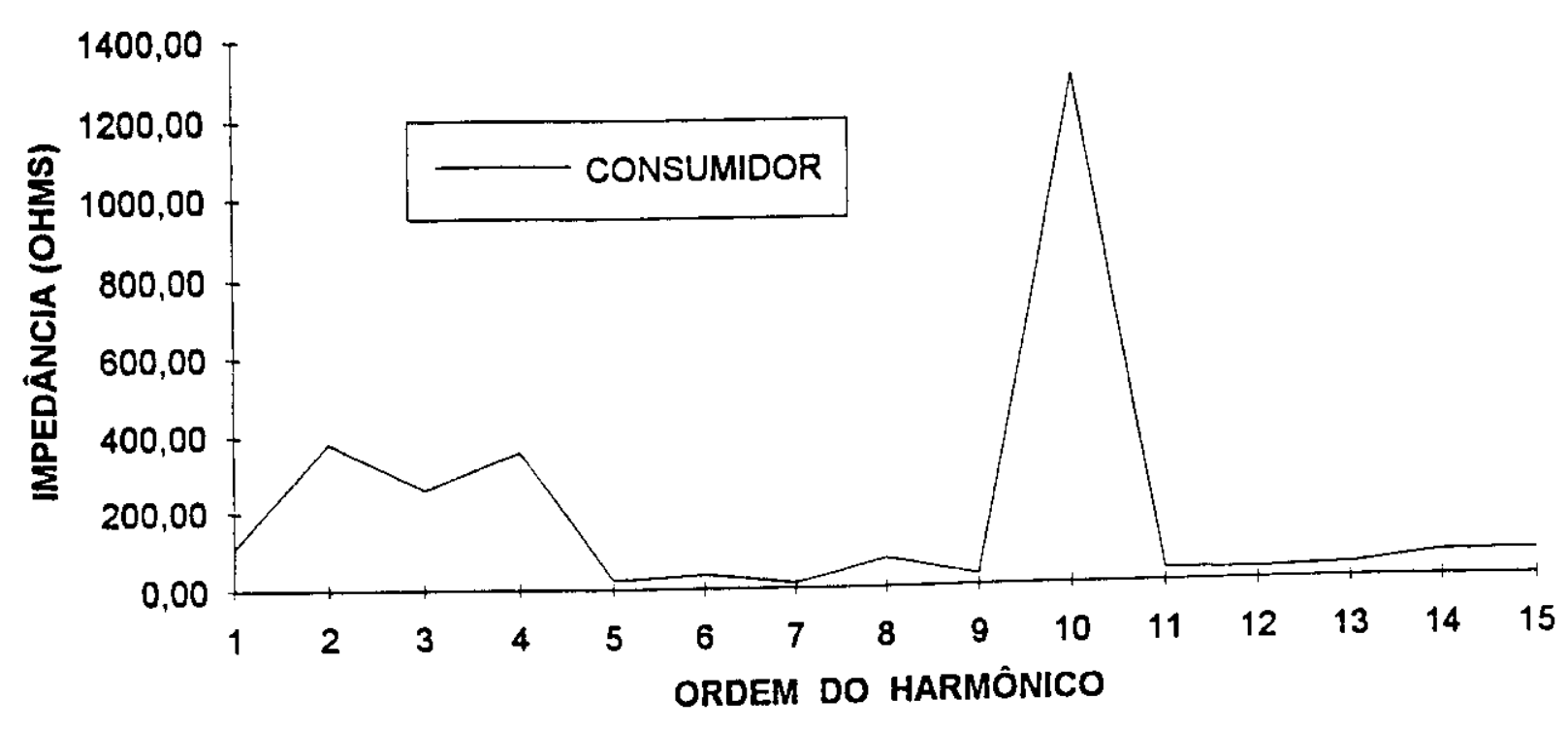

Figura 6.3.5 - Valores típicos medidos em campo da impedância harmônica

\section{ANÁLISE E DISCUSSÃO DOS RESULTADOS}

Todos os parâmetros medidos diretamente e indiretamente determinados, neste capitulo, referem-se a 1 (um) ciclo de potência de 60 $\mathrm{Hz}$, na fase "R".

Os parâmetros de interesse para o estudo são listados a seguir:

$V_{\text {ef }}=$ tensão eficaz por fase $[V]$

$\mathrm{I}_{\mathrm{e}}=$ corrente eficaz por fase $[\mathrm{A}]$

F.P. $=$ Fator de Potência 
$\mathrm{Z}=$ impedância harmônica $[\Omega]$

DHTv = distorção harmônica total da tensão [\%]

DHTi = distorção harmônica total da corrente [\%]

$\mathrm{P}=$ Potência Ativa da fase $[\mathrm{W}]$

O período de medidas realizado em campo corresponde a quinze dias de dados efetivamente utilizados, compreendido entre os dias 26/10/94 e 15/11/94, com algumas interrupções, porém este espaço de tempo analisado representa um conjunto de dados representativo de valores típicos de dias com atividade e dias sem atividade do consumidor.

Esta amostragem, que é de aproximadamente 360 medidas, deste total, foram extraídas em torno de $8 \%$, por se tratarem de dados com comportamento equivalente a sinais espúrios devido a fenômenos tais como: ruidos, transitórios, chaveamentos, etc.

1. Potência Ativa de Fase, Trifásica e Energia consumida

Primeiramente, foram analisados os valores de Potência Ativa de fase definida pela expressão:

$\mathrm{P}_{\mathrm{i}(\text { (fase) }}=\operatorname{Vef}_{\mathrm{i}(\text { fase })} * \operatorname{Ief}_{\mathrm{i}(\text { (lima) }} * \operatorname{cosi} \phi=$ Potência ativa de fase de cada hora (i)

Observações importantes:

Como o R.C.C 2.0 mediu a tensão de linha (VL) e a corrente de linha ( $\left.\mathrm{I}_{\mathrm{L}}\right)$, é necessário a divisão por raiz de 3 no valor da tensão de linha, para que o cálculo da Potência ativa de fase esteja correto. 
Devido ao fato da medição ter sido realizada na configuração delta aberto, nos Tp's e nos Tc's, há necessidade da correção do fator de Potência para obtenção do valor correto ( vide capítulo 6).

Para a Potência Ativa de fase calculou-se hora a hora, o valor médio $\left(P_{m i}\right)$ e o desvio padrão $\left(\sigma P_{m i}\right)$, da hora $(i)$, segundo as expressões abaixo:

$$
\begin{aligned}
& {\left[\sum \mathrm{P}_{\mathrm{i}}\right] / \mathrm{K}=\text { VALOR MÉDIO }=\mathrm{P}_{\mathrm{mi}}^{\mathrm{N}=\mathrm{K}}} \\
& {\left[\mathrm{N}_{\mathrm{N}=\mathrm{K}}\left(\mathrm{P}_{\mathrm{i}}-\mathrm{P}_{\mathrm{mi}}\right) / \mathrm{K}\right]_{\mathrm{N}=1}^{1 / 2}=\text { DESVIO PADRÃO DE } \mathrm{P}_{\mathrm{mi}}=\sigma \mathrm{P}_{\mathrm{mi}}}
\end{aligned}
$$

Devido a significativa variação do comportamento da Potência ativa de fase em função da atividade de produção do consumidor, foi estratificado por intervalos definidos a seguir:

- horas com produção em dias com atividade (dias úteis + sábados)

- horas sem produção em dias com atividade (dias úteis + sábados)

- horas sem produção em dias sem atividade (feriados e domingos)

As figuras 7.1, 7.2 e 7.3 ilustram o valor médio e o desvio padrão hora a hora dos intervalos estratificados: 
POTENNG A ATI VA DE FASE (COM PROOUÇÃ

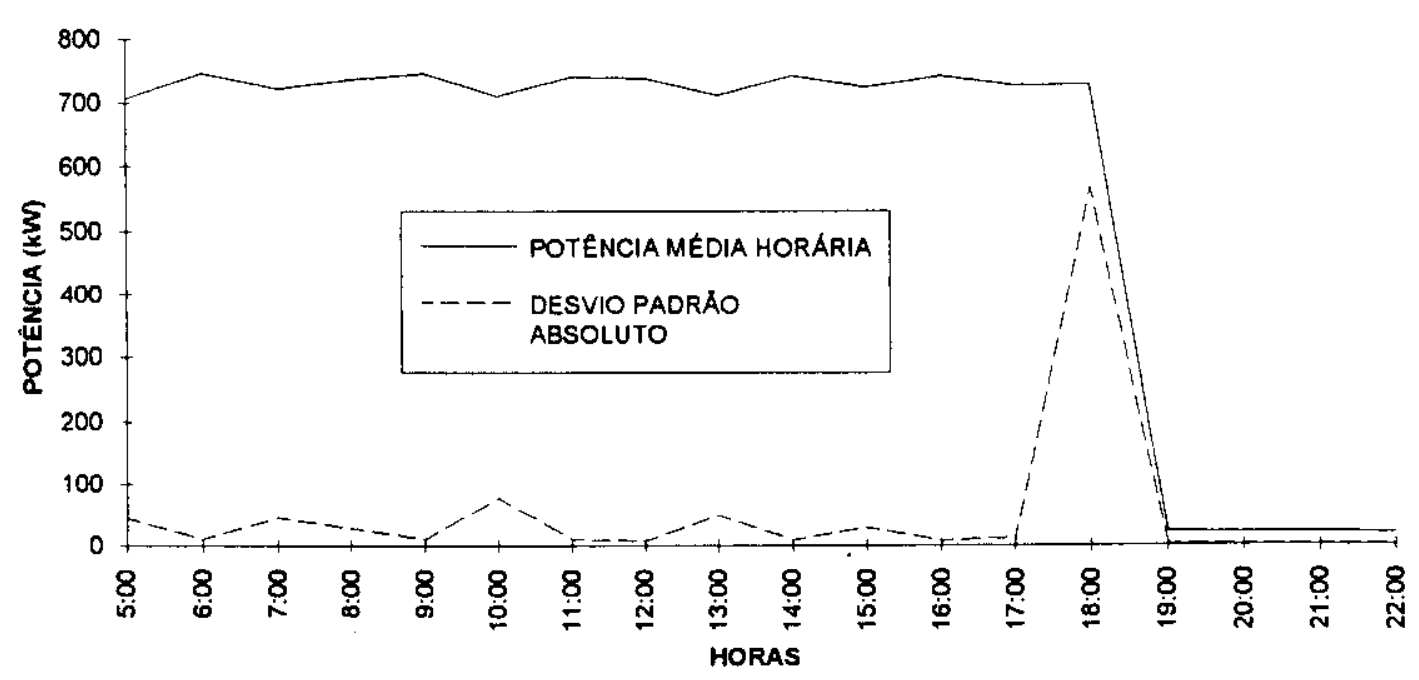

Figura 7.1 - Potência ativa de fase das horas com produção em dias com atividade (dias úteis + sábados)

POTÉNGAA ATIVA DE FASE (SEM PRODUÇÃO)

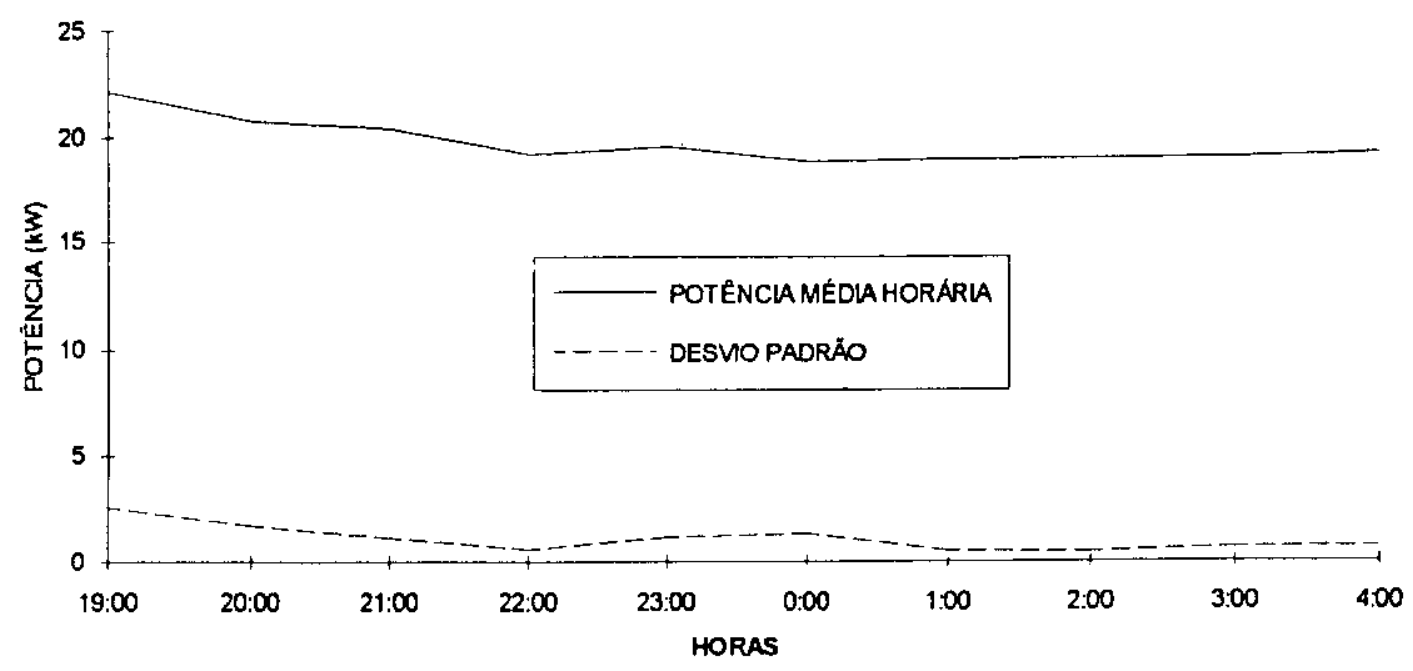

Figura 7.2 - Potência ativa de fase das horas sem produção em dias sem atividade (feriados ou domingos) 
POTÊNCIAATIVA DE FASE (SEM PRODUÇÃO)

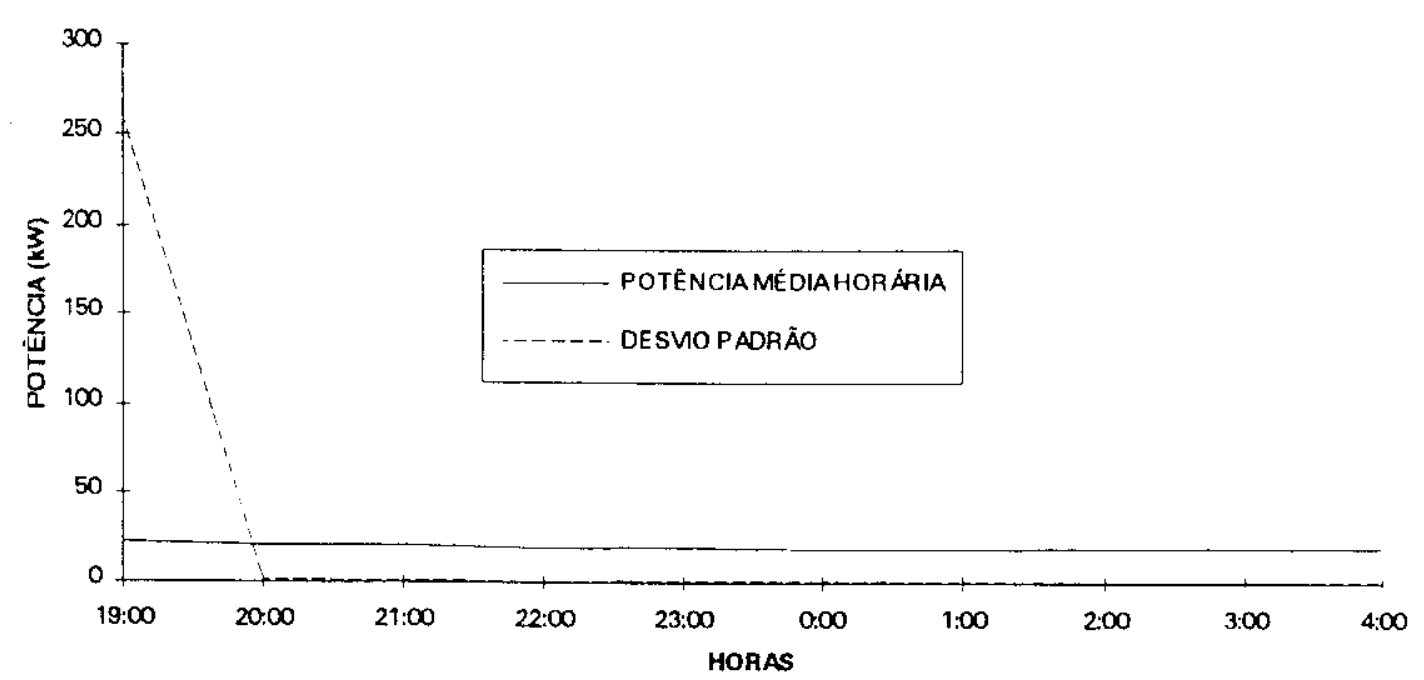

Figura 7.3 - Potência ativa de fase das horas sem produção em dias com atividade (dias úteis + sábados)

Os valores do desvio padrão mostrados nos gráficos anteriores, validam o valor médio da Potência ativa de fase, hora a hora. Indicando ainda que a pequena variação existente, permite calcular a média da Potência ativa de fase dos três intervalos analisados, usando as seguintes expressões:

$\left[\Sigma \mathrm{P}_{\mathrm{i}}\right] / 14=\mathrm{P}_{\mathrm{c}}=$ Média da Potência ativa de fase representativa das horas com atividade nos dias úteis + sábados (14 horas de atividade). 
10

$$
\begin{aligned}
\left.\sum \mathrm{P}_{\mathrm{i}}\right] / 10=\mathrm{P}_{\mathrm{s}}= & \text { Média Potência ativa de fase } \\
\mathrm{I} & \begin{array}{l}
\text { representativa das horas sem atividade } \\
\text { nos dias úteis }+ \text { sábados. }
\end{array}
\end{aligned}
$$

24

$\left[\Sigma \mathrm{P}_{\mathrm{i}}\right] / 24=\mathrm{P}_{\mathrm{sd}}=$ Média da Potência ativa de fase

1 representativa das horas sem atividade aos domingos.

24

$\left[\Sigma \mathrm{P}_{\mathrm{i}}\right] / 2=\mathrm{P}_{\mathrm{sf}}=$ Média da Potência ativa média de fase

1

representativa das horas

sem atividade aos feriados.

Observação: Os valores $\mathrm{P}_{\text {sd }}=\mathrm{P}_{\mathrm{sf}}$ podem ser aproximados devido ao comportamento de seus valores médios e do desvio padrão.

A figura 7.4 ilustra o valor médio e o desvio padrão para as Potências ativas de fase $P_{a} P_{s} P_{s d}-P_{s f}$ : 


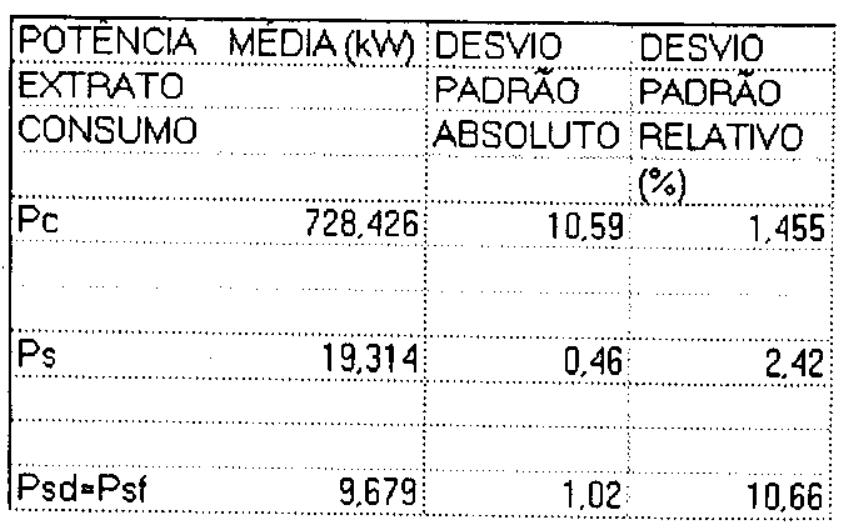

Figura 7.4 - Valor Médio e Desvio Padrão para $\mathbf{P}_{\mathrm{c} .} \mathrm{P}_{\mathrm{s},} \mathrm{P}_{\mathrm{sd}}, \mathrm{P}_{\mathrm{sf}}$

Os resultados da tabela 7.4 mostram que o desvio padrão é baixo em relação a média, indicando a que os valores de $\mathrm{P}_{c}, \mathrm{P}_{\mathrm{s}}, \mathrm{P}_{\mathrm{sd}}, \mathrm{P}_{\mathrm{sf}}$ representam os intervalos estratificados por periodo de atividade, permitindo então o cálculo da Energia consumida.

Para o mês de novembro de 1994 , no qual o período de medidas inseriu-se, o número de dias de atividade é de 24 e o número de dias sem atividade é 6, equivalente a 4 (quatro) domingos e a 2 (dois) feriados. Portanto a Energia consumida é determinada pela expressão abaixo:

$$
\begin{aligned}
& \mathrm{E}=24 *\left(3 * 14 * \mathrm{P}_{\mathrm{c}}+3 * 10 * \mathrm{P}_{\mathrm{s}}\right)+6 *\left(3 * 24 * \mathrm{P}_{\mathrm{sd}}\right) \\
& \mathrm{E}=752340 \mathrm{kWh}
\end{aligned}
$$

O fator 3 (três) que multiplica cada valor de Potência Ativa de fase, representativa dos intervalos estratificados, é necessário para a conversão da Potência Ativa de fase em Potência Ativa Trifásica, pois após uma análise criteriosa do comportamento das três fases verificou-se que estão balanceadas.

$\mathrm{O}$ valor calculado da energia consumida $(752340 \mathrm{kWh})$, foi comparado com o consumo de energia elétrica declarado pela concessionária de $580553 \mathrm{kWh}$, no mês de novembro de 1994 , indicando 
uma relação de aproximadamente $77 \%$, entre o valor da energia registrada pela concessionária e o valor da energia calculada.

Outra comparação foi realizada calculando-se a média anual de consumo da empresa que foi de $603856 \mathrm{kWh}$, com pequeno desvio padrão, com o valor do consumo calculado, chegando-se a uma relação de aproximadamente $80 \%$, entre o valor registrado e o calculado pelos registros do RCC, vide tabela 7.5.

\begin{tabular}{|c|c|c|}
\hline & \multicolumn{2}{|c|}{ Média Anual da Energia (kWh) } \\
\hline $\operatorname{mar} / 95$ & 816460 & \\
\hline fev/95: & 720636 & \\
\hline jan/95 & 672057 & \\
\hline $\operatorname{dez} / 94$ & 612744 & \\
\hline nov/94 & 580553 mes & de medição \\
\hline out 94 & 595708 mes & de medição \\
\hline set/94 & 639065 & \\
\hline ago/94 & 593573 & \\
\hline jul/94: & 563474 & \\
\hline jun/94: & 529691 & \\
\hline $\mathrm{mai} / 94$ & 474596 & \\
\hline$a b r / 94$ & 447721 & \\
\hline média anual: & 603856.500 & \\
\hline mínimo & 447721 & \\
\hline máximo & 816460 & \\
\hline desv.pad & 97357.0211 & \\
\hline
\end{tabular}

Tabela 7.5 - Média anual de Energia (kWh), registrada pela concessionária

A explicação para este fato $[4,55,56]$ é que o medidor de energia da concessionária, sendo um equipamento eletromecânico, não possui a mesma exatidão do R.C.C., ao realizar medições de corrente e tensão com formas de onda distorcida. 
$\mathrm{Na}$ literatura pesquisada $[4,55,56]$ encontra-se resultados semelhantes aos valores encontrados neste estudo de caso, quanto a imprecisão dos valores registrados por medidores indutivos de energia.

Portanto isto demonstra a necessidade de investigações mais abrangentes, quanto ao comportamento dos medidores de energia elétrica. principalmente os eletromecânicos, quando submetidos a sinais distorcidos, provocados por distorções harmônicas.

\section{Distorção Harmônica Total:}

A partir dos dados de Distorção Harmônica Total da Tensão (DHTv) e da Corrente (DHTi), plotou-se quatro gráficos de Distribuição Normal, sendo dois gráficos de distribuição normal (relativa e absoluta) da corrente. DHTi, e dois gráficos de distribuição normal (relativa e absoluta) da tensão. DHTv, que retratam o comportamento médio, hora a hora, desses dois parâmetros.

Foram analisados e retirados os dados de distorção harmônica da corrente no período das 19 as $4 \mathrm{~h}$, pois os valores apresentaram um desvio padrão elevado em relação à média.

A explicação é que fora do horário de produção o consumo de energia elétrica é baixo, fazendo com que o transformador de corrente (T.C.'s) opere fora de suas características normais.

Quando a corrente que está sendo monitorada nos T.C.'s, atinge no enrolamento primário, um valor abaixo de $10 \%$ da sua corrente nominal de operação, ocorre a distorção do sinal de saída no enrolamento secundário. Esta corrente é distorcida, pois corresponde a curva de magnetização dos T.C's, vide capítulo 3 , página 20 , não tendo relação com o estudo.

Os dados de distorção harmônica da tensão, foram todos utilizados, pois a tensão nos enrolamentos primários dos transformadores de potencial 
(T.P.'s) permanecem dentro do valor nominal, não apresentando distorção não-relacionada diretamente com o fenômeno analisado neste estudo.

- Limites para a distorção harmônica na corrente:

Idealmente, a distorção harmônica causada por um simples consumidor, deve ser limitada a um nível aceitável para qualquer ponto do sistema e este deve ser operado sem valores significativos de distorção harmônica em qualquer ponto do sistema.

Os limites de distorção harmônica recomendados pela norma IEEE 519-92 estabelecem a distorção de corrente máxima permitida para um consumidor. Esses limites de distorção da corrente são conceituados com o seguinte índice:

DDT: Distorção na demanda total (SSR), distorção na corrente harmônica em valor percentual (\%) da máxima demanda da corrente de carga (15 ou 30 minutos de demanda).

Os limites listados nas tabelas 7.6, 7.7 e 7.8, devem ser usados como valores de projeto do sistema na condição de pior caso, em condições de operação normal (em intervalo de tempo maior do que uma hora). Para períodos mais curtos, durante a partida do sistema ou condições anormais, os limites podem exceder a $50 \%$.

Os valores indicados nas tabelas, são aplicáveis a retificadores de seis pulsos e para situações de distorções em geral, coerentes com a carga que 0 estudo se propõe a analisar. Entretanto, quando existem transformadores que provocam deslocamento de fases ou são usados conversores com o número de pulsos (q) maiores do que seis, os limites para a ordem dos harmônicos característicos são aumentados por um fator igual a $(q / 6)^{1 / 2}$ que estabelece as amplitudes dos harmônicos não-característicos, quando são menores do que $25 \%$ dos limites especificados. 
A tabela 7.6 fornece os limites de corrente harmônica baseado na dimensão da carga em função da dimensão do sistema de potência ao qual a carga é conectada. A relação Isc/Il é estabelecida entre a corrente de curto circuito disponivel no ponto de acoplamento comum (P.A.C.), e a corrente de carga máxima na freqüência fundamental, no caso analisado a freqüência fundamental é $60 \mathrm{~Hz}$. É recomendável que a corrente de carga, Il, seja calculada como sendo a média da corrente da máxima demanda dos 12 (doze) meses antecedentes a análise. Então como diminui a dimensão da carga do usuário com relação a dimensão do sistema de potência, aumenta a porcentagem da corrente harmônica que é permitida ao usuário injetar dentro do sistema de potência da concessionária. Isto protege outros usuários no mesmo alimentador, assim como a concessionária, à qual é requisitada para fornecer uma tensão com qualidade aos seus consumidores.

Todos os sistemas de geração de potência quando conectados a outros sistemas tais como: distribuição, subtransmissão, e transmissão de energia elétrica, são tratados como concessionárias de distribuição e estão enquadrados nessas recomendações práticas. 


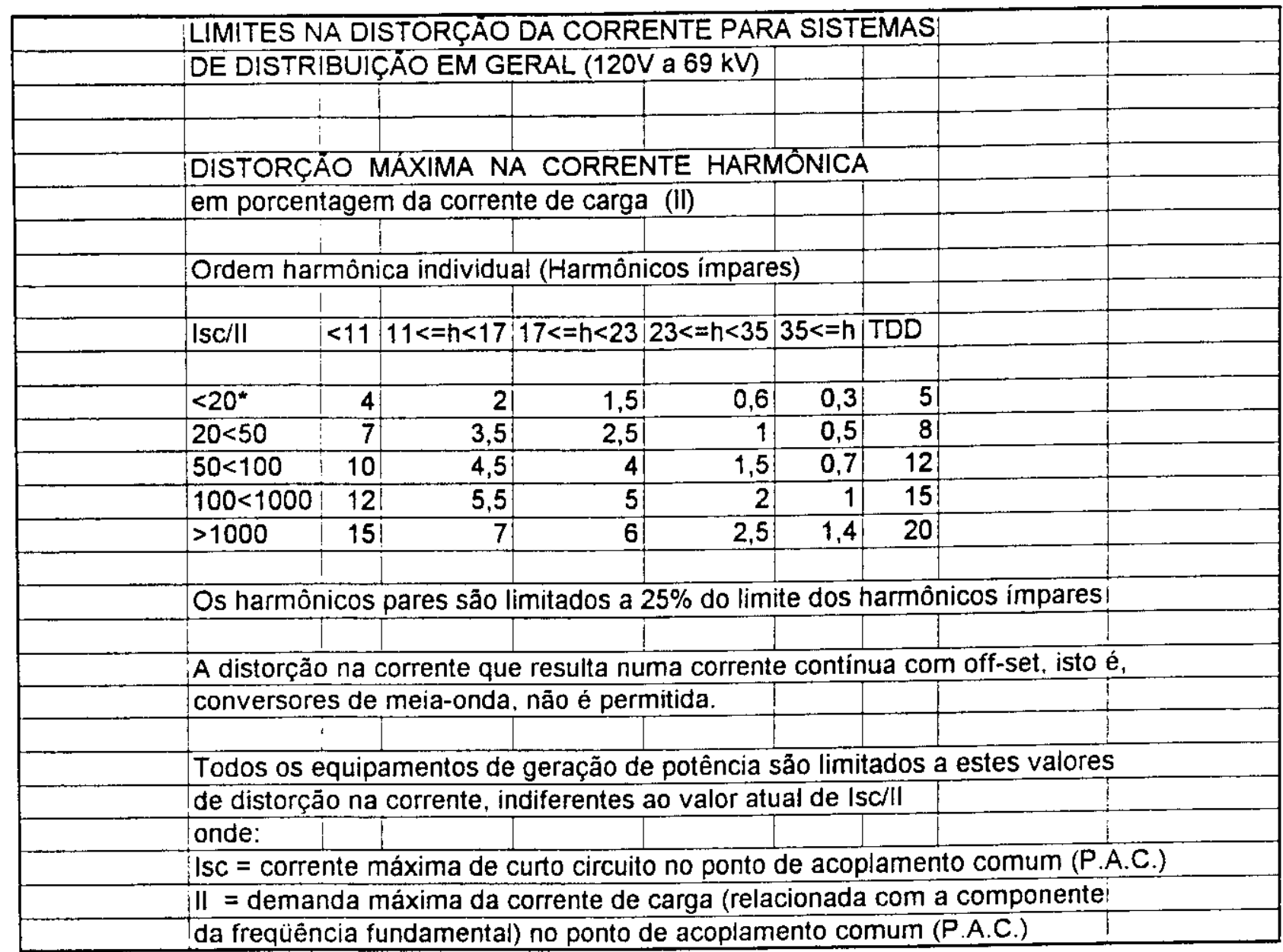

Tabela 7.6 - Limites na distorção da corrente - tensōes de $120 \mathrm{~V} \mathrm{a} 69 \mathrm{kV}$ 


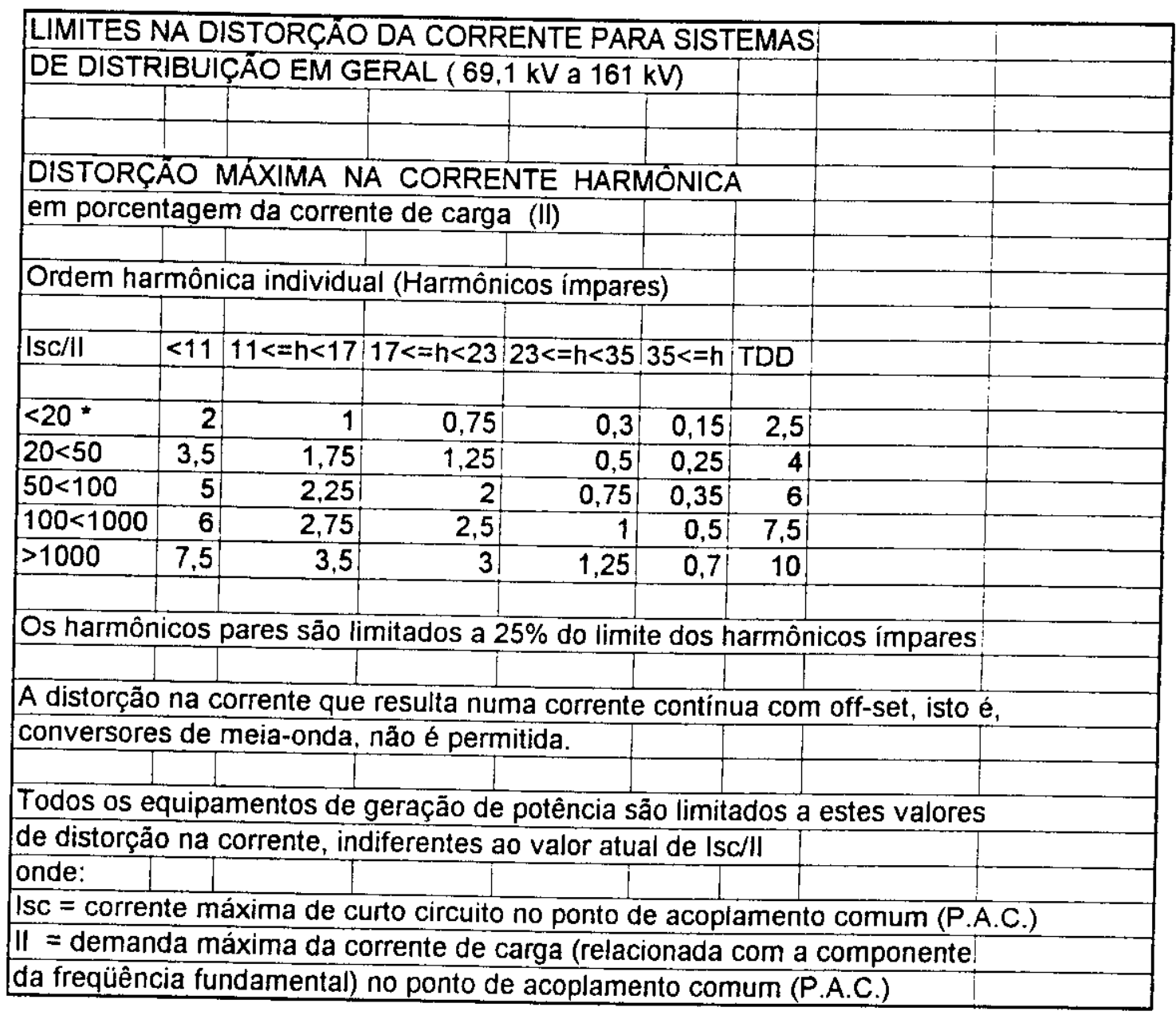

Tabela 7.7 - Limites na distorção da corrente - tensões de $69,1 \mathrm{kV}$ a $161 \mathrm{kV}$ 


\begin{tabular}{|c|c|c|c|c|c|c|c|c|}
\hline \multicolumn{7}{|c|}{ LIMITES NA DISTORÇÃO DA CORRENTE PARA SISTEMAS } & & \\
\hline \multicolumn{9}{|c|}{ DE DISTRIBUIÇĀO EM GERAL $(>161 \mathrm{kV})$, } \\
\hline \multicolumn{9}{|c|}{ Geração e Cogeração distribuídas } \\
\hline & & & & & & & & \\
\hline & & & & & & & & \\
\hline & & & & & & & & \\
\hline & & & & & & & & \\
\hline \multicolumn{9}{|c|}{ Ordem harmônica individual (Harmônicos ímpares) } \\
\hline & & & & & & & & \\
\hline \multirow[t]{2}{*}{$\mid \mathrm{sc} / 11$} & $<11$ & $11<=h<17$ & $17<=h<23$ & $23<=h<35$ & $35<=h$ & THD & & \\
\hline & & & & & & & & \\
\hline$\angle 50^{\circ}$ & 2 & 1 & 0,75 & 0,3 & 0,15 & 2,5 & & \\
\hline \multirow[t]{2}{*}{$>=50$} & 3 & 1,5 & 1,15 & 0,45 & 0,22 & 3,75 & & \\
\hline & & & & & & & & \\
\hline \multicolumn{9}{|c|}{ Os harmônicos pares são limitados a $25 \%$ do limite dos harmônicos impares } \\
\hline & & & & & & & & \\
\hline \multicolumn{9}{|c|}{ A distorção na corrente que resulta numa corrente contínua com off-set, isto é, } \\
\hline \multirow{2}{*}{\multicolumn{9}{|c|}{ conversores de meia-onda, não é permitida. }} \\
\hline & & & & & & & & \\
\hline \multirow{2}{*}{\multicolumn{9}{|c|}{ Todos os equipamentos de geração de potência são limitados a estes valores }} \\
\hline \multirow{2}{*}{\multicolumn{8}{|c|}{ de distorção na corrente, indiferentes ao valor atual de Isc/ll }} & \\
\hline onde: & & & & & & & & \\
\hline \multicolumn{9}{|c|}{ Isc = corrente máxima de curto circuito no ponto de acopiamento comum (P.A.C.) } \\
\hline \multicolumn{9}{|c|}{\begin{tabular}{|l|l|}
$\|$ I = demanda máxima da corrente de carga (relacionada com a componente \\
da freqüência fundamental) no ponto de acoplamento comum (P.A.C.)
\end{tabular}} \\
\hline
\end{tabular}

Tabela 7.8 - Limites na distorção da corrente - tensões $>161 \mathrm{kV}$ 
Os parâmetros da demanda da carga que compõem a pesquisa estão descritos na tabela 7.7.1.(a). Sabendo-se de antemão que o transformador que alimenta o consumidor é energizado com uma tensão no primário de 138 $\mathrm{kV}$, trifásica, e sua potência aparente é de $50 \mathrm{MVA}$, calcula-se a demanda máxima de corrente de carga e a corrente máxima de curto-circuito.

$O$ consumidor analisado possui em seu sistema de potência uma demanda máxima de corrente de carga de $I l=62,755 \mathrm{~A}$, e uma corrente máxima de curto-circuito de $I s c=2,51 \mathrm{kA}$, verifica-se que a razão $I s c / I l=40$ dados estes fornecidos pela própria concessionária e confirmados através de cálculos.

Com o auxílio da tabela 7.7 , pois o consumidor pesquisado é alimentado por um transformador cuja tensão do primário é de $138 \mathrm{kV}$, portanto, com uma tensão de alimentação entre $69,1 \mathrm{kV}$ e $161 \mathrm{kV}$, sumariza-se os resultados nas tabela 7.7.1 (a), (b) e (c) a seguir:

\begin{tabular}{|c|c|c|c|c|}
\hline & \multicolumn{3}{|c|}{ DEMANDA DA CARGA } & \\
\hline \multicolumn{2}{|c|}{ TRAFO } & \multicolumn{2}{|c|}{ CORRENTES } & \\
\hline POTENCIA & TENSĀO & CARGA & CURTO & RELACCAO \\
\hline APARENTE & PRIMARIO & & CIRCUITÓ & \\
\hline $\mathbf{S}$ & $\overline{V p}$ & IIL & Isc & Rs $=$ isc/IL \\
\hline (MVA) & $(\mathrm{kV})$ & (A) & (kA) & \\
\hline 50 & 138 & 62.755 & 2.51 & 40 \\
\hline & & & & \\
\hline & & tabela 7.7 .1 & & \\
\hline
\end{tabular}

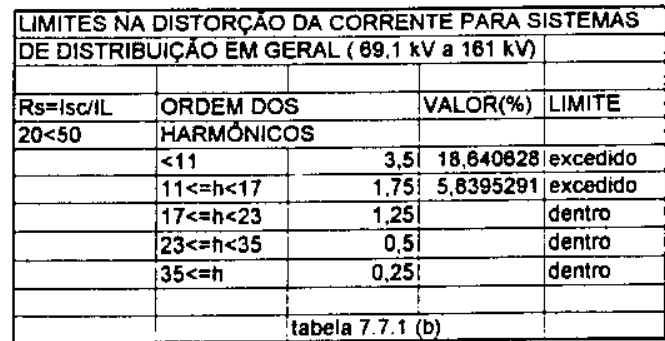

Tabela 7.7.1(a)-Demanda da Carga Tabela 7.7.1(b)-Norma IEEE 519-92 


\begin{tabular}{|c|c|}
\hline \begin{tabular}{|l|} 
DISTORÇA \\
INDIVIDUA \\
\end{tabular} & $\begin{array}{l}\text { HARMONICA } \\
\text { TOTAL DA }\end{array}$ \\
\hline & RENTE \\
\hline harmônico & valor(\%) \\
\hline 13 & 0,125033491 \\
\hline 15 & 15,85246048 \\
\hline$\sqrt{17}$ & 9815129052 \\
\hline & \\
\hline 111 & 5,001339645 \\
\hline 113 & 3,00973475 \\
\hline & \\
\hline 115 & 0,26792891 \\
\hline DHTi(\%) & 19,54646627 \\
\hline & \\
\hline
\end{tabular}

Tabela 7.7.1(c) - Distorção harmônica de corrente no consumidor

A tabela 7.7.1(b) indica a existência de valores acima do limite estabelecido pela norma IEEE 519-92 para distorção harmônica na corrente, portanto deve-se tomar medidas corretivas a fim de se evitar a propagação da corrente harnônica pelo sistema com conseqüências graves para a concessic nária e os demais consumidores que estão ligados ao alimentador que fornece energia elétrica ao consumidor sob investigação, ver capitulo 3 .

Nos histogramas representados nas figuras 7.5 e 7.6 , verifica-se que $o$ comportamento da distorção harmônica total da corrente apresenta uma tendência acentuada de permanecer entre 18 e $20 \%$, com $19 \%$ sendo o valor que apresenta maior probabilidade de ocorrência.

Conforme a análise da figura 7.6, verifica-se que a corrente harmônica permanece pelo menos $32 \%$ do tempo de produção com o valor em torno de $19 \%$ e aproximadamente $85 \%$ deste tempo entre 18 e $20 \%$. 
Sabendo-se que a carga principal do consumidor é um retificador de 6 (seis) pulsos, foi pesquisado o comportamento típico da corrente harmônica com estas caracteristicas.

$\mathrm{Na}$ revisão bibliográfica realizada [32] encontra-se resultados equivalentes aos valores encontrados neste estudo de caso, pois se trata de valores típicos de distorção harmônica total da corrente harmônica, para a carga principal do consumidor, que são dois fornos de indução alimentados por dois sistemas com retificadores de 6 pulsos. O espectro de corrente que foi gerado por estes sistemas, vide capítulo 6 (figura 6.3.3), também encontra resultados equivalentes na bibliografia consultada.

Em nivel internacional norma IEEE 519-92, na qual se baseou esta análise, procura indicar a metodologia seguida acima a fim de constatar a propagação dos harmônicos de corrente através de análises de comportamento de todo o sistema elétrico de potência.

No Brasil, ainda não existe uma legislação ou mesmo normatização direcionada para os efeitos da corrente harmônica nos sistemas elétricos de potência. 
DISTORÇÃO HARMÓNICA DA CORRENTE

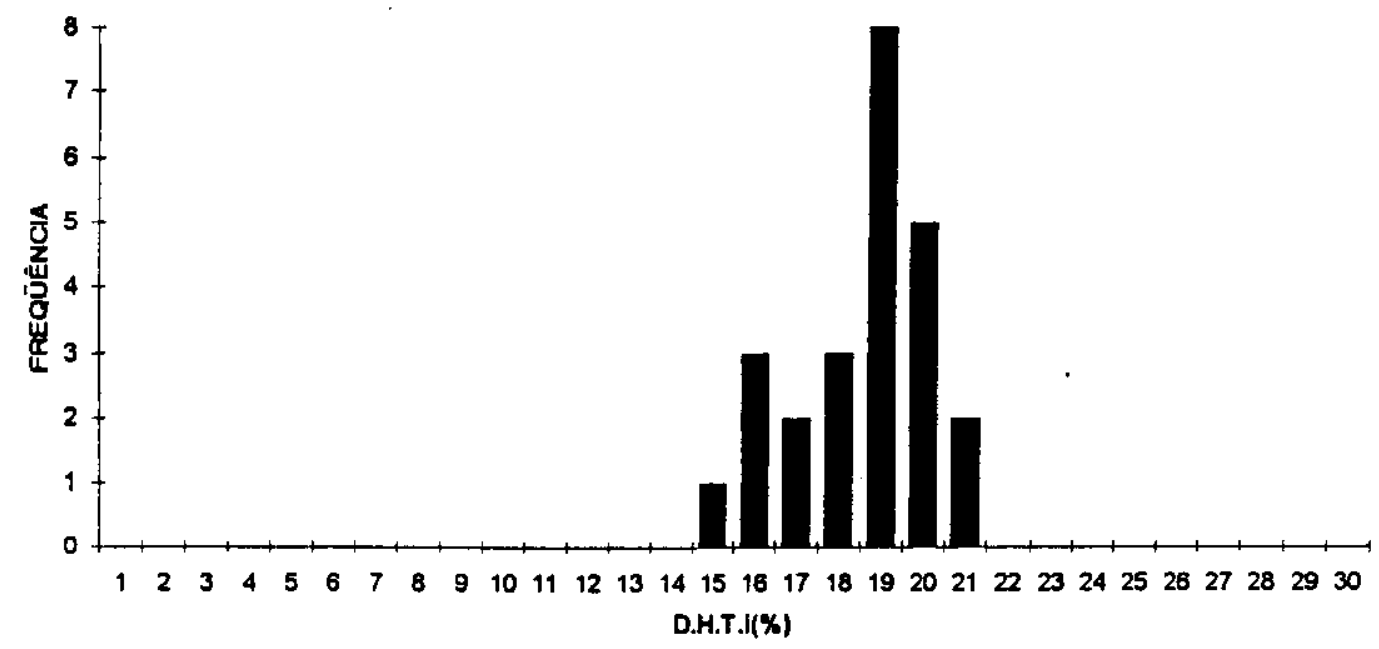

Figura 7.5 oistribuição normal da Distorção Harmônica de corrente em função da freqüência absoluta

$$
\text { DISTORÇĀO HARMÔNICA DA }
$$

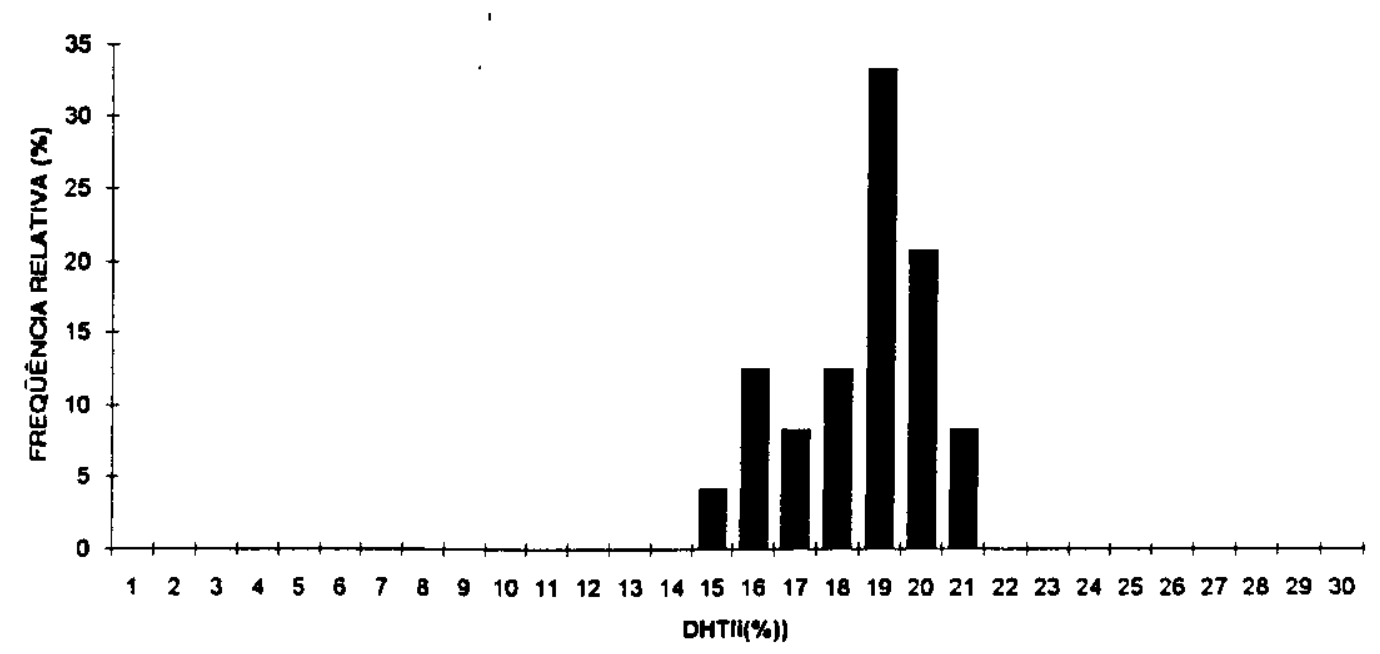

Figura 7.6 Distribuição normal da vistorção Harmônica total de corrente em função da freqüência relativa 
-Limites de Distorção harmônica na tensão:

Nos histogramas representados na figura 7.11 e 7.12 , verifica-se que o comportamento da distorção harmônica total da tensão apresenta uma tendência acentuada de permanecer entre dois valores, com maior probabilidade de ocorrência entre 2,6 e $2,9 \%$ e entre 3,7 e $4,4 \%$, isto significa a existência de dois tipos de comportamentos na distorção harmônica da tensão.

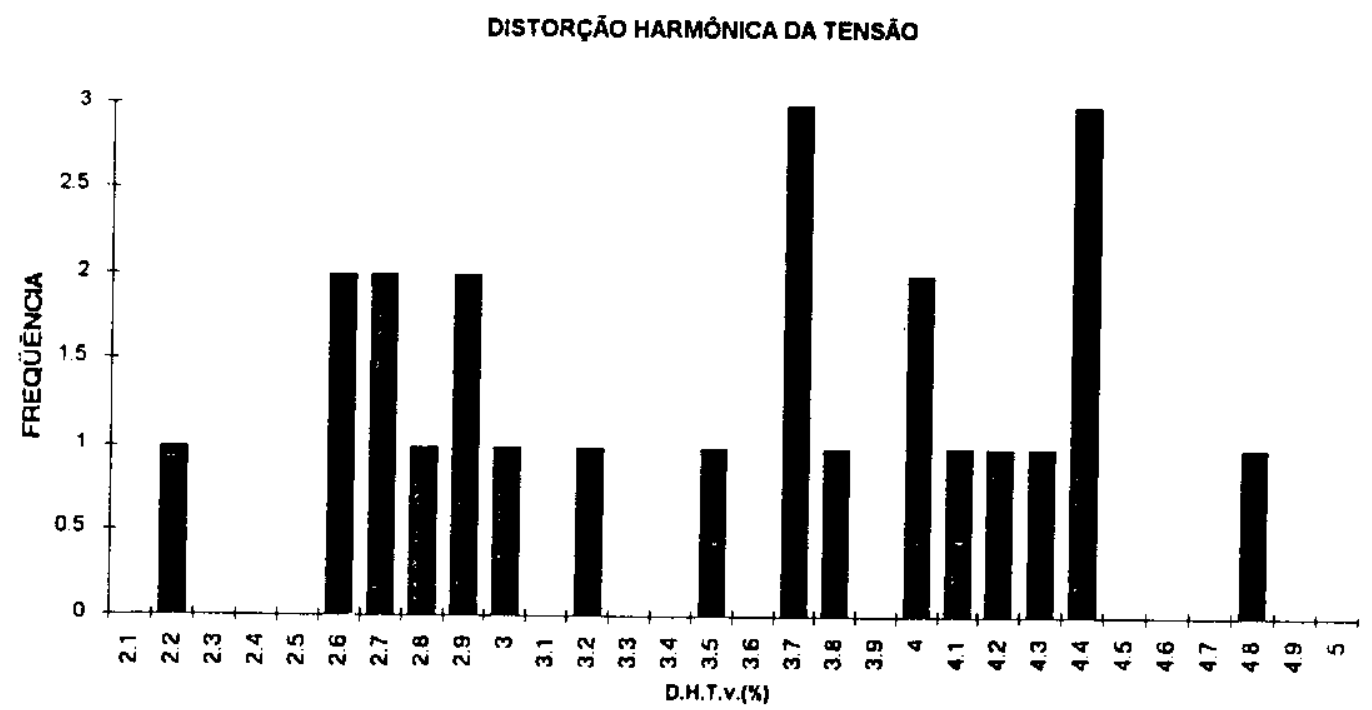

Figura 7.11- Distribuição normal da Distorção Harmônica Total de Tensão em função da frequiência absoluta 
DISTORÇĀO HARMÔNICA DA TENSÃO

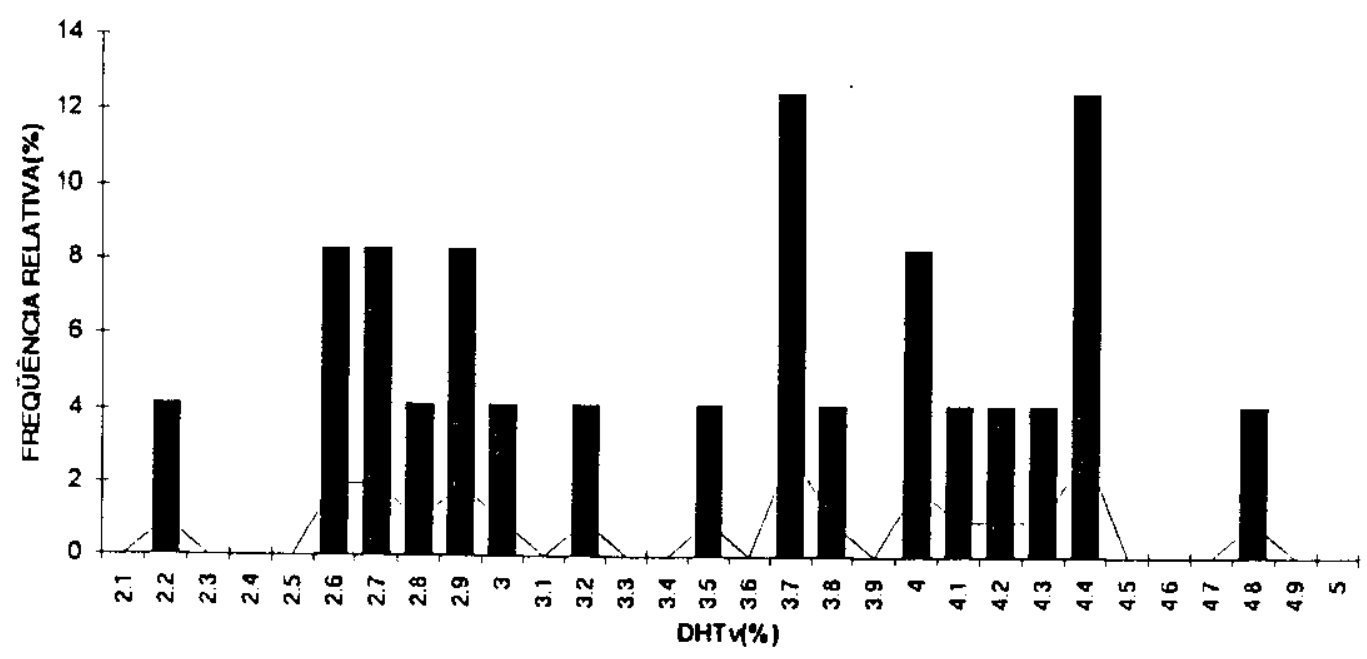

Figura 7.12- Distribuição normal da Distorção Harmônica

Total de Tensão em função da freqüência relativa

Após uma pesquisa nos horários que possibilitaram este tipo de comportamento, chegou-se a conclusão que o período de maior distorção harmônica na tensão, entre 3,7 e $4,4 \%$, é durante o processo produtivo, tipicamente das 5 às 18 horas, enquanto que o periodo de menor distorção harmônica ocorre fora do horário de produção tipicamente das 19 às 4 horas.

O espectro de tensão que foi gerado por estes sistemas, vide capitulo 6 (figura 6.3.4), também encontra resultados equivalentes na bibliografia consultada. Existe no país um grupo coordenado pela Eletrobrás [3], que emite recomendações e critérios para consumidores com cargas especiais, no caso da distorção harmônica total da tensão, as tabelas 7.8 e 7.9 ilustram os niveis permissiveis. 


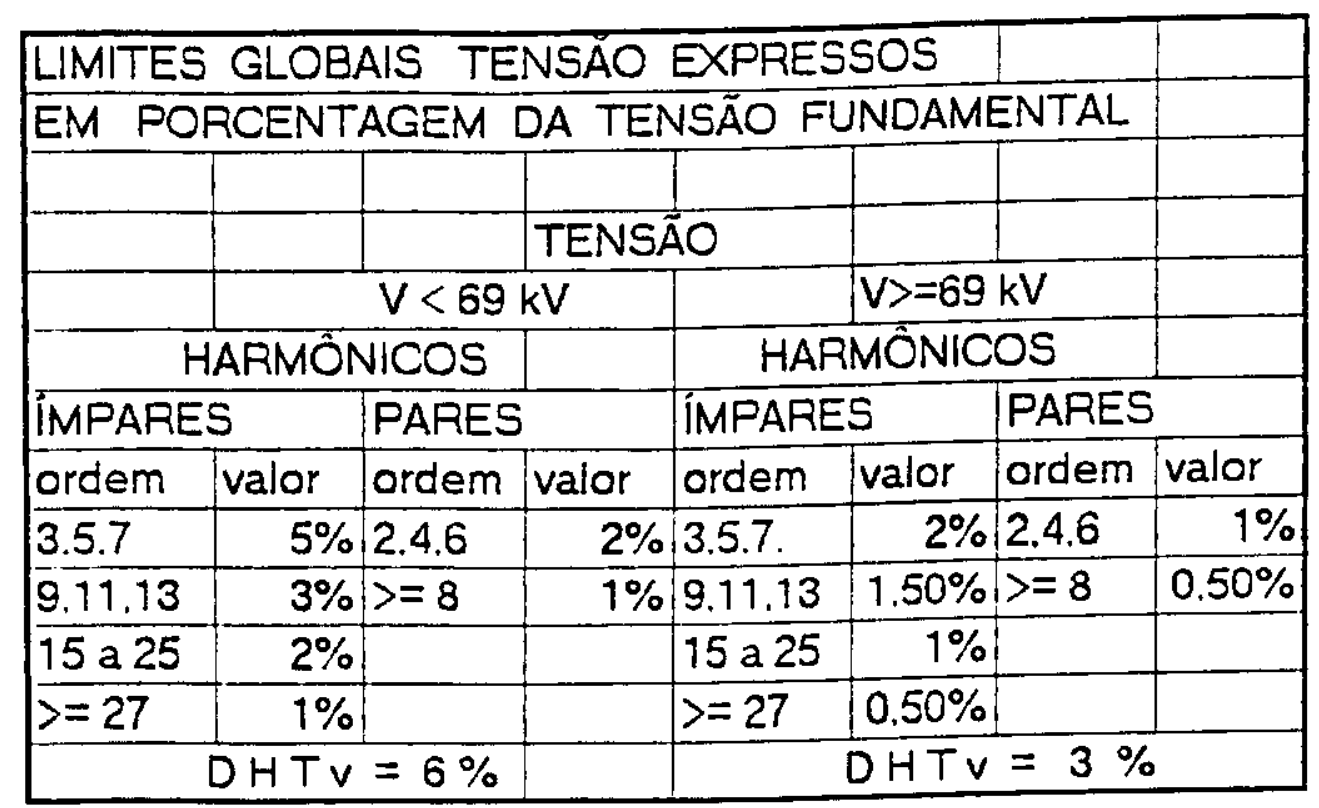

Tabela 7.8 - Limites Globais de tensão em (\%) da fundamental

\begin{tabular}{|c|c|c|c|c|c|c|c|}
\hline & LIMITE & $E S D E$ & TENSA & $10 \mathrm{POAC}$ & $\overline{\mathrm{CON}}$ & MIDOR & \\
\hline & EXPRE & ESSOS & $E M$ & PORCE & NTAG & & \\
\hline & DATE & NSĂO & FUNDAI & MENTAL & & & \\
\hline & & & & & & & \\
\hline & & & TENS & & & & \\
\hline & & $V<69$ & & & $v>=6$ & $\mathrm{kV}$ & \\
\hline & AARMO & VICOS & & $\mathrm{HAF}$ & YMONI & 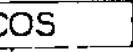 & \\
\hline IMPARE & & PARES & & IMPARE & & PARES & \\
\hline ordem & valor & ordem & valor & ordem & valor & ordem & valor \\
\hline 3 ate 25 & $1.50 \%$ & todos & $0.60 \%$ & 3 ate 25 & $0.60^{\circ}$ & itodos & $0.30 \%$ \\
\hline$>=27$ & $0.70 \%$ & & & $>=27$ & $0.40^{\circ}$ & & \\
\hline & $\mathrm{DHTV}$ & $=3 \%$ & & & $D H T$ & $=1.5$ & $\%$ \\
\hline
\end{tabular}

Tabela 7.9- Limites de tensão por consumidor em (\%) da fundamental 
Comparando os valores obtidos na medição em campo com os valores das recomendações do grupo GCOI/ELETROBRÁS [3], consultando a tabela 7.10, onde os limites de tensão por consumidor são apresentados, e considerando o ponto de acoplamento comum entre concessionária e consumidor como sendo o alimentador que energiza o consumidor, cuja alimentação é em $138 \mathrm{kV}$, percebe-se existência de alguns valores interessantes a serem comentados e analisados.

No fornecimento da tensão está sendo excedido o limite máximo da distorção harmônica total na maior parte do tempo, cujo valor é de $1,5 \%$ para a tensão maior ou igual a $69 \mathrm{kV}$, enquanto que os valores medidos no barramento do consumidor estão entre $2,2 \%$ e $4,8 \%$, durante $100 \%$ do tempo analisado. Quanto aos limites de distorção harmônica individual temos os valores do consumidor excedendo os valores máximos para o $5^{\circ}$ (quinto), $7^{\circ}$ (sétimo), $11^{\circ}$ (décimo primeiro), $13^{\circ}$ (décimo terceiro) harmônicos, com valores típicos de 3,73\%; 1,25\%; 1,45\%; $1 \%$. A recomendação da Eletrobrás [3], indica que estes valores não poderiam exceder a $0,60 \%$. A tabela 7.10 , mostra os valores típicos obtidos na medição em campo para distorção harmônica total na tensão.

Estes valores indicam a necessidade de adotar medidas corretivas pela concessionária, pois havendo níveis elevados de distorção harmônica total na tensão no barramento do consumidor, estes valores serão propagados para o sistema de potência da concessionária e afetarão de maneira significativa a Qualidade de Energia fornecida, provocando perdas nos cabos de alimentação, mau funcionamento nos equipamentos alimentados por este barramento e podendo criar condições propícias para o surgimento de um fenômeno conhecido como ressonância, que é a resposta do sistema com um máximo de amplitude na tensão, quando impulsionado por uma tensão harmônica de amplitude constante, na presença de capacitores e 
indutores dentro do próprio sistema de potência, provocando sua sintonia para uma determinada freqüência, diferente da fundamental $(60 \mathrm{~Hz})$.

\begin{tabular}{|c|c|c|c|c|c|c|}
\hline LIMITE & ORDEM DO & $\mathrm{DHTV}(\%)$ & & $|V\rangle=69$ & & \\
\hline & HARMOONICO & & HAR & MOONNIC & OS & \\
\hline & & 0 & IMPARE & & PARES & \\
\hline & & 0 & ordem & valor & ordem & valor \\
\hline & 2 & 0.35 & 3 até 25 & $0.60 \%$ & todos & $0,30 \%$ \\
\hline & 3 & 0,3043 & $>=27$ & $0.40 \%$ & & \\
\hline & 4 & 0,1498 & & $\mathrm{DHTV}$ & $=1.5$ & $\%$ \\
\hline EXCEDIDO & 5 & 3.7322 & & & & \\
\hline & 6 & 0.0829 & & & & \\
\hline EXCEDIDO & 7 & 1.2588 & & & & \\
\hline & 8 & $0.07 \overline{9}$ & & & & \\
\hline & 9 & 0,0918 & & & & \\
\hline & 10 & 0.1081 & & & & \\
\hline EXCEDIDO & 11 & 1.4524 & & & & \\
\hline & 12 & 0.0625 & & & & \\
\hline EXCEDIDO & 13 & 1.0115 & & & & \\
\hline & 14 & 0.031 & & & & \\
\hline & 15 & 0.1612 & & & & \\
\hline EXCEDIDO & DHTV & 4.353 & & & $\ldots$ & $-\cdots$ \\
\hline
\end{tabular}

Tabela 7.10 - Comparação entre a recomendação do GCOI [3] e os valores de campo. 
Portanto, havendo aumento na tensão eficaz no alimentador podem ocorrer danos irreversíveis aos equipamentos a ele conectados.

Em nivel internacional, a norma IEEE 519-92, apresenta praticamente os mesmos valores das recomendações do GCOI da Eletrobrás, para valores globais. A tabela 7.11 mostra que os valores limites para a distorção harmônica na tensão da norma IEEE 519-92 são menos rigorosos em termos de distorções harmônicas individuais, pois não particularizam valores para os harmônicos pares e ímpares, colocando apenas um valor global para todos de $3 \%$. Quanto a distorção harmônica total da tensão, o valor da nonna IEEE $519 / 92$ é, por exemplo, de $5 \%$ para tensões até $69 \mathrm{kV}$ enquanto que a recomendação do GCOI é de $6 \%$, para a mesma faixa de tensão. portanto menos rigorosa, mas bastante próxima. Acredita-se que a análise feita anteriomnente para a distorção harmônica da tensão, por uma recomendação mais rigorosa e mais elaborada, que é a da Eletrobrás. preenche e conclui este capitulo.

\begin{tabular}{|c|c|c|}
\hline & \multicolumn{2}{|l|}{ LIMITES DE DISTORCAAOA } \\
\hline & \multicolumn{2}{|l|}{ HARMÓNICA DE TENSÄO } \\
\hline & & \\
\hline TENSEÁ̃ NO PONTO & DISTORÇÃO HARMONICA & DISTORCAAO HARMONICA \\
\hline DEA OOPLAMENTO & INDIVIDUAL DA TENSĀO & TOTAL DA TENSÄO \\
\hline COM UM (P.A.C.) & $(\%)$ & $(\%)$ \\
\hline$<=69 \mathrm{kV}$ & 3 & 5 \\
\hline$>69 \mathrm{kV}<=161 \mathrm{kV}$ & 1.5 & 2.5 \\
\hline$>161 \mathrm{kV}$ & 1 & 1.5 \\
\hline
\end{tabular}

Tabela 7.11 - Valores da norma IEEE 519-92 


\section{CONCLUSÕES E RECOMENDAÇÕES}

As crises do petróleo de 1973 e 1979, fizeram com que as indústrias metalúrgicas e siderúrgicas procurassem meios de fabricar seus produtos com menor custo.

Sendo assim, como a maior parcela de custos do produto final, advêm da energia consumida, essas indústrias iniciaram um processo de substituição dos equipamentos consumidores de combustíveis fósseis (petróleo), por energia elétrica.

Somada a essa mudança, os componentes eletrônicos de potência experimentaram um desenvolvimento vertiginoso durante este periodo, possibilitando sua utilização em larga escala nos sistemas de fornos e fundições, facilitando ainda mais a substituição do petróleo pela eletricidade, cujo custo era mais interessante.

Simultaneamente, iniciou-se através da informática e da microeletrônica uma revolução com o lançamento no mercado de equipamentos baseados em microprocessadores que passaram a fazer parte do nosso cotidiano, mas com características muito especiais, exigindo, cada vez mais, energia elétrica com elevado nível de qualidade, ou seja, sem distúrbios. Estes equipamentos são conhecidos como "cargas sensiveis".

A utilização dos componentes eletrônicos de potência nos equipamentos, também conhecidos como cargas "não-lineares" ou especiais, em substituição aos antigos equipamentos, alimentados por combustiveis fósseis, provocou distúrbios nos sistemas alimentadores de energia elétrica que supriam as indústrias e os consumidores em geral. Inicialmente com pouca intensidade, mais tarde provocando graves problemas às concessionárias e até a outros consumidores ligados ao mesmo ponto de acoplamento comum. 
Estes distúrbios são conhecidos como distorções harmônicas, que se caracterizam pela distorção da corrente, da tensão ou ambas, fazendo com que as cargas acopladas aos sistemas elétricos de potência, tenham seu desempenho prejudicado.

Para medir estas distorções de maneira segura foi desenvolvido um equipamento digital controlado por microprocessadores, o registrador de curvas de carga (R.C.C.), que demonstrou ao longo de sua utilização, antes e durante este trabalho, possuir um desempenho altamente eficaz. Todos os resultados relatados neste estudo constataram que os dados por ele adquiridos são confiáveis.

As análises que foram feitas até aqui, indicam que neste caso estudado, a alimentação de energia elétrica do consumidor está com uma distorção harmônica na corrente e na tensão fora dos limites do ponto de vista de nonmas nacionais e internacionais.

Outro fato analisado foi a diferença entre o valor de consumo registrado pelo medidor da concessionária e o valor registrado pelo R.C.C., baseando-se sempre em valores médios do comportamento dos extratos de consuno de energia elétrica do consumidor, foi mostrado um componamento uniforme, das horas sem produção e com produção nos dias com ativitade e sem atividade.

Mlas, devido a série histórica ser pouco expressiva, é necessário aprofundar as pesquisas em direção de uma verificação mais rigorosa do desempenho dos medidores indutivos e eletromecânicos de energia elétrica. mesmo com a literatura internacional indicando vários casos semellantes. aos encontrados neste estudo, precisa-se de um espaço amostral maior, para chegar-se em conclusões apoiadas fortemente em séries de medidas mais abiangentes. 
Este estudo foi embasado numa pesquisa bibliográfica que cobriu de 1888 até 1994 , sobre o fenômeno harmônicos. Para medir e quantificar o fenômeno foi utilizado o R.C.C., produto nacional de baixo custo e com grande viabilidade tecnológica, se comparado com similares estrangeiros.

Possibilitou-se um amplo espaço para pesquisas futuras, que é a análise técnico-econômica das perdas nos sistemas elétricos de potência devido às distorções harmônicas. Atualmente, um assunto de grande relevância na área energética e que possibilitará a avaliação da relação custo-beneficio da utilização em larga escala de equipamentos, conhecidos como cargas "não-lineares"; das perdas de energia elétrica nos cabos provocadas pelos harmônicos; da instalação de elementos atenuadores deste fenômeno, tais como filtros (ativos e passivos); do mau funcionamento das cargas especiais, entre outros.

Segundo estudos da Eletrobrás, o Brasil desperdiça cerca de $18 \%$ da energia que produz, ou seja, 6,5 milhões de quilowatts (40,2 bilhões de quilowatts hora), representando cerca de U\$\$2 bilhões por ano. Sendo que o setor industrial consome $50 \%$ da energia produzida, e o consumidor final desperdiça 24,7 bilhões de $\mathrm{kWh}$ representando U\$\$ 1,1 bilhões. É necessário que se avalie quanto de energia elétrica é desperdiçada com as distorções harmônicas.

Esta análise técnico-econômica poderá esclarecer, se os custos globais envolvidos para a manutenção de cargas não-lineares, operando nos sistemas elétricos de potência, não aumentarão significativamente o custo final para consumidores e concessionárias. Sabe-se que em função do crescimento elevado da quantidade destas cargas, será necessário desenvolver-se uma metodologia de avaliação para a previsão do comportamento dos alimentadores em cenários de curto, médio e longo prazo, em função dos custos. 
A deteção do fluxo de harmônicos, não foi possivel ser efetuada satisfatoriamente, pois a topologia do sistema de distribuição estudado, não permitiu uma conclusão segura da propagação dos harmônicos pelo sistema, deixando dúvidas sobre qual(is) o(s) consumidor(es) estava(m) contribuindo para uma maior proliferação do fenômeno analisado. Este também é outro assunto muito importante e que encontra um caminho aberto a pesquisas futuras. 


\section{BIBLIOGRAFIA}

[1] Martzloff, F. D.; Gruzs, T. M. Power quality site surveys: facts, fiction, and fallacies. IEEE Transactions on Industry Applications, v. 24, $\mathrm{n}^{\circ}$ 6, p. 1005-81, nov/dec., 1988.

[2] Emanuel, A. E. Powers in nonsinusoidal situations, a review of definitions and physical meaning. IEEE Transactions on Power Delivery, v. 5, nº 3, p.1377-89, July 1990.

[3] ELETROBRÁS, Critérios e procedimentos para o atendimento a consumidores com cargas especiais. Grupo coordenador para operação interligada, fevereiro/93.

[4] Wagner, V. E.; Effects on harmonics on equipment. IEEE Transactions on Power Delivery, v. 8, n 2, p. 672-80, April 1993.

[5] Gulachenski, E. M. A survey of harmonic voltages and currents at the costumer's bus. IEEE Transactions on Power Delivery, v. 8, $\mathrm{n}^{\circ} 1$, p. 411-21, January 1993.

[6] Pillegi, D. J. et al. Voltage distortion in distribution feeders with nonlinear loads. IEEE Transaction on Power Delivery, v. 9, $\mathrm{n}^{\circ} 1$, p. 79-87, January 1994.

[7] Yang, M.; Pileggi, D. J. ; Emanuel, A. E. The engineering economics of power systems harmonics in subdistribution feeders. A preliminary study. IEEE Transactions on Power Systems, v. 6, $\mathrm{n}^{\circ} 3$, p. 1092-98, August 1991.

[8] Stanley, W. Phenomena of retardation in the induction coil. Transaction on American Institute of Electrical Engineers, v. V, n ${ }^{\circ} 4$, p. 97-115, January 1888 .

[9] Shallenberger, O. B. The distribution of electricity by alternative current, Electrical World, p. 114-15, March 1888. 
[10] Steinzmetz, C.P. Theory of alternating current phenomena. New York, Mc Graw Hill, 1897.

[11] Houston, E. J.; Kennelly, A. E. On the causes producing phase differences in ac. Electrical World, p. 651, 1895.

[12] Iliovici, M. Definition et mesure de la puissance et de l'energie reatives. Bulletin de la Soc. Française des Eletriciens, p. 931, 1925.

[13] Budeanu, C. Reactive and fictitious power. Bucaresti, Rumanian National Institute Bucaresti, 1927, (Publ, 2).

[14] Emde, F. Entohmung. Elektrotechnische Zeitschrift, v. 15, p.533, April 1930.

[15] Knowlton, A. E. Reactive power concepts. Transaction of American Institute of Electrical Engineers, v. 52, p. 259, April 1933.

[16] Fortscue, C. L. Power, power factor and reactive volt amperes. Electrical Engineer, p. 319, 1933.

[17] Fryze, S. Active, reactive and apparent power in networks with nonsinusoidal waveforms of voltage and current, ETZ, v. 53, $n^{\circ} 25$, p. 596-99, 1932.

Active, reactive and apparent power in networks with nonsinusoidal waveforms of voltage and current, pt I. ETZ, v. $53, \mathrm{n}^{\circ} 26$, p. $625-27,1932$.

Active, reactive and apparent power in networks with nonsinusoidal waveforms of voltage and current, pt II. ETZ, v. $53, \mathrm{n}^{\circ} 27$, p. $700-02,1932$.

[18] International Eletrotechnical Commission. Reactive power in nonsinusoidal situations. Geneve, IEC, 1979. (Tc 25/W67/Secretariat 113). 
[19] SYSTEM DESIGN AND DEVELOPMENT COMMITTEE. Limits for harmonics in the United Kingdom Electricity Supply System. 1976. (Engineering recommendation G5/3).

[20] NEW ZELAND GAZETTE OF \#rd. Limitation of Harmonics Levels, December 1981.

[21] Goes, N. Análise - modelagem e simulação de fontes geradoras de harmônicos. Itajubá, 1981. 250 p. Dissertação (mestrado) Faculdade de Engenharia Elétrica, Universidade Federal de Itajubá. [22] Pinheiro, R. F. Equipamentos estáticos para compensação de reativos e desequilibrios em sistemas elétricos. Itajubá, $1980.150 \mathrm{p}$. Dissertação (mestrado) - Faculdade de Engenharia Elétrica, Universidade Federal de Itajubá.

[23] Wanener, E. The static compensator as means of limiting the disturbance caused by iteavy industrial loads on the power supply - Brown Boveri.

[24] Oliveira, A. Uma contribuicão do estudo da instabilidade causada por conversores estáticos. Campinas, 1983. 185 p. Dissertação (mestrado) - Faculdade de Engenharia Elétrica. Universidade Estaciual de Campinas.

[25] Stratford, R. P. Rectifier harmonics in power systems. IEEE

Transactions on Industry Applications, v. IA-16, n 2, p. 271-76 March/April, 1980.

[26] Aran, G. P. Generation of abnormal harmonics in high-voltage ACDC power systems. IEEE Transactions on Power Apparatus and Systems, v. 87, $\mathrm{n}^{\circ} 3$, p. 873-82, March.1968, .

[27] Reeve, J.; Krishnayya, P. C. S. Harmonics D.C. line voltage arising from H.V. power conversion. IEEE Transactions on Power Apparatus and Systems, v. 87, $\mathrm{n}^{\circ} 3$, p. 883-93, March 1968. 
[28] Reeve, J.; Baron, J. A. Harmonic D.C. line voltages arising from H.V. power conversion. IEEE Transactions on Power and Apparatus and Systems, v. 89, nº 7, p. 1619-24, September/October 1970.

[29] Subbarao, T.; Reeve, J. Harmonics caused by imbalanced transformer impedances and imperfect twelve - pulse operation in HVDC conversion. IEEE Transactions on Power Apparatus and Systems, v. 95, n 5, p. 1732-37, September/October 1976.

[30] Oliveira, J. C.; Oliveira, A. Apostila de sistemas estáticos de conversão e aplicações em acionamentos elétricos. Uberlândia,Universidade Federal de Uberlândia, 1983.

[31] UNIVERSIDADE FEDERAL DE UBERLÂNDIA. Projeto e construção de um instrumento para análise espectral.

Uberlândia, Universidade Federal de Uberlândia, 1987. (Projeto de pesquisa - FINEP/UFU, convênio No 52860519).

[32] INSTITUTE OF ELECTRICAL ELECTRONICS ENGINEERS IEEE recommended practices and requirements for harmonic control in electrical power systems. New Jersey, IEEE, 1992 (IEEE std 519).

[33] Fuchs, E. F. et al. Impact of harmonics on Home appliances. U.S. Department of Energy, 1981. (Topical Report, AC-02 - 80ra50150) [34] Goldberg, G. Behavior of apparatus under the influence of voltage and current harmonics. Bulletin de la Societe Belge Electriciens, $v$. 91, nº 4, October/December, p. 225-35, 1975.

[35] Warber, S. B. et al. The influence of rectifier harmonics in a railway system on the dielectric stability of $33 \mathrm{kV}$ cables. Proc. IEE, v 98, p. 399-421, 1951. 
[36] Key, T. S. Diagnosing power quality - related computer problems. IEEE Transactions on Industry Applications, v. Ia-15, p. 381-93, July 1979.

[37] Linders, J. R. Electric wave distortions: their hidden cost and containment. IEEE Transactions on Industry Applications, v. Ia-15, p. 458-69, September, 1979.

[38] Faucett, M. A.; Keener, C. A. Effects of harmonics on Watt-hour meter accuracy. Electrical World, p 82-84, October 1945.

[39] Chalmers, B. J.; Sarkar, B. R. Induction motor losses due to nonsinusoidal supply waveforms. Proc. IEE, v. $115, \mathrm{n}^{\circ} 12$, p. 1777-81, December 1968.

[40] Xia, D.; Heydt, G.T. Harmonic power flow studies, part I and part II. IEEE Transactions on Power Apparatus and Systems, v. 101, $n^{\circ} 6$, p. 1257-70, June 1982.

[41] Kuussaari, M.; Pesonen, A. J. Measured power - line harmonics currents and induced telephone noise interference with special reference to statistical approach. In: CONFERENCE INTERNATIONAL DES GRANDS RESEAUX ELETRIQUES A HAUTE TENSION, Paris, 1974. Cigré: Proceedings. Paris, 1976. p. $3(j-05 / 1-10$.

[42] Arrillaga, J.; Bradley, D. A.; Bodger, P. S. Power Svstem Harmonics. New York, John Wiley \& Sons, 1985.

[43] Oliveira, J. G. et al. Relatónio final de avaliação do projeto registrador de curvas de carga em rede de distribuicão elétrica. São Paulo, IEE-USP, 1993. 3 v. (LDH.01.RT.01).

[44] Lembo F.; D'Onofrio, V. H. Distribution harmonics cause breaker problems. Electrical World, p. 121 - 122, September 1981. 
[45] Brozek, J.P.The effects of harmonics on overcurrent protection devices, Transactions on Industry Applications, p. 1965-67, 1990.

[46] Kennelly, A. E.; Laws, F. A.; Pierce, P. H. Experimental researches on skin effects in conductors. Transaction on American Institute of Electrical Engineers, v. 34, p. 1953 - 2018, 1915.

[47] Rice, D. E. Adjustable speed drive and power rectifier harmonics : their effect on power system components. IEEE Transactions on Industry Applications, v. LA-22, $\mathrm{n}^{\circ}$ 1, p. 161-77, Jan/Fev 1986.

[48] Gruzs, T. M. A survey of neutral currents in three-phase computer power systems. IEEE Transactions on Industry Applications, v. 26, nº 4, p. 719-25, Jul/Aug 1990.

[49] Girgis, A. A. et al. Effect of voltage harmonics on the operation of solid state relays in industrial applications. IEEE Transactions on Industry Applications, p. 1821-28.

[50] Ludbrook, A. Harmonic filters for notch reduction. IEEE on IndustryApplications, v. 24, $\mathrm{n}^{\circ}$ 5, p. 947-54, Sept/Oct 1988.

[51] INSTITUTE OF ELECTRICAL AND ELECTRONICS ENGINEERS. Guide for harmonic control and reactive compensation of static power converters. New Jersey, IEEE, 1981 (IEEE std. 519).

[52] Fuchs, E. F.; Roesler D. J.; Kovacs, K. P.. Sensivity of electrical appliances to harmonics and fractional harmonics of the power system's voltage. Part II: television sets, induction Watthour meters and universal machines. IEEE Transactions on Power Delivery, v. 2, $\mathrm{n}^{\circ} 2$, April 1987.

[53] Kaufman, J. E. IES Lighting Handbook, New York, Illuminating Engineering Society of North America, 1981. 
[54] Oldham, N. M.; Nelson, T. L. Influence of nonsinusoidal waveform on voltmeters, ammeters, and phase meters. IEEE Tutorial Course (Publication 90).

[55] Filipski, P. S.; Arseneau, R. Behavior of Wattmeters and Watthour meters under distorted waveform conditions. IEEE Tutorial Course (Publication 90).

[56] Goldberg S.; Horton, W. F. An experimental study of the effects of nonsinusoidal currents on the registration of induction watthour meters. In: 21st ANNUAL NORTH AMERICAN POWER SYMPOSIUM, 1989. University of Missouri-Rolla: ProceedingS, October 1989.

[57] IEEE PES POWER SYSTEM RELAYING COMMITTEE. Fault induced wave distortion of interest to relay engineers. IEEE Transactions on Power Apparatus and Systems, v. 104, $\mathrm{n}^{\circ} 12$, p.3574 - 3584, December 1985.

[58] IEEE PES POWER SYSTEM RELAYING COMMITTEE. Sine-Wave distortions in power systems and the impact on protective relaving. In: IE:EE Power Winter Meeting, 1984.

[59] Jost, F. A.; Menzies, D. F.; Swift, G. W. Effect of system harmonics on power systems relays. In: Transactions of the Operation and Planning Division of the Canadian Electric Association Conference, v. 3, March 1974.

[60] Saramaga, D. E.; Menzies, R. W.; Swift, G. W. Effect of harmonic currents on induction disc operating torque. In: IEEE Power Eletronics Specialist Conference. 
[61] WAVE DISTORTION ON CONSUMER'S INTERCONNECTION WORKING GROUP. The Impact of sine-wave distortions on protective relays. IEEE Transactions on Industry Applications, v. IA- 20, n 2, p. 335-43, Marcl//April 1984.

[62] Horton, W. F.; Goldberg, S. The effect of harmonics on the operating points of electromechanical relays. IEEE Transactions on Power Apparatus and Systems, v. 104, n 5, p. 1178-86, May 1985.

[63] Jewell, W. T. The effect of voltage and current distortion on power system protective relay operation. Kansas, Kansas Electric Utilities Research Program, September 1989.(Project 245).

[64] Erickson, C. J. Motor design features for adjustable-frequency drives. IEEE Transactions on Industry Applications, v. 24, nº 2, p. 192-198, Mar/Apr 1988.

[65] Fuchs, E. F.; Roesler, D. J.; Alashhab, F. S. Sensivity of electrical appliances to harmonics and fractional harmonics of the power system's voltage. Part I: transformers and induction machines. IEEE Transactions on Power Delivery, v. 2, $n^{\circ} 2$, p. 437-44, Apr 1987.

[66] Fuchs, E. F.; Roesler, D. J.; Kovacs, K. P. Aging of electrical appliances due to harmonics of the power system's voltage. IEEE Transactions on Power Delivery, v. 1, nº 3, p. 301-7, July 1986.

[67] Hanna, R. A. Harmonics and technical barriers in adjustable speed drives. IEEE Transactions on Industry Applications, v. $25, \mathrm{n}^{\circ} 5$, p. 894-900, Sep/Oct 1989.

[68] Murphy, J. M. D.; Egan, M. G. A comparison of pwm strategies for inverter-fed induction motors. IEEE Transactions on Industry Applications, v. IA-19, n 3, p. 363-69, May/Jun 1983. 
[69] Boys, J. T.; Walton, S. J. A loss minimized sinusoidal pwm inverter. IEE Proceedings, v. 132, pt. b, nº 5, p. 260-68, Sept 1985.

[70] Andersen, E. C.; Bieniek, K. On the torques and losses of voltage and current-source inverter drives. IEEE Transactions on Industry Applications, v. IA-20, nº 2, p. 321-327, Mar/Apr 1984.

[71] Connors, D. P.; Jarc, D. A.; Daugherty, R. H. Considerations in applying induction motors with solid-state adjustable frequency controllers. IEEE Transactions on Industry Applications, v. IA-20, $n^{\circ} 1$, p. 113-21, Jan/Feb 1984.

[72] Green, R. M.; Boys, J. T. Inverter ac-drive efficiency. IEE Proceedings, v. 129, pt. b, n 2, p. 75-81, March 1982.

[73] Buch, F. G. G.; Gistelinck, P.; Backer, D. A simple but reliable loss model for inverter-supplied induction motors. IEEE Transactions on Industry Applications, v. IA-20, nº 1, p. 190-202, Jan/Feb 1984.

[74] Kirschen, D. S.; Novotny, D. W.; Suwanwisoot, W. Minimizing induction motor losses by excitation control in variable frequency drives. IEEE Transactions on Industry Applications, v. IA-20, $\mathrm{n}^{\circ}$, p. 1244-50.

[75] Jamil, M. K.; Demerdash, N.A. Effects of chopper control circuits on core losses of permanent magnet DC motors. IEEE Transactions on Magnetics, v. 25, nº 5, p. 3572-3574, September/October 1989.

[76] Jamil, M. K.; Demerdash, N. A. Harmonic analysis of permanent magnet DC motors operated by chopper control circuits. In: IEEE Power Eletronics Specialist Conference, p. 799-806, 1989.

[77] Jamil, M. K.; Demerdash, N. A. Harmonics and core losses of permanent magnet $\mathrm{DC}$ motors controlled by chopper circuits. IEEE Transactions Energy Conversion, v. 5, $n^{\circ} 2$, p. 408-414, June 1990. 
[78] Bowes, S. R.; Bullough, R. I. Harmonic minimization in microprocessor controlled current fed PWM drives.

IEE Proceedings, v. 134, Pt. B. nº 1, p. 25-41, January 1982.

[79] Belmans, R. J. M.; Vandenput, A. J.; Geysen, W. Influence of unbalanced magnetic pull on the radial stability of flexible-shaft induction machines. IEE Proceedings, v. 134, Pt. B, $\mathrm{n}^{\circ} 2$, p. 101-109, March 1987.

[80] Sheppard, D. J. Torsional vibration resulting from adjustabe-frequency AC drives. IEEE Transactions on Industry Applications, v. 24, $\mathrm{n}^{\circ}$ 5, p. 812-817, September/October 1988.

[81] Belmans, R. J. M.; D’Hondt, L.; Vandenput, A. J.; Geysen, W. Analysis of the audible noise of three-phase squirrel-cage induction motors supplied by inverters. IEEE Transactions on Industry Applications, v. 23, nº 5, p. 842-847, September/October 1987.

[82] Belmans, R. J. M.; Verdyck, D.; Geysen, W.; Findlsy, T. Electromechanical analysis of the audible noise of an inverter-fed squirrelcage induction motor. In: IEEE Transactions on Industry Applications, p. 232-237, October 1-5, 1989.

[83] Wallace, A. K.; Spree, R.; Martin, L. G. Current harmonics and acoustic noise in AC adjustable-speed drives. IEEE Transactions on Industry Applications, v. 26, n 2, p. 267-273, March/April 1990.

[84] IEEE WORKING GROUP. Power line harmonic effects on communication line interference. IEEE Transactions Power Apparatus and Systems, v. 104, n 9 , p. 2578-2587, September 1985. 
[85] ANSI/IEEE STANDARD C57.110-1986. Recommend practice for establishing transformer capability when supplying nonsinusoidal load currents.

[86] ANSI/IEEE STANDARD C57.91-1981. Guide for loading mineral-oilimmersed overhead and pad-mounted distribution transformers rated $500 \mathrm{kVA}$ and less with $65^{\circ} \mathrm{C}$ or $55^{\circ} \mathrm{C}$ average winding rise.

[87] ANSI/IEEE STANDARD C57.92-1981. Guide for loading mineral-oilimmersed power transformers up to and including 100 MVA with $65^{\circ} \mathrm{C}$ or $55^{\circ} \mathrm{C}$ average winding rise.

[88] ANSI/IEEE STANDARD C57.96-1989. Guide for loading dry-type distribution and power transformers.

[89] ANSI/IEEE STANDARD C57.12.00-1987. General requirements for liquid-immersed distribution, power, and regulating transformers. [90] ANSI/IEEE STANDARD C57.12.01-1989. General requirements for dry-type distribution and power transformers including those with solid cast and/or resin-encapsulated windings.

[91] Hwang, M. S.; Grady, W. M.; Sanders Jr., H. W. Distribution transformer winding losses due to nonsinusoidal currents. EEE Transactions on Power Delivery, p. 140-146, January 1987.

[92] Dini, D.A. The nature of harmonic distortion and its impact on electrical safety. IAEI News, p. 33-37, July/August 1991.

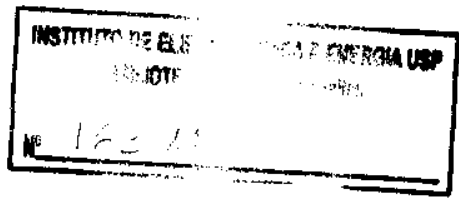

